IBSIR 77-1279
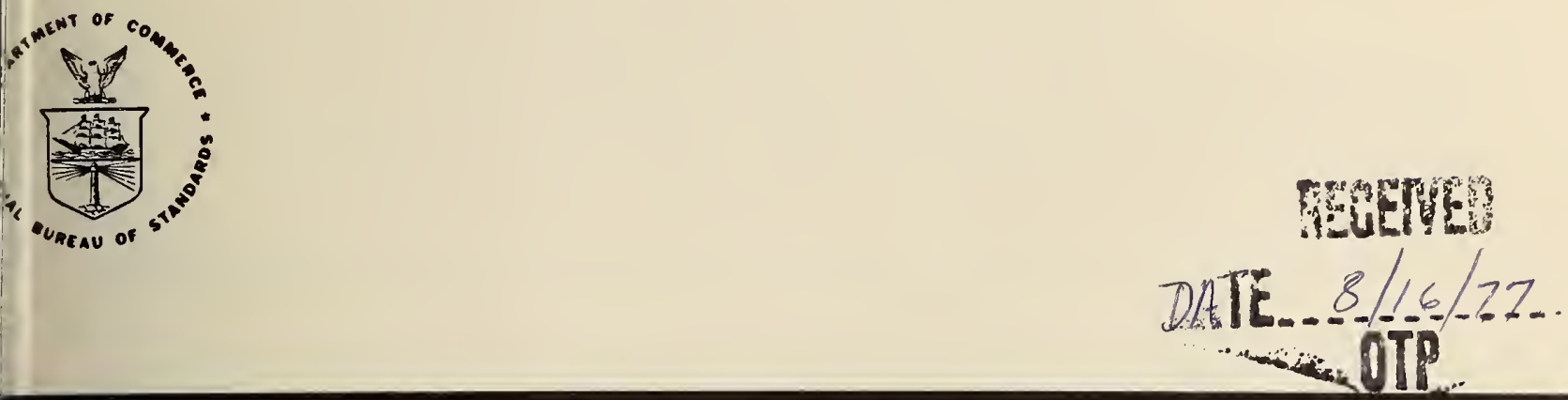

U.S. DEPARTMENT OF COMMERCE , National Bureau of Standards

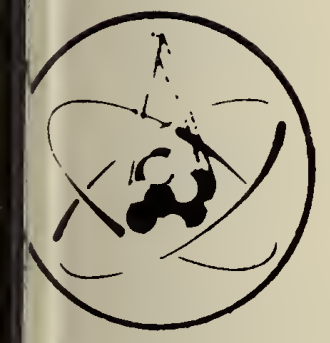

Cross Sections and Yields for High Energy Neutron Source Reactions

July 1977
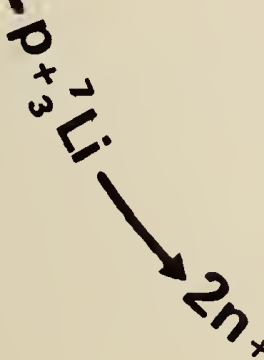

$+$

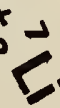
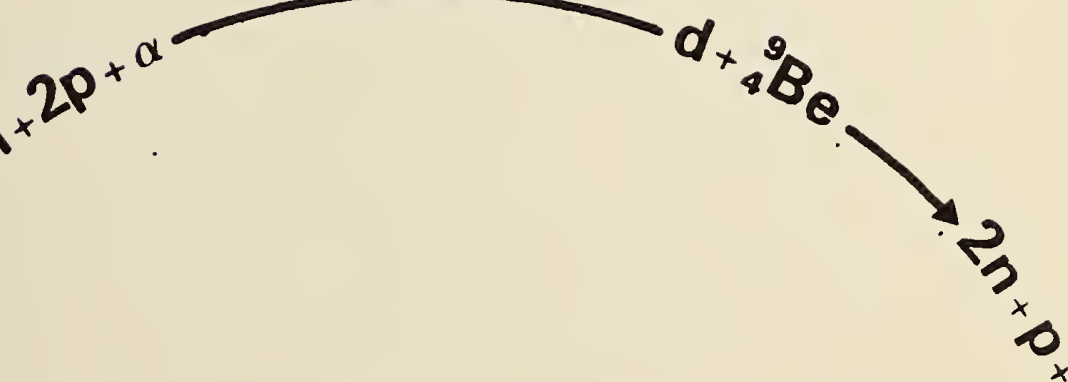
NBSIR 77-1279

\section{Cross Sections and Yields for High Energy Neutron Source Reactions}

Edited by:

M. A. Lone

Chalk River Nuclear Laboratories

Chalk River, Ontario, Canada KOJ-IJO

L. Stewart

Los Alamos Scientific Laboratory

Los Alamos, New Mexico 87545

A. D. Carlson and C. D. Bowman

Center for Radiation Research

Institute for Basic Standards

National Bureau of Standards

Washington, D.C. 20234

July 1977

U.S. DEPARTMENT OF COMMERCE, Juanita M. Kreps, Secretary

Dr. Sidney Harman, Under Secretary

Jordan J. Baruch, Assistant Secretary for Science and Technology

NATIONAL BUREAU OF STANDARDS, Ernest Ambler, Acting Director 
The need for intense sources of high energy neutrons for cancer therapy and materials radiation damage studies for CTR programs has led to renewed interest in the measurements of differential and total neutron thick target yields from charged particle induced reactions over a wide range of neutron energies. Knowledge of both the absolute neutron source strength and the neutron spectral distributions is important for these programs.

The accuracy of the measured differential and total neutron yields depends on the neutron standards and other data used for calibration of the neutron spectrometers. Because this is a relatively new field there is a lack of adequate neutron standards and relevant data in the energy range of interest. Consequently in some instances there are discrepancies between the data reported by different groups on the same source reaction.

A session, primarily a workshop, was organized in conjunction with the International Specialists Symposium on Neutron Standards and Applications held at the National Bureau of Standards, Gaithersburg, Maryland site from March 28-31, 1977. The session was scheduled on the third evening of the Symposium, March 30, 1977, from 8:00 to 10:30 p.m. and was chaired by Professor H. H. Barschall of the University of Wisconsin. Approximately sixty delegates attended the special session.

When commercial equipment, instruments and materials are mentioned or identified in this report it is intended only to adequately specify experimental procedure. In no case does such identification imply recommendation or endorsement by the National Bureau of Standards, nor does it imply that the material or equipment identified is necessarily the best available for the purpose.

M. A. Lone

Chalk River Nuclear Laboratories Canada

L. Stewart

Los Alamos Scientific Laboratory

Los Alamos, New Mexico

A. D. Carlson and

C. D. Bowman

National Bureau of Standards

Washington, D. C. 
Eight papers were presented at a workshop on thick-target yields from high-energy neutron source reactions on March 30th, 1977 in Bethesda, MD. Presentations were made on several source reactions including $D(d, n)$, $\mathrm{Li}(\mathrm{p}, \mathrm{n}), \mathrm{Li}(\mathrm{d}, \mathrm{n}), \mathrm{Be}(\mathrm{p}, \mathrm{n}), \mathrm{Be}(\mathrm{d}, \mathrm{n})$, and $\mathrm{C}(\mathrm{d}, \mathrm{n})$ including energy and angular distributions. Special emphasis was placed on these sources due to the needs in medical applications and for studies of radiation damage expected in an operating fusion reactor.

Key words: $D(d, n)$ source, $L i(p, n)$ source, $L i(d, n)$ source, $B e(p, n)$ source, $\operatorname{Be}(d, n)$ source, $c(d, n)$ source, dosimetry, thick-target yields, neutrons, nuclear reactions, neutron energy distributions, neutron angular distributions. 


\section{CROSS SECTIONS AND YIELDS FOR \\ HIGH ENERGY NEUTRON SOURCE \\ REACTIONS*}

Chairman: H. H. Barschall

$\underline{\text { Page }}$

1. Neutron Spectra From Deuteron and Proton Bombardment of Thick Lithium Targets,

by C. E. Nelson, F. O. Purser, P. Von Behren, and H. W. Newson. . . . . . . . . . I

2. Neutron Spectral Distributions from Proton and Deuteron Bombardment of Thick

Li \& Be Targets at 14.8, 18 \& $23 \mathrm{MeV}$, by M. A. Lone . . . . . . . . . . . . . . . 5

3. 35 and $65 \mathrm{MeV}$ Protons and $35 \mathrm{MeV}$ Deuterons on Lithium and Beryllium,

by M. Awschalom. . . . . . . . . . . . . . . . . . . . . 10

4. Spectral Measurements of 25 to $55 \mathrm{MeV}$ Neutron Beams,

by S. W. Johnsen . . . . . . . . . . . . . . . . . . . 15

5. Protons and Deuterons on $\mathrm{Be}$ at $\mathrm{E}_{\mathrm{p}}=100 \mathrm{MeV}$ and $\mathrm{E}_{\mathrm{d}}=80 \mathrm{MeV}$

by G. H. Harrison, C. R. Cox, E. B. Kubiczek, and J. E. Robinson . . . . . . . . 19

6. Neutron Yields and Dosimetry for $B e(d, n)$ and $L i(d, n)$ Neutron Sources at $E_{d}=40 \mathrm{MeV}$, by M. J. Saltmarsh, C. A. Ludemann, C. B. Fulmer, and R. C.

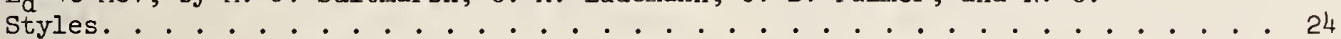

7. Neutron Spectra and Doses from Deuteron Bombardment of Light Nuclei, by H. H. Barschall. . . . . . . . . . . . . . . . . . 30

8. Neutron Spectral Measurements and Interpretation at the Naval Research Laboratory, by L. S. August, P. Shapiro, and R. B. Theus. . . . . . . . . . . . . 31

*Organized by M. A. Lone, Chalk River Nuclear Laboratories, Ontario, CANADA 

C.E. Nelson, F.O. Purser, P. Von Behren and H.W. Newson

Triangle Universities Nuclear Laboratory tand Duke University

Durham, North Carolina 27706, U.S.A.

Neutron energy spectra and yields produced by the bombardment of thick lithium targets by deuterons and protons have been measured using the time-of-flight method. Measurements were made at angles up to $45^{\circ}$ for deuteron energles of 8,12 and $15 \mathrm{MeV}$ and a proton energy of $15 \mathrm{MeV}$. The average neutron energy of the $(d, n)$ reactions is shown to vary approximately at $.44 \mathrm{E}_{\mathrm{d}}$. The $(p, n)$ reaction has $\overline{\mathrm{E}}_{\mathrm{n}}=4.7 \mathrm{MeV}$.

(energy spectra, yields; neutrons; thick target; ${ }^{7} \mathrm{Li}(\mathrm{d}, \mathrm{n})^{8} \mathrm{Be},{ }^{7} \mathrm{Li}(\mathrm{p}, \mathrm{n}){ }^{7} \mathrm{Be} ; \mathrm{E}_{\mathrm{d}}=8,12$, $15 \mathrm{MeV}, \mathrm{E}_{\mathrm{p}}=15 \mathrm{MeV}$; time-of-flight)

\section{INTRODUCTION}

Present efforts to develop a hospital based fast neutron source for cancer therapy are concentrated on the D-T generator ${ }^{1)}$. This machine uses the ${ }^{3} \mathrm{H}(\mathrm{d}, \mathrm{n})^{4} \mathrm{He}$ reaction with several hundred $\mathrm{keV}$ deuterons to obtain an intense monoenergetic source of $14 \mathrm{MeV}$ neutrons.

A possible alternative to the $D-T$ generator for a hospital based neutron source is a compact medical cyclotron. Table 1 lists the specifications of some of the cyclotrons presently installed in hospitals in the United States.

\section{Table 1}

Medica1 Cyclotron Specifications*

$\begin{array}{lccc}\begin{array}{c}\text { Cyclotron } \\ \text { Model No. }\end{array} & \text { Particle } & \begin{array}{r}\text { Energy } \\ (\mathrm{MeV})\end{array} & \begin{array}{c}\text { Extracted } \\ \text { Beam } \\ (\mu \mathrm{A})\end{array} \\ \text { CS } 15 & \mathrm{p} & 15 & 100 \\ & \mathrm{~d} & 8 & 100 \\ & & & \\ \text { CS } 22 & \mathrm{p} & 22 & 50 \\ & \mathrm{~d} & 12 & 50 \\ \text { CS } 30 & & & \\ & \mathrm{p} & 26 & 60 \\ & \mathrm{~d} & 15 & 100\end{array}$

\section{${ }^{*}$ Cyclotron Corporation}

It is known that at the deuteron energies available to these cyclotrons, a thick beryllium target produces an intense neutron flux, which has an average energy of approximately $.4 \mathrm{E}_{\mathrm{d}}{ }^{2}$ ). The resultant neutron beam is, however, of limited usefulness for radiation therapy because of its poor penetration into tissue. The ${ }^{9} \mathrm{Be}(\mathrm{d}, \mathrm{n})$ reaction at $\mathrm{E}_{\mathrm{d}}=16 \mathrm{MeV}$, for example, has a central axis depth dose curve which falls to $50 \%$ of the surface dose at $9.2 \mathrm{~cm}$ for a $10 \times 10 \mathrm{~cm}$ fleld at $125 \mathrm{~cm}$ $\mathrm{TSD}^{3)}$, whereas Brennan has suggested $10 \mathrm{~cm}$ as an acceptable depth for $50 \%$ of the surface dose for a $5 \times 5 \mathrm{~cm}$ field 4 ).

The large positive Q-value $(+15.03 \mathrm{MeV})$ of the ${ }^{7} \mathrm{LI}(\mathrm{d}, \mathrm{n})^{8} \mathrm{Be}$ reaction suggests that bombarding a thick lithium target with deuterons could result in a substantial increase in the average neutron energy of the resultant neutron yield. Previous measurements of this average neutron energy for these lower energy deuterons are in disagreement, indicating an average neutron energy of $.4 \mathrm{E}_{\mathrm{d}}$ to $.55 \mathrm{E}_{\mathrm{d}}$ for $\left.\mathrm{E}_{\mathrm{d}}<15 \mathrm{MeV}^{2}, 5,6\right)$.
The ${ }^{7} \mathrm{LI}(\mathrm{p}, \mathrm{n})^{7} \mathrm{Be}$ reaction is known to be a prolific source of high energy neutrons for thin targets, with over $60 \%$ of the neutrons from this reaction going to the ground or first excited state of $7_{\mathrm{Be}}{ }^{7}$ ). Thick target spectra have not been measured for proton energies above $\mathrm{E}_{\mathrm{p}}=4.0 \mathrm{MeV}$.

The Triangle Universities Nuclear Laboratory neutron time-of-flight facility has been used to determine the average neutron energy and yield of thick lithium $(d, n)$ and $(p, n)$ reactions at deuteron energies of 8,12 and $15 \mathrm{MeV}$ and a proton energy of $15 \mathrm{MeV}$ to determine whether these reactions are suitable for fast neutron therapy.

\section{EXPER IMENTAL}

Neutron energy spectra were measured using timeof-flight techniques. A pulsed beam of protons or deuterons from the Triangle Universities Nuclear Laboratory Model FN Tandem Van de Graaff accelerator was used in conjunction with the TUNL neutron time-offlight facility. Beam currents of 2-5 nA with a time resolution of 1.5 to $2.0 \mathrm{nS}$ were used.

The 1ithium target was enriched to $99.99 \%{ }^{7} \mathrm{Li}$ and was encapsulated in an aluminum contalner under a helium atmosphere. The upstream face of the lithium was covered with a $3.5 \mu \mathrm{m}$ molybdenum foil and the target length was $1.9 \mathrm{~cm}$, sufficient to stop $15 \mathrm{MeV}$ deuterons.

The charged particle beam passed through a $3.2 \mathrm{~mm}$ tantalum collimator $15 \mathrm{~cm}$ upstream of the lithium target. Collimator currents were kept to less than .1 nA. Beam spot sizes on target were kept to less than $5 \mathrm{~mm}$ diameter. Target beam currents, with appropriate electron suppression, were integrated to determine the incident charged particle flux.

The 1ithium target was mounted at the pivot of the main neutron detector shield at the end of the all metal, wide aperture neutron time-of-flight beam line. The very small collimator currents, combined with the extremely well shielded detector made beam and room associated background measurements unnecessary.

The neutron detector consisted of a $8.89 \mathrm{~cm}$ dlameter by $5.04 \mathrm{~cm}$ thick NE 2181 iquid scintillator coupled to a 56 DVP photomultiplier. Pulse shape discrimination was used to discriminate against gamma ray events. This detector was housed in a massive (7300 $\mathrm{kg}$ ) shield to reduce time uncorrelated background events to a negligible amount ${ }^{8)}$. A smaller detector, located at a fixed angle to the charged particle beam, monitored the neutron flux.

Standard time-of-flight electronics, including 
pulse shape discrimination, were used for all datataking which was done with the TUNL DDP 224 computer. Main detector ADC dead times were kept to less than $20 \%$. Spectra were measured at $0^{\circ}, 10^{\circ}, 20^{\circ}, 30^{\circ}$ and $45^{\circ}$.

The efficiency of the detector as a function of energy must be known to convert the time-of-flight spectra to energy spectra. The previous measurements of neutron yield have used a detector bias level corresponding to 1.6 to $2.5 \mathrm{MeV}$ neutron energy and have been required to extrapolate the neutron yleld to zero neutron energy. The low energy cut - fff of the main detector for this work was set at $1 / 10$ the ${ }^{137} \mathrm{Cs}$ compton edge, corresponding to a neutron energy of 200$300 \mathrm{keV}$, in order to minimize errors introduced by such arbitrary extrapolations. Calculations of detector efficiencies are very unreliable with such low energy thresholds. Thus the relative efficiency of the main detector was measured over the range of $.7 \mathrm{MeV}$ to $24 \mathrm{MeV}$, using two different techniques.

For neutrons between $.7 \mathrm{MeV}$ and $5 \mathrm{MeV}$, the angular distribution of neutrons of $7.5 \mathrm{MeV}$ scattered from hydrogen was measured. A $6 \mathrm{~mm}$ diameter by $2.55 \mathrm{~cm}$ high polyethylene scattering sample was used and spectra were taken from $35^{\circ}$ to $72^{\circ}$ in the laboratory system. The data, when corrected for finite geometry effects and normalized to the known $\mathrm{H}(\mathrm{n}, \mathrm{n}) \mathrm{H}$ differential cross section, yield a relative efficiency curve. The efficiency from $4.0 \mathrm{MeV}$ to $24 \mathrm{MeV}$ neutron energy was measured by using the well-known $\mathrm{T}(\mathrm{p}, \mathrm{n}){ }^{3} \mathrm{He}$ and $\mathrm{T}(\mathrm{d}, \mathrm{n})^{4} \mathrm{He}$ reactions at several charged particle energies 9,10$)$. The measured ylelds, normalized to the differential cross sections, give a family of curves spanning different, overlapping neutron energy regions. These curves were overlapped and normalized to the $H(n, n) H$ measurement to yield the relative efficiency data shown in $\mathrm{fig}$. 1. The absolute efficiency of the detector was obtained by normalizing this relative efficiency at $\mathrm{E}_{\mathrm{n}}=4.0 \mathrm{MeV}$ to a monte carlo calculation of the efficiency of our detector done at Oak Ridge National Laboratory 11 ). A least squares fit was then made to this combined data. This fit was used to obtain the calculated efficiency as a function of neutron energy and is shown as the smooth curve in fig. 1.

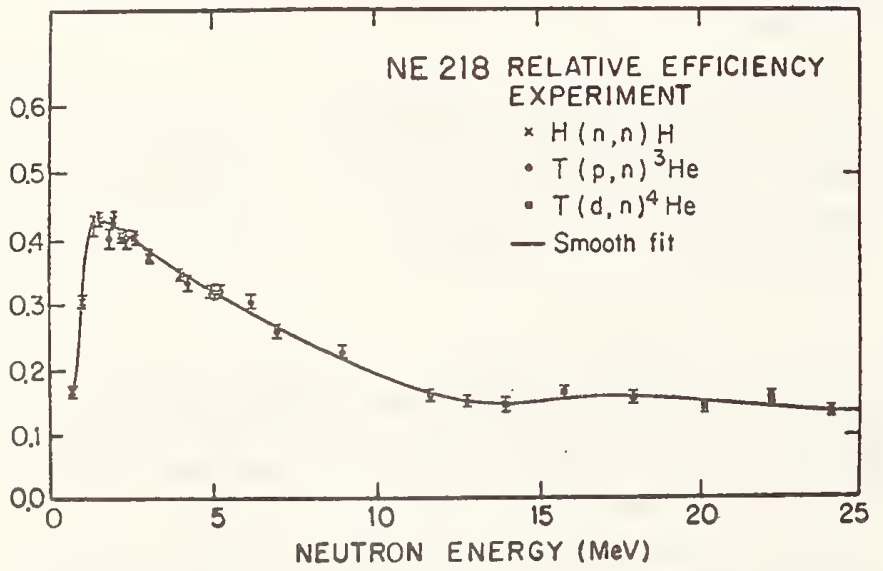

Fig. 1 Efficlency of the main neutron detector.

The time-of-flight spectra, after correction for computer dead time and relativistic effects, were converted to neutron energy spectra using this calculated efficiency curve. The steep slope of the efficiency curve below $\mathrm{E}_{\mathrm{n}}=1.0 \mathrm{MeV}$ precludes an accurate determination of the neutron yield in this region. All subsequent calculations of neutron yields and average energy, therefore, use $\mathrm{E}_{\mathrm{n}}=1.0 \mathrm{MeV}$ as the low energy cut-off point.

\section{NEUTRON SPECTRA AND YIELDS}

The zero degree energy spectra of neutrons obtained with 8,12 and $15 \mathrm{MeV}$ deuteron bombardment of a thick 1ithium target are shown in figs. 2,3 , and 4

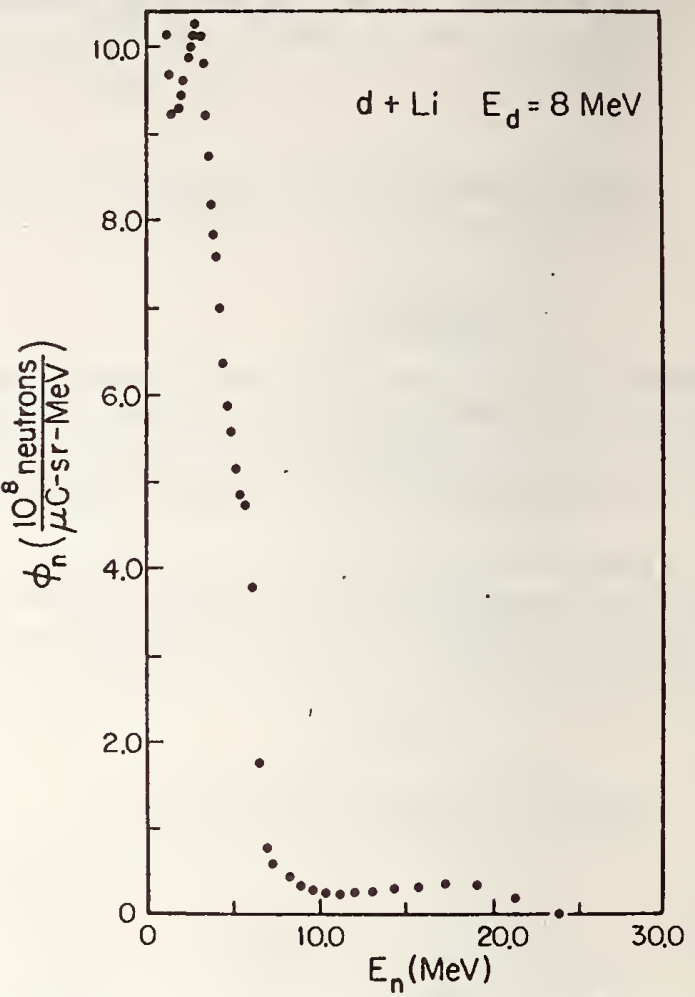

Fig. 2 Neutron energy spectra at zero degrees for $8 \mathrm{MeV}$ deuterons on 11 thium.

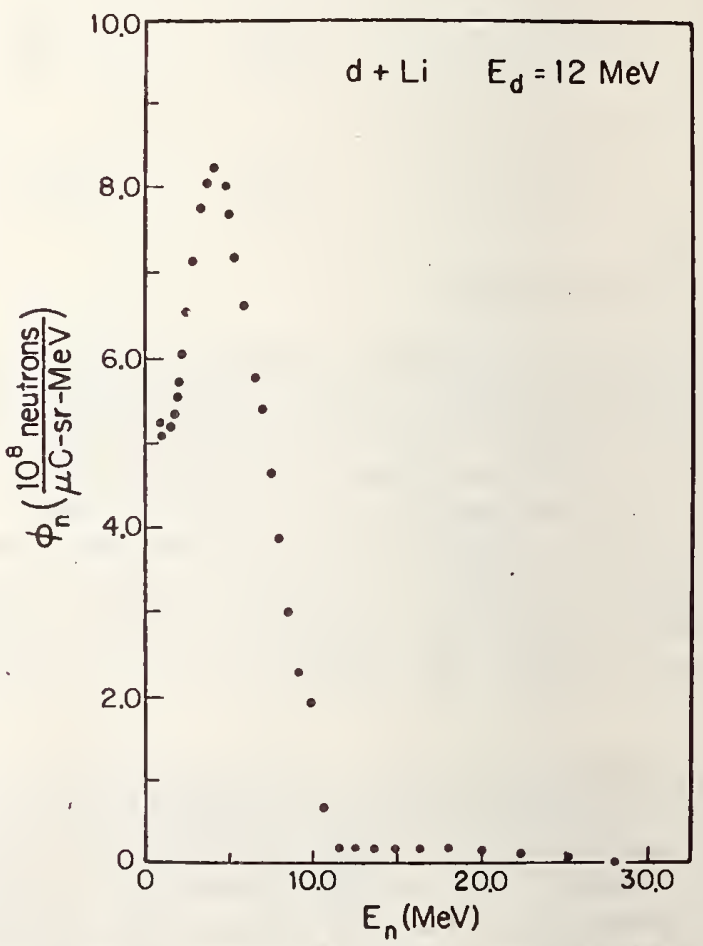

Fig. 3 Neutron energy spectra at zero degrees for $12 \mathrm{MeV}$ deuterons on 11thium. 


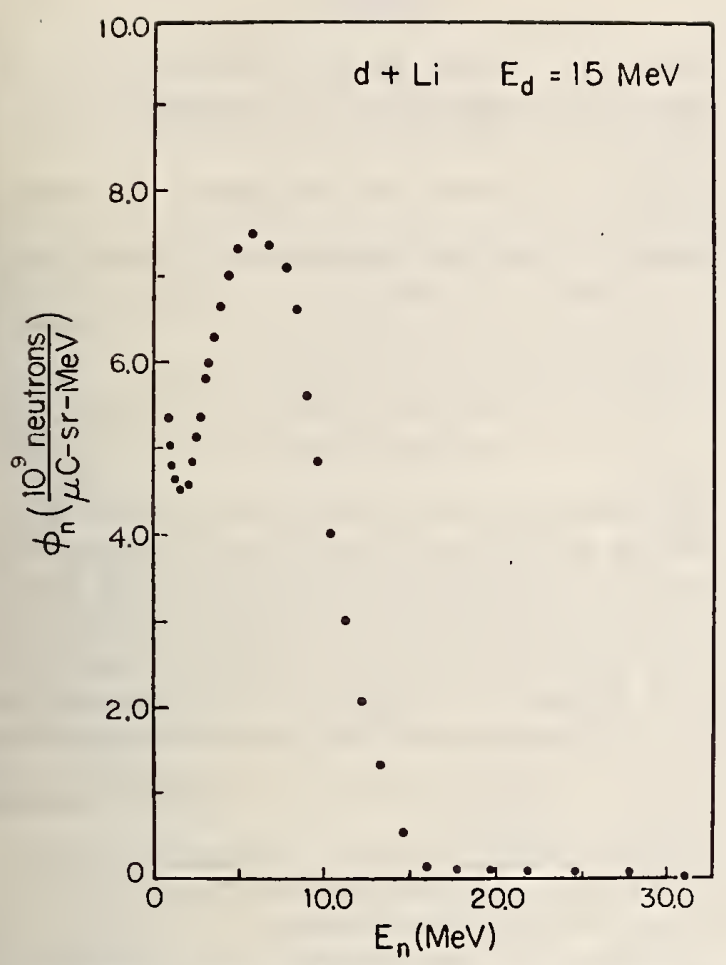

Fig. 4 Neutron energy spectra at zero degrees for $15 \mathrm{MeV}$ deuterons on 11 thlum.

These spectra are characterized by 1) a broad peak in the energy distribution at approximately $.4 \mathrm{E}_{\mathrm{d}}$, 2) a very small high energy tail and 3) a low energy tail which appears to be increasing rapidly below $E_{n}=1.0 \mathrm{MeV}$, the low energy cut off point for these measurements.

F1g. 5 shows the zero degree energy spectrum for $15 \mathrm{MeV}$ proton bombardment of a thick lithium target.

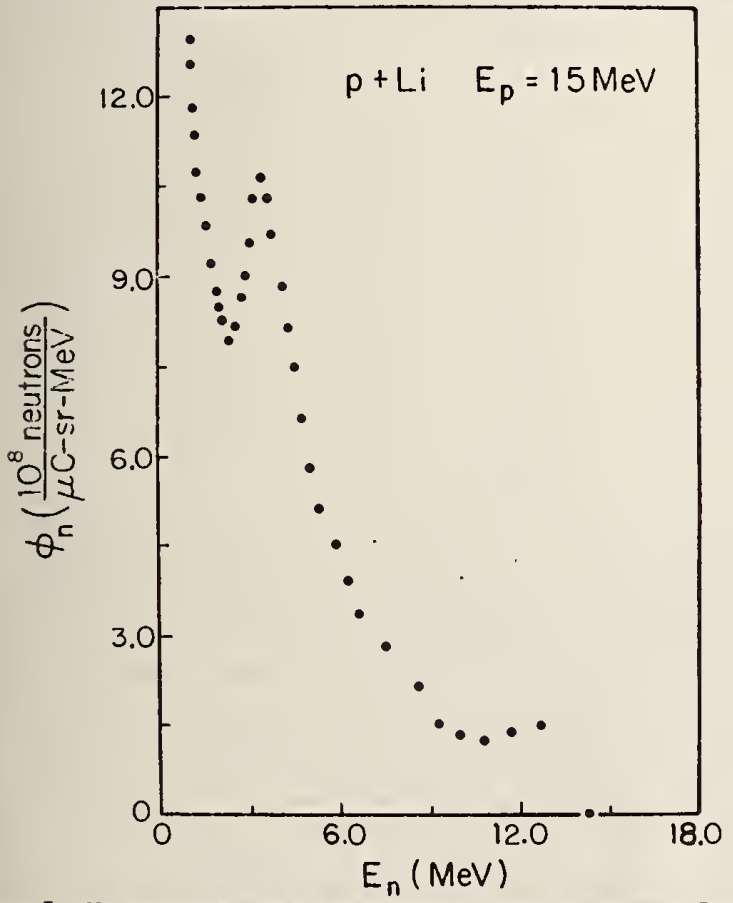

Fig. 5 Neutron energy spectra at zero degrees for $15 \mathrm{MeV}$ protons on Iithium.

It is characterized by

1) a peak in the energy dis- tribution at $E_{n}=3.4 \mathrm{MeV}$ and 2) a decrease in $\mathrm{y} 1 \in \mathrm{Ld}$ with neutron energy, varylng approximately as $1 / E_{n}$.

The neutron spectra at each angle were integrated to obtaln the yleld versus laboratory angle data shown in $\mathrm{fig} .6$.

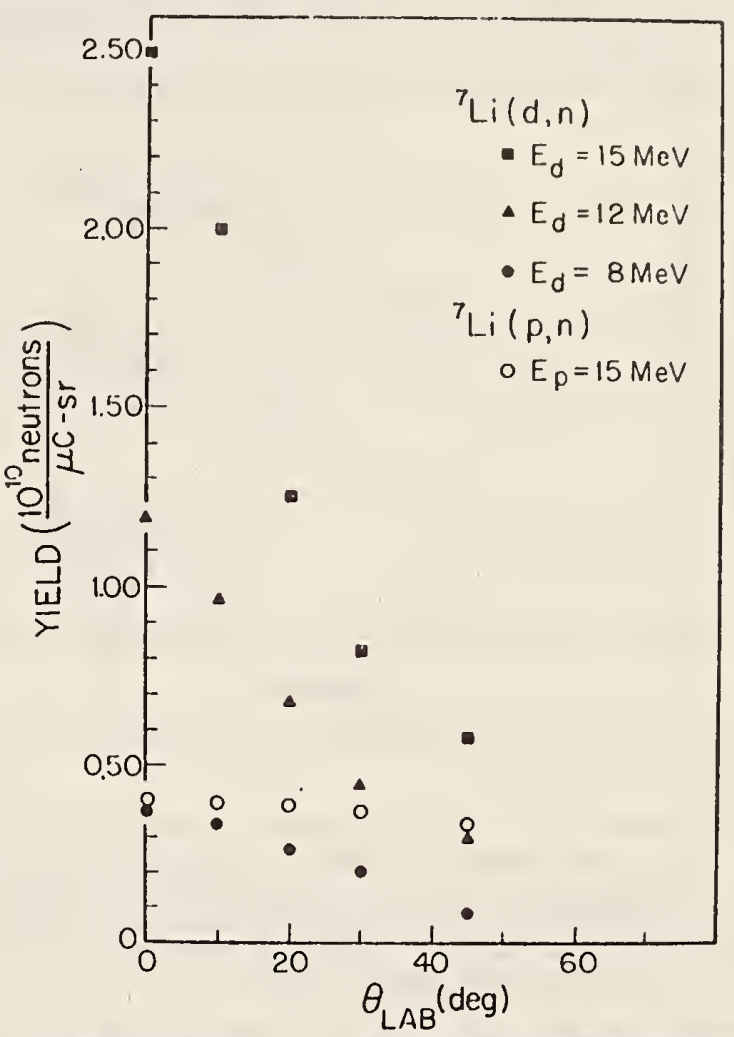

Fig. 6 Neutron yield for $E_{n}>1.0 \mathrm{MeV}$ versus laboratory angle.

The ${ }^{7} \mathrm{Li}(\mathrm{d}, \mathrm{n})$ data indicate a peak in the yield at zero degrees, which becomes more pronounced with increasing deuteron energy, while the ${ }^{7} \mathrm{LI}(\mathrm{p}, \mathrm{n})$ data are essentlally isotropic.

Table 2 gives the average neutron energies calculated from these neutron yleld data and numerical values of the yields.

Table 2

Thick Target Y1elds and Average Neutron Energles for $E_{n}>1.0 \mathrm{MeV}$ $E_{d}=8 \mathrm{MeV} \quad E_{d}=12 \mathrm{MeV} \quad E_{d}=15 \mathrm{MeV} \quad E_{p}=15 \mathrm{MeV}$

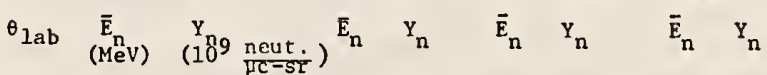

$\begin{array}{lllllllll}0 & 4.4 & 3.8 & 5.5 & 12 . & 6.5 & 25 . & 4.7 & 4.1\end{array}$

$\begin{array}{lllllllll}10 & 4.5 & 3.4 & 5.7 & 9.6 & 6.6 & 20 . & 4.6 & 4.0\end{array}$

$\begin{array}{lllllllll}20 & 4.8 & 2.7 & 5.9 & 6.7 & 6.6 & 13 . & 4.5 & 4.0\end{array}$

$\begin{array}{lllllllll}30 & 5.7 & 2.0 & 5.7 & 4.5 & 5.9 & 8.2 & 4.5 & 3.8\end{array}$

$\begin{array}{lllllllll}45 & 6.0 & 0.85 & 5.3 & 3.0 & 5.4 & 5.8 & 4.5 & 3.4\end{array}$ 
There are several earlier measurements of neutron spectra from thick 11thlum targets $2,5,6)$. Comparisons of the present data with these measurements are shown in $\mathrm{fig} .7$, where both the yleld and average neutron energy are plotted as a function of deuteron energy.

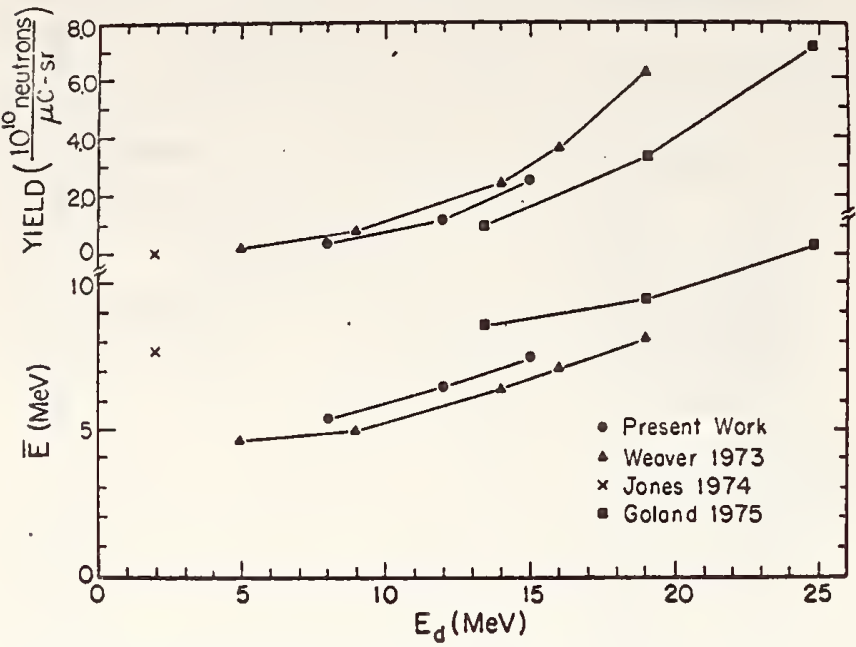

F1g. 7 Average neutron energy and yleld versus deuteron energy.

The present data are in substantlal agreement with the previous measurements of Weaver et a1.2 The discrepancy between the present work and Weaver for the average neutron energy (approximately 10\%) is consistent with the different low energy cut off and extrapolation to zero neutron energy used.

The large discrepancles between the present work and that of Jones et al. and Goland are $11 \mathrm{kely}$ the result of similar extrapolation differences. 5,6 The present work, because it extends to a neutron energy of $1.0 \mathrm{MeV}$, is less dependent on extrapolations to zero neutron energy than the previous measurements, some of which extrapolated from $E_{n} \sim 4.0 \mathrm{MeV}$ to zero neutron energy 6 ).

The present data show that at the deuteron energies available to the smaller cyclotrons, the ${ }^{7} \mathrm{Ll}(\mathrm{d}, \mathrm{n})$ reaction is not a practical source of neutrons for fast neutron therapy. The neutron yleld compares favorably with the neutron yleld from thick beryllium targets. However, the average neutron energy is substantlally lower than $10 \mathrm{MeV}$ for all deuteron energies, varying with deuteron energy approximately as $\mathrm{E}_{\mathrm{n}}=.44 \mathrm{Ed}$. Th1s is similar to the relationship found for beryllium targets by Weaver, $\overline{\mathrm{E}}_{\mathrm{n}}=.42 \mathrm{E}$. Both the average neutron energy and yleld of the $7 \mathrm{Li}(p, n)$ reaction indicate that it is not suitable for fast neutron therapy at $E_{p}=15 \mathrm{MeV}$. The average neutron energy 1s only $4.7 \mathrm{MeV}$ while the yleld is only $.4 \times 10^{10} \mathrm{n} / \mu \mathrm{C}-\mathrm{sr}$.

To conclude, the present work Indicates that neither the deuteron induced or the $15 \mathrm{MeV}$ proton induced reactions on thick lithium produce a sultable fast neutron beam for therapy. The average neutron energy is such as to provide only marginal penetration in tissue.
1. Kelsey, C.A., 1975, Medica1 Physics 2, 185.

2. Weaver, K.A., Anderson, J.D., Barschall, H.H. and Davis, J.C., 1973, Nuclear Sclence and Englneering $52,35$.

3. Parnel1, C.J., 1971, Brit1sh Journal of Rad1ology, 44,612 .

4. Brennan, J.T., 1969, Radiological Clinics of North America, 7, 365.

5. Jones, D.T.L. and Bartle, C.M., 1974, Nuclear Instruments and Methods, $118,525$.

6. Goland, A.M., Snead, C.L. Jr., Parker, D.M. and Theus, R.B., 1975, Reported at the Charged Particle Accelerator Conference, Washington, D.C. IEEE, NS521.

7. Jungerman, J.A., Brady, F.P., Knox, W.J., Montgomery, T., McGie, M.R., Romero, J.L. and Ishizak1, $\mathrm{Y}, 1971$, Nuclear Instruments and Methods 94, 421.

8. Glasgow, D., Purser, F.O., Clement, J.C., Mack, G. Stelzer, K., Boyce, J.R., Epperson, D.H., Hogue, H.H., Bllpuch, E.G., Newson, H.W. and Gould, C.R., 1975, NBS Special Publication 425, Proceedings of Nuclear Cross Sections and Technology Conference 1 , 99.

9. Drosg, M., 1974, Los Alamos Sclent1f1c Laboratory Report LA-5732-MS.

10. McDaniels, D.K., rosg, M., Hopkins, J.C. and Seagrave, J.D., 1973, Physica1 Review C, 882.

11. Morgan, private communication.

* Supported by Nat1onal Cancer Institute Research Fellowsh1p 非 F22 CA00332-01

$\dagger$ Supported by U.S. ERDA 
M.A. Lone

Atomic Energy of Canada Limited, Chalk River Nuclear Laboratories, Chalk River, Ontario, Canada KoJ 1Jo

This report compares the spectral distributions of neutrons of energies greater than 300 keV produced by bombarding thick ${ }^{7} \mathrm{Li}$ and ${ }^{9} \mathrm{Be}$ targets with protons and deuterons of energies 14.8 , 18 and $23 \mathrm{MeV}$. The experimental technique used to measure the scattered neutron background is described and the data are compared with previously reported spectral distributions.

(Nuclear reactions; ${ }^{7} \mathrm{Li}\left({ }_{\mathrm{p}}^{\mathrm{d}}, \mathrm{n}\right),{ }^{9} \mathrm{Be}\left(\mathrm{p}_{\mathrm{p}}^{\mathrm{d}}, \mathrm{n}\right)$; measured neutron spectral distributions for $\mathrm{E}_{\mathrm{n}}>0.3 \mathrm{MeV} ; \theta=0^{\circ}, 10^{\circ}, 20^{\circ}, 30^{\circ}, 40^{\circ} ; \mathrm{E}=14.8,18,23 \mathrm{MeV}$ )

\section{Introduction}

The usefulness of neutron sources for cancer therapy and materials radiation damage studies for CTR Programs critically depends on the absolute neutron source strength and the neutron spectral distributions. The intense neutron fluxes for such studies can be obtained from the $(d, n)$ and $(p, n)$ reactions on $L i$ and Be targets at moderate projectile energies. From these reactions the energy distributions of the neutrons are quite broad and depend on the target thickness, the incident projectile energy and the reaction channels open.

Low energy neutrons are to be expected in these reactions even with thin targets because of two processes: first, the compound nucleus formation and the subsequent statistical neutron decay to the highly excited states in the residual nucleus and second, multibody break-up reactions which give rise to a general continuum of low energy neutrons. Thresholds for several such reactions are given in Table 1.

Table I

Q VALUES OF NEUTRON PRODUCING CHANNELS

\begin{tabular}{|clclc|}
\hline TARGET & REACTION & a(MeV $)$ & REACTION & Q( MeV $)$ \\
\hline${ }^{9} \mathrm{Be}$ & $(d, n)^{10} \mathrm{~B}$ & +4.4 & $(p, n)^{9} \mathrm{~B}$ & -1.9 \\
& $(d, 2 n)^{9} \mathrm{~B}$ & -4.1 & $\left(p,{ }^{5} \mathrm{He}\right)^{5} \mathrm{Li}$ & -4.4 \\
& $(d, p n)^{9} \mathrm{Be}$ & -2.2 & $(p, n \alpha)^{5} \mathrm{Li}$ & -3.5 \\
& $(d, p 2 n) 2^{4} \mathrm{He}$ & $-3 . \mathrm{B}$ & $(p, p n)^{6} \mathrm{Be}$ & -1.7 \\
& $(d, p) 2^{5} \mathrm{He}$ & -5.7 & $(p, p \alpha)^{5} \mathrm{He}$ & -2.5 \\
& $\left(d,{ }^{5} \mathrm{Ho}\right)^{6} \mathrm{Li}$ & -1.0 & $(p, n p \alpha)^{4} \mathrm{He}$ & -1.6 \\
& $(d, n)^{8} \mathrm{Be}$ & +15.0 & $(p, n)^{7} \mathrm{Be}$ & -1.7 \\
& $(d, 2 n)^{7} \mathrm{Be}$ & -3.9 & $(p, 2 n)^{6} \mathrm{Be}$ & -123 \\
& $(d, 3 n)^{6} \mathrm{Be}$ & -14.5 & $(p, p n)^{6} \mathrm{Li}$ & -7.3 \\
& $(d, p n)^{7} \mathrm{Li}$ & -2.2 & $(p, p d)^{5} \mathrm{He}$ & -9.6 \\
& $(d, \alpha)^{5} \mathrm{He}$ & +14.2 & $\left(p,{ }^{3} \mathrm{He}\right)^{5} \mathrm{He}$ & -4.1 \\
& & & $(p, n \alpha)^{3} \mathrm{He}$ & -3.2 \\
\hline
\end{tabular}

Several measurements ${ }^{1-18}$ of the neutron spectral distributions from $\mathrm{Li}$ and Be targets from proton and deuteron projectiles have been reported. Most of these measurements have been made with detector thresholds set above $2 \mathrm{MeV}$. None of these data extend to neutron energies below $1 \mathrm{MeV}$. In particular, the previous compilations ${ }^{8,19-21}$ of the neutron spectral distributions from $\mathrm{Be}+\mathrm{d}$ reactions with thick targets tend to imply almost negligible neutron yields below $1 \mathrm{MeV}$ neutron energy. For cancer therapy applications a quantitative knowledge of the low energy neutron yields is important in order to estimate the dose to the skin of a patient.

This report, which is based on a measurement ${ }^{22}$ at the CRNL MP Tandem accelerator, compares the yields and spectral distributions of neutrons above $0.3 \mathrm{MeV}$ from the bombardment of thick ${ }^{7} \mathrm{Li}$ and ${ }^{9} \mathrm{Be}$ targets with deuterons and protons.

\section{Experiment}

The measurements were made with a pulsed beam from the Chalk River Tandem Accelerator using the experimental set-up shown in figure 1. The metallic

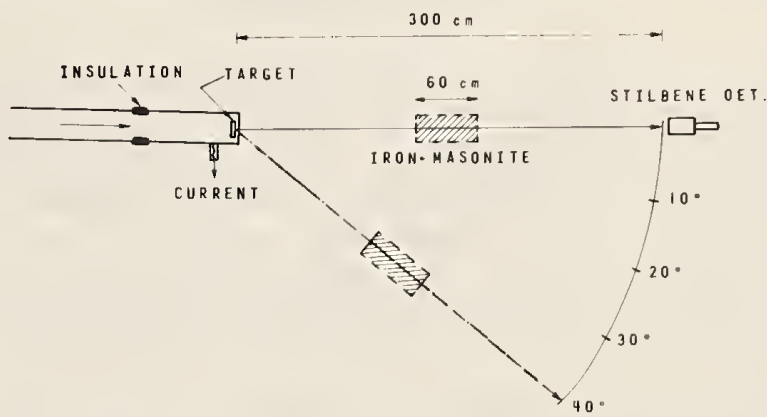

Fig. 1. Schematic illustration of the experimental setup.

${ }^{7} \mathrm{Li}\left(0.82 \mathrm{~g} \cdot \mathrm{cm}^{-2}\right)$ and ${ }^{9} \mathrm{Be}\left(0.82 \mathrm{~g} \cdot \mathrm{cm}^{-2}\right)$ targets were mounted on a thin $(0.12 \mathrm{~mm})$ stainless steel window at the end of a $12 \mathrm{~cm}$ long tube that was insulated from the rest of the beam line and served as a Faraday cup. An unshielded $13.2 \mathrm{~cm}^{3}$ cubical stilbene crystal was used for neutron detection. A $60 \mathrm{~cm}$ long iron-masonite $150 \%$ iron) block placed midway between the target and the detector was used to block off the direct neutron beam for the purpose of measuring the scattered neutron and $\gamma$-ray background for each projectile energy and angle.

A schematic diagram of the electronics is shown in figure 2. The neutron events were separated from the

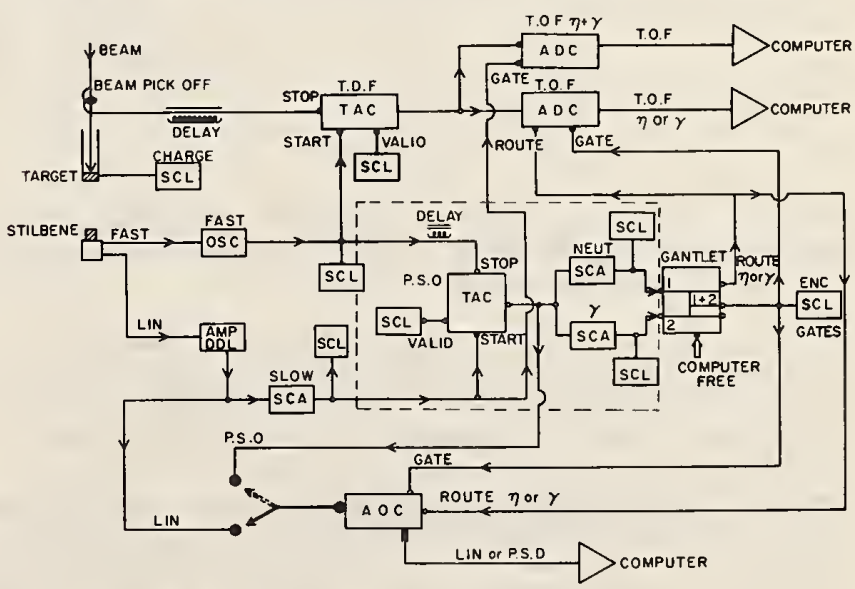

Fig. 2. Block diagram of the electronics.

$\gamma$-ray events by pulse shape discrimination (PSD) which separates the pulses according to their rise times determined by the time difference between the leading edge (measured with a constant-fraction timing unit) and the cross over point of a double-delay-line differentiated linear signal. The neutron energy was determined by the 
time-of-flight (T.O.F.) technique. For each energy and angle a set of four spectra were recorded (ungated T.O.F., neutron T.O.F., $\gamma$-ray T.O.F., linear pulseheight or PSD time-to-amplitude converter (TAC) output). The lower threshold of the single channel analyser (SCA), which provided start signals to the PSD TAC, was set slightly higher than that of the discriminator (DSC) providing start signals to the T.O.F. TAC. This procedure ensured that the detector bias was determined by the SCA threshold alone. This threshold was set at 0.04 $\mathrm{MeV}$ electron energy and was monitored at intervals with a ${ }^{22} \mathrm{Na} \gamma$-ray source to safeguard against drifts that would have affected the detector efficiency.

A number of scalers (SCL) were used to monitor the dead times of the T.O.F. TAC, the PSD circuit, the analogue-to-digital converter ( $A D C)$ and the computer individually. The overall system dead time was of the order of $20 \%$.

\section{Background Checks}

As mentioned earlier the background events due to scattered neutrons and $\gamma$-rays were measured by blocking the direct path between the source and the detector with a $60 \mathrm{~cm}$ long iron-masonite block placed midway in the flight path. This location of the block minimized its effect on the background events reaching the detector from the room walls, the floor and the beam tubes. The block was sufficiently long that the secondary radiation from it was almost isotropic and consequently, because the two solid angles involved were small, its effect on the detector was negligible. For the direct measurements the block was moved well away from the flight path in order to eliminate small angle scattered events reaching the detector.

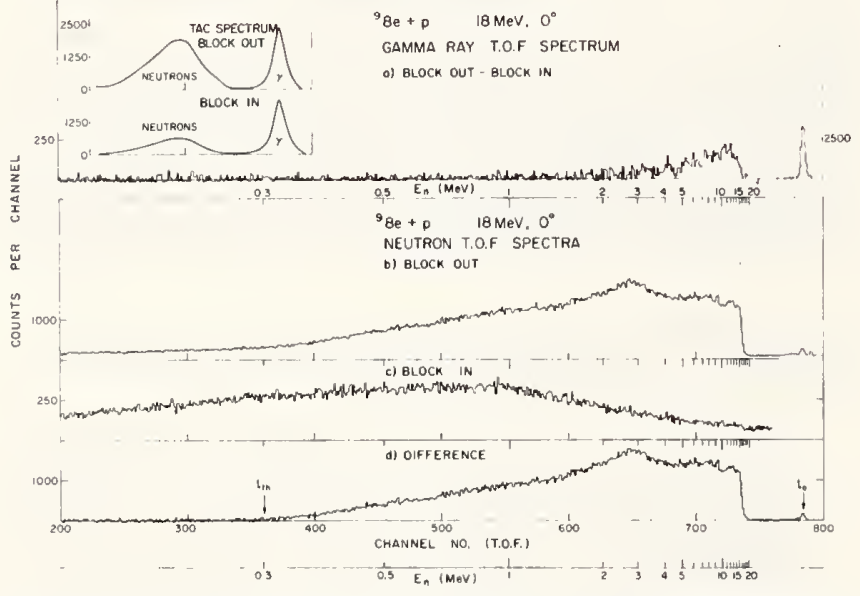

Fig. 3. T.O.F. spectra; a) $\gamma$-rays; b) neutrons with no block in the flight path; c) with block in; d) the difference between $b$ ) and $c$ ).

The T.O.F. spectra shown in figure 3 demonstrate the effectiveness of this blocking technique in eliminating the background events from the neutron T.O.F. spectrum. Figure $3(a)$ shows the difference of the T.O.F. spectra of $\gamma$-ray events (gated with the $\gamma$-ray peak in the PSD TAC pulse height spectrum, inset figure 3) recorded with block out and block in. The $\gamma$-ray events above channel 700 are from the inelastic scattering of fast neutrons in the vicinity of the detector.

The spectrum (d) in figure 3 is the difference between the dead time corrected spectra (b) taken without the block and spectrum (c) taken with the block. As expected the difference spectrum (d) contains no events beyond the prompt $\gamma$-ray peak, nor at channels below the T.O.F. corresponding to the neutron detection threshold which was set at $0.3 \mathrm{MeV}$ neutron energy.

\section{Detector Efficiency}

The detector efficiency was calculated with the aj, of the program DETEFF which is based on an earlier ver sion by $\mathrm{Kurz}^{23}$. The program includes contributions to the scintillation light output from the $(n, n)$ reaction in $H$ as well as the $(n, p),(n, \gamma),\left(n, n^{\prime} \gamma\right)$ and $\left(n, n^{\prime} 3 \alpha\right)$ reactions in $\mathrm{C}$. Thornton and $\mathrm{Smith}^{24}$ have carried out extensive tests of this program and have found the cal culated efficiencies to be accurate to within $\pm 10 \%$.

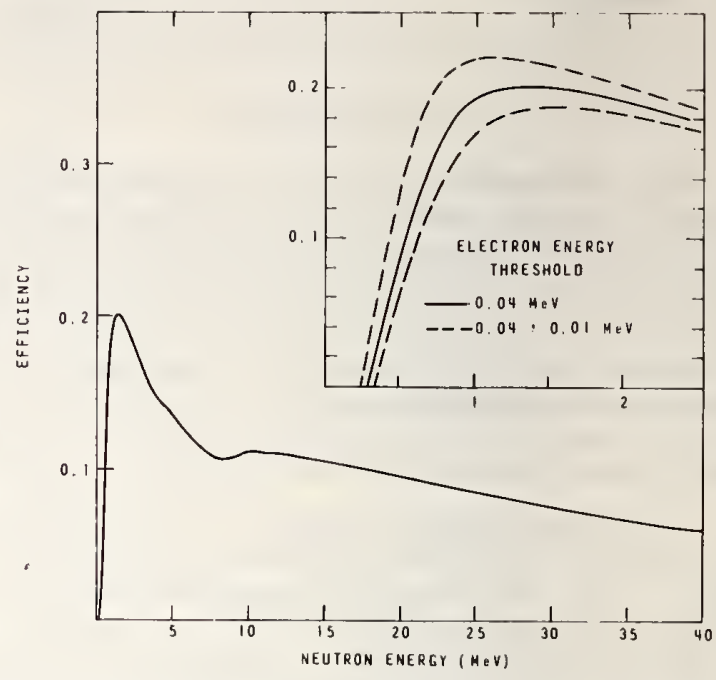

Fig. 4. Neutron detection efficiency of the $13.2 \mathrm{~cm}^{3}$ stilbene crystal calculated with the program DETEFF ${ }^{23}$.

The calculated efficiency of the $13.2 \mathrm{~cm}^{3}$ stilbent crystal is shown in figure 4 for an electron energy threshold of $0.04 \mathrm{MeV}$. The dotted lines in the figure represent the calculated efficiency with the threshold varied by $\pm 25 \%$. The uncertainty, due to energy calibration and resolution, in setting the threshold relative to the Compton edge of the $0.511 \mathrm{MeV} \gamma$-rays from the ${ }^{22} \mathrm{Na}$ source was less than 258 .

\section{Results: Spectral Distributions}

The spectral distributions were measured at flight paths of $3 \mathrm{~m}$ for the $(p, n)$ reactions and $3.76 \mathrm{~m}$ for the $(d, n)$ reactions. The overall time resolution in the T.O.F. spectra was $2.8 \mathrm{~ns}$. The resultant energy resolution was $5.8 \%$ at $5 \mathrm{MeV}$ and 11.48 at $20 \mathrm{MeV}$ for the $(p, n)$ measurements and $4.6 \%$ at $5 \mathrm{MeV}$ and 9.18 at $20 \mathrm{MeV}$ for the $(d, n)$ measurements.

The experimental uncertainties in the spectral distributions come primarily from three sources. First, there are the statistical uncertainties which are indicated by error bars in figures 5-8. Second, there is the beam current (at the Faraday cup) integrator uncertainty which was less than $3 \%$. Third, there are uncertainties due to the detector efficiency. These are difficult to assess but based on previous tests ${ }^{24}$ these are' expected to be $\pm 10 \%$ for $E_{n}>2 \mathrm{MeV}$. For $E_{n}<2 \mathrm{MeV}$ the uncertainty is shown by the dotted curves in the inset in figure 4 . The resultant overall systematic uncertainty is estimated to be less than \pm 15 \% for $\mathrm{E}_{\mathrm{n}}>2 \mathrm{MeV}$.

$\underline{\mathrm{Li}+\mathrm{d}}$

The thick target neutron spectral shapes from ${ }^{7} \mathrm{Li}$ and natural $\mathrm{Li}\left(93 \%{ }^{7} \mathrm{Li}\right)$ targets for deuteron energies 13 to $23 \mathrm{MeV}$ are shown in figure 5 . Curves 1,3 and 5 show our $0^{\circ}$ results from 23, 18 and $14.8 \mathrm{MeV}$ deuteron bombardment. The error bars represent the uncertainty due to counting statistics alone. The small bumps 
between 8 and $10 \mathrm{MeV}$ are probably an artifact of the calculated detector response function. Curve 2 shows the neutron spectrum at $3.5^{\circ}$ from $19 \mathrm{MeV}$ deuteron bombardment reported by Weaver et al.'

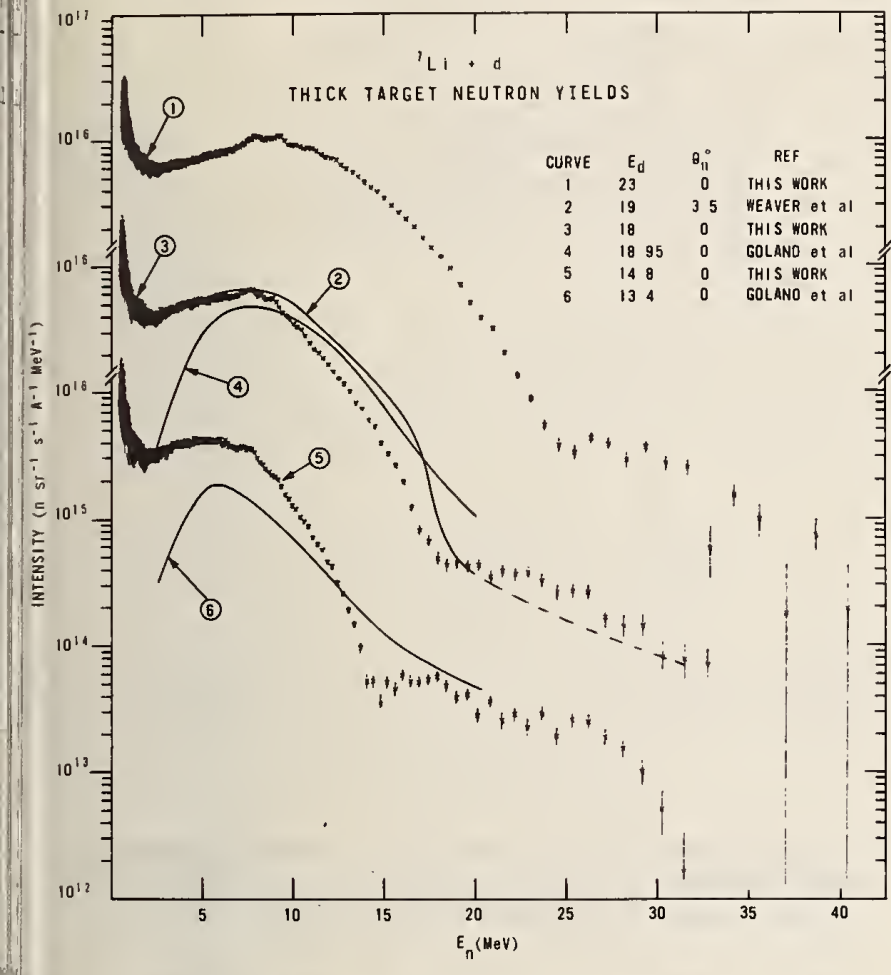

Fig. 5. Neutron spectral distributions from $L i+d$ reactions. Curves 1,3 and 5 for targets enriched in ${ }^{7} L i$; the other curves are for natural Li.

The spectral shapes, curves 4 and 6 , reported by Goland et al. 9 for $18.95 \mathrm{MeV}$ and $13.4 \mathrm{MeV}$ show considerably less yield at neutron energies below $5 \mathrm{MeV}$ than is shown by our measurements.

$\mathrm{Be}+\mathrm{d}$

The neutron spectral distributions from thick ${ }^{9} \mathrm{Be}$ targets bombarded with deuterons in the energy range 14 to $23 \mathrm{MeV}$ are shown in figure 6 : Curves 1,3 and 5 give our measurements at $0^{\circ}$ from 23,18 and $14.8 \mathrm{MeV}$ deuteron bombardment respectively. Curve 2 shows the measurements of Daruga and Matusevich ${ }^{5}$. They used a stilbene neutron detector but the neutron yields were extracted by converting the amplitude distributions into neutron energy spectra. Curve 4 shows the neutron yields at $3.5^{\circ}$ from $18 \mathrm{MeV}$ deuteron bombardment measured by Weaver et al. ' with a Ne213 detector with the detector , threshold set at $2.3 \mathrm{MeV}$. Curve 6 shows the spectral distributions from $15 \mathrm{MeV}$ deuteron bombardment reported by Cohen and $\mathrm{Falk}^{6}$. The neutron spectral distributions from $15 \mathrm{MeV}$ deuteron capture reported by Meulders et al.? are also in good agreement with the shapes shown in figure 4. However, several other compilations ${ }^{8,19-21}$ of the neutron spectral distributions from the Betd reactions show a rapid decrease of neutron yields at $E_{\mathrm{n}} \leqslant 0.3 \mathrm{E}_{\mathrm{d}}$ in disagreement with our observations.

\section{$\underline{L i+p}$}

The neutron spectral distributions are shown in figure 7. The uncertainty due to the counting statistics is shown by vertical bars. Unlike those from the $(d, n)$ reactions the neutron yields from the $(p, n)$ reactions show an essentially monotonic decrease with increasing neutron energy. Our results are in disagreement with the thick target spectral distributions calculated by Chaudhri et al. ${ }^{25}$

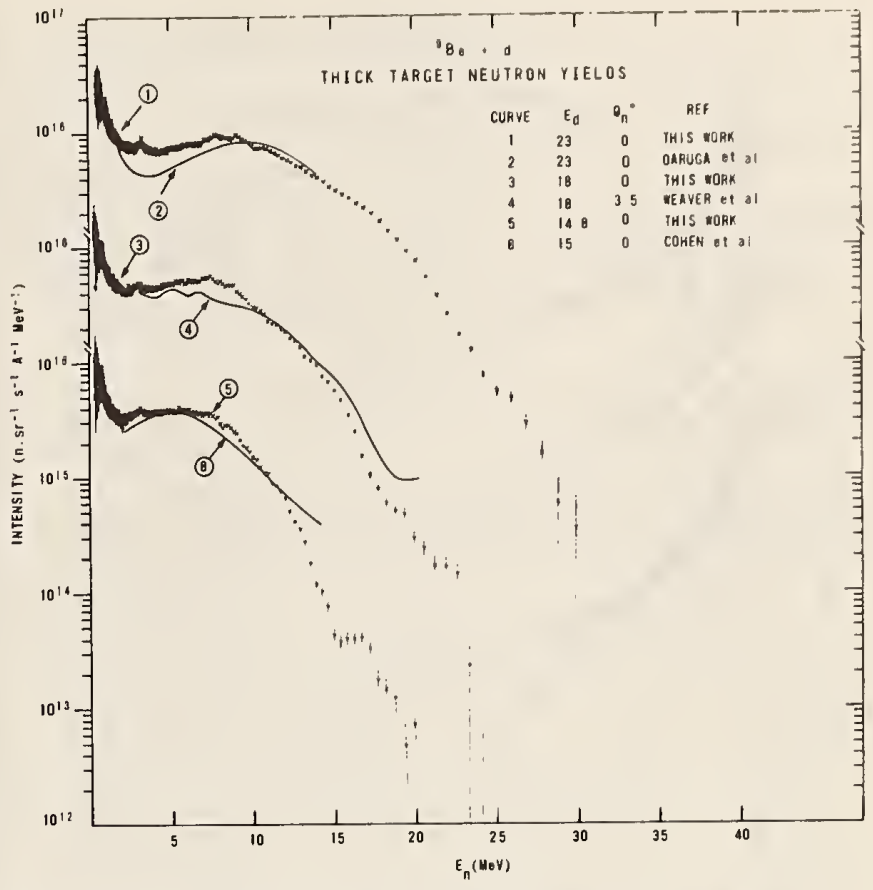

Fig. 6. Neutron spectral distributions from the ${ }^{9}$ Betd reactions in thick targets.

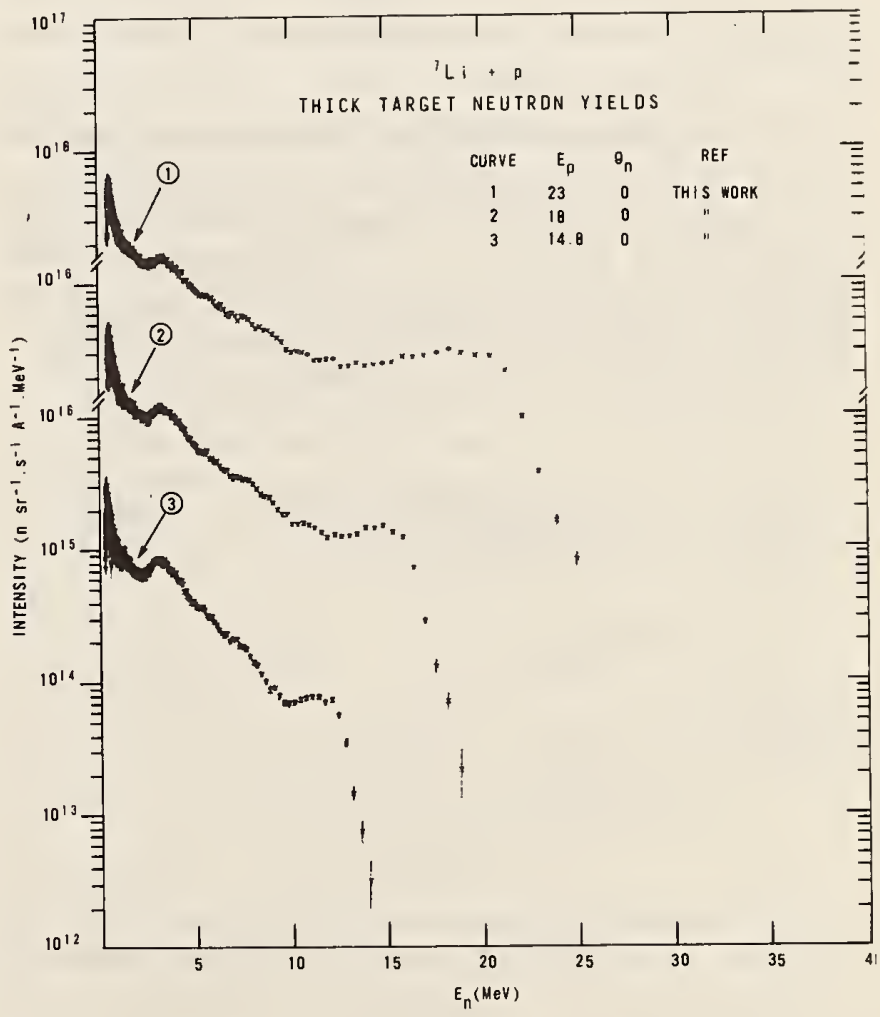

Fig. 7. Neutron spectral distributions from the ${ }^{7} L i+p$ reactions.

$\underline{B e+p}$

The neutron spectral distributions from a thick ${ }^{9}$ Be target are shown in figure 8 . Curve 4 shows the results of Kuchnir et al. ${ }^{2}$ measured at $15^{\circ}$ with 14.8 $\mathrm{MeV}$ protons. 


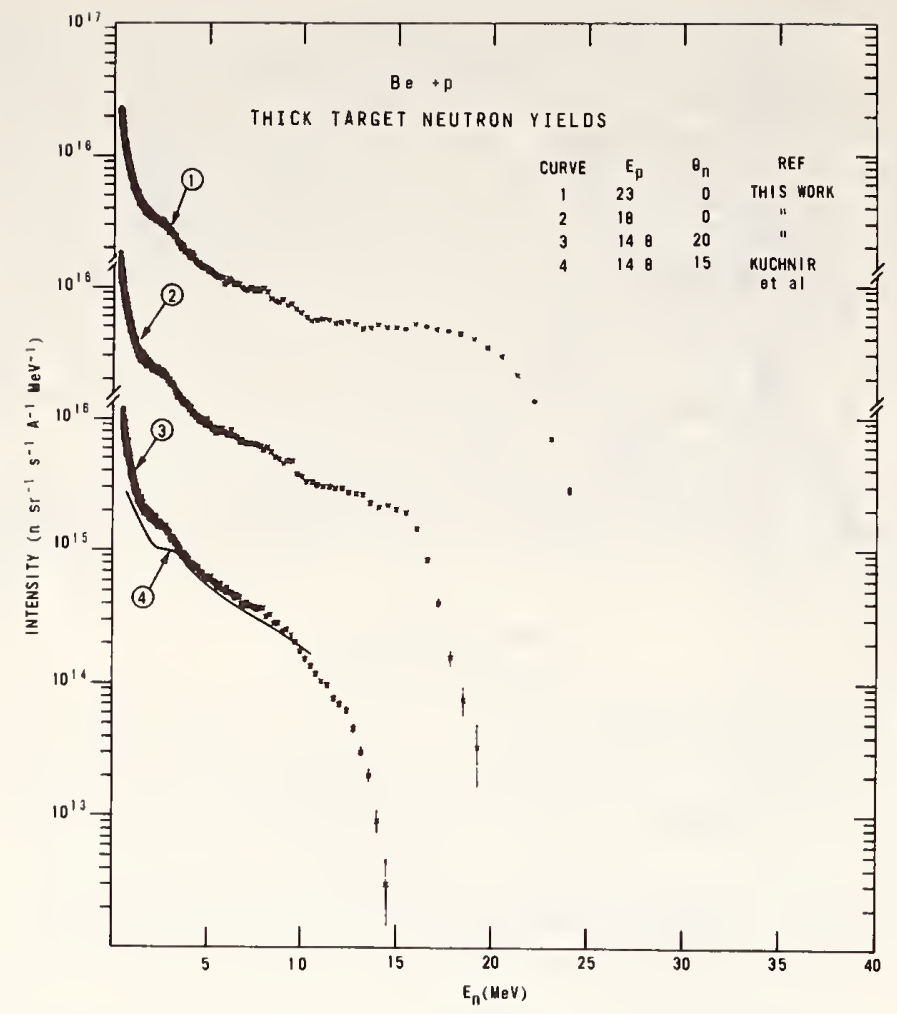

Fig. 8. Neutron spectral distributions from the ${ }^{9} \mathrm{Be}+\mathrm{p}$ reactions.

\section{Low Energy Neutrons and the Average Neutron Energies}

In several previous measurements ${ }^{1-18}$ the spectral distributions have been measured with neutron detector thresholds set above $\sim 2 \mathrm{MeV}$. Figure 9 shows the relative magnitude of the low energy neutrons $E_{n}<2.3 \mathrm{MeV}$ observed in different reactions at $0^{\circ}$. The target thicknesses were $1.5 \mathrm{~cm}$ for ${ }^{7} \mathrm{Li}$ and $0.45 \mathrm{~cm}$ for ${ }^{9} \mathrm{Be}$. The dotted curves are simply to guide the eye.

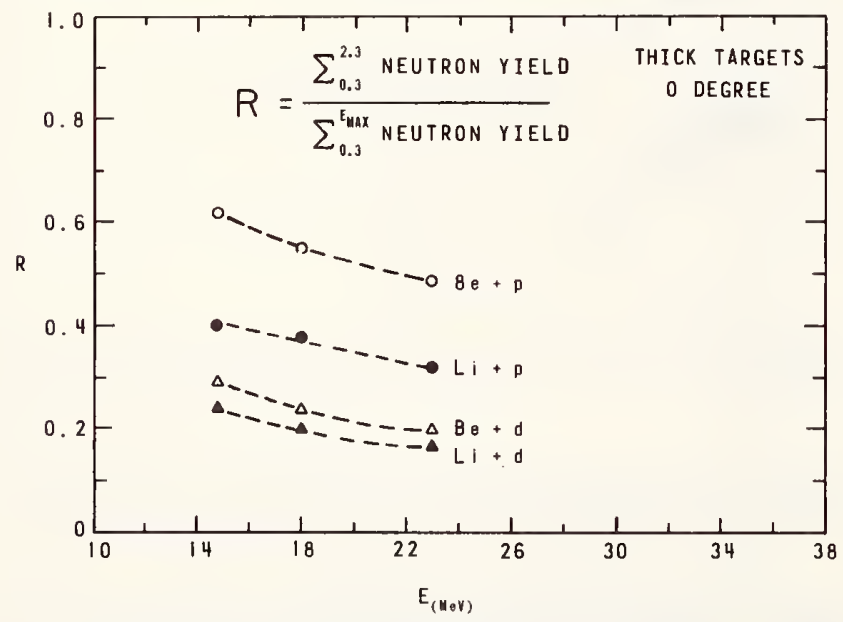

Fig. 9. Relative magnitude of the low energy $E_{n}<2.3$ neutron component as a function of the projectile energy.

The relative magnitude of the low energy component decreases at higher projectile energies. However, it should be pointed out that our targets were thicker than needed to stop the protons and deuterons of energies less than $25 \mathrm{MeV}$ and we have not as yet investigated the effects of this extra thickness on the spectrum shapes.
The average neutron energy decreases with increas ing angle. The dependence of the average neutron ene: gies on the angle is shown in figures 10 and 11.

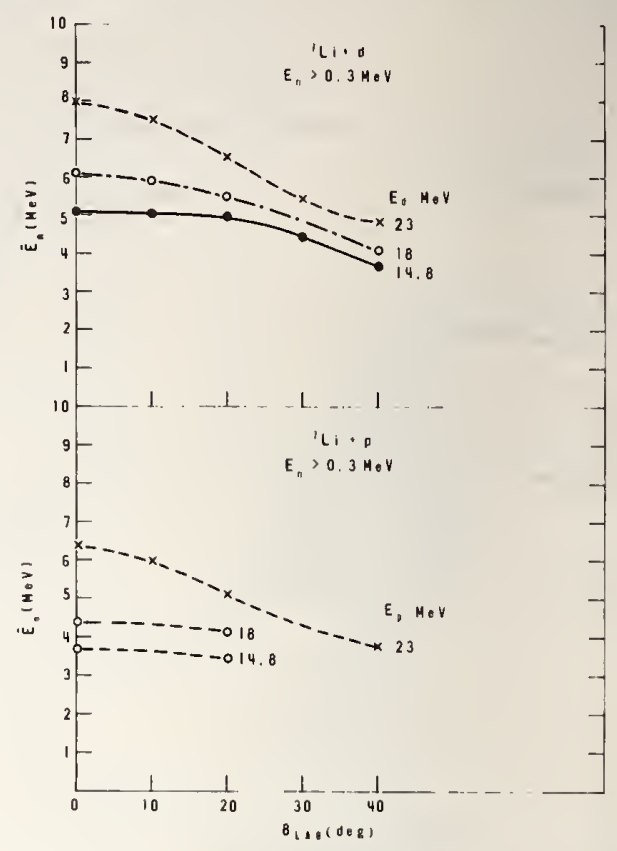

Fig. 10. Variation of the average neutron energy $\bar{E}_{n}$ with the neutron emission angle for the ${ }^{7} \mathrm{Li}+d$ and ${ }^{7} \mathrm{Li}+\mathrm{p}$ reactions with thick targets.

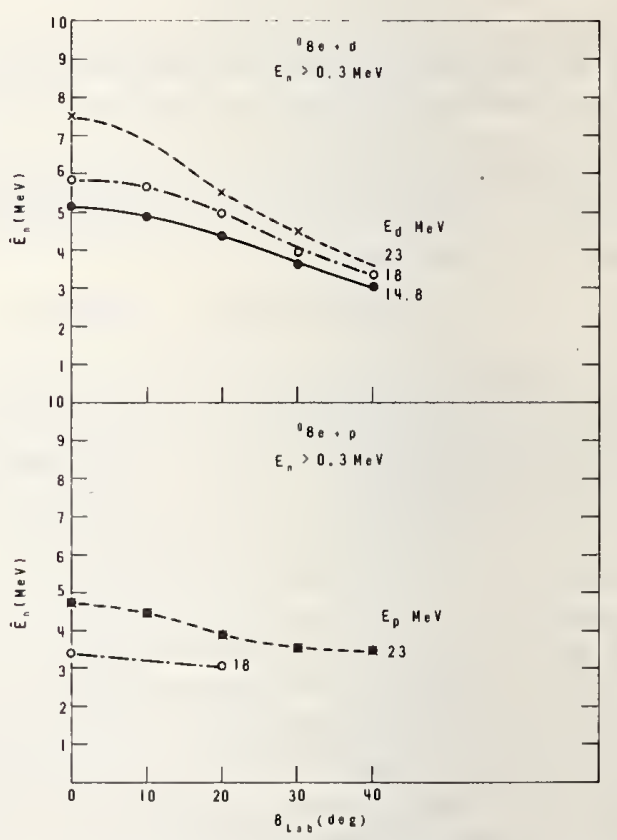

Fig. 11. Variation of the average neutron energy $\bar{E}_{n}$ with the neutron emission angle from the ${ }^{9}$ Betd and ${ }^{9} \mathrm{Be}+\mathrm{p}$ reactions with thick targets.

\section{Angular Distributions}

The angular distributions are shown in figures 12 and 13. As observed previously $1,2,5$ the angular distributions from the $(d, n)$ reactions are much more strongly forward peaked than those from the $(p, n)$ reactions. 


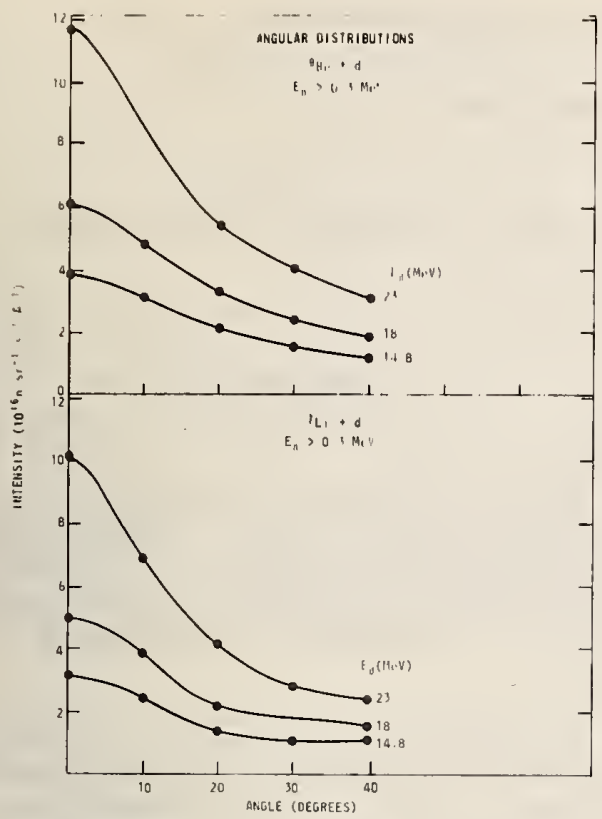

Fig. 12. Angular distributions of the neutron intensity from the ${ }^{9} \mathrm{Be}+d$ and ${ }^{7} \mathrm{Li}+d$ reactions with thick targets.

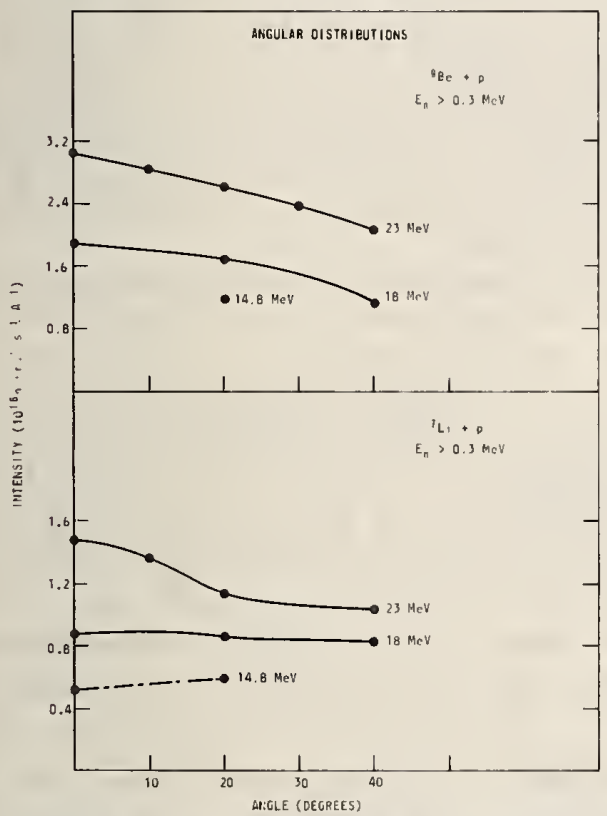

Fig. 13. Angular distributions of the neutron intensity from the ${ }^{9} \mathrm{Be}+\mathrm{p}$ and ${ }^{7} \mathrm{Li}+\mathrm{p}$ reactions with thick targets.

\section{References}

1. K.A. Weaver, J.D. Anderson, H.H. Barschall and J.C. Davis, Nucl. Sci. and Eng. 52 (1973) 35.

2. F.T. Kuchnir, L.S. Skaggs, A.J. Elwyn, F.P. Mooring and N.A. Frigerio, Cyclotron-1972, Ed. J.J. Bugerjon and A. Strathdee (Am. Inst. of Physics, New York, 1972) p. 638.

3. E.A. Kuzmin, A.A. Ogloblin, N.I. Sidorov, A.R. Faiziev and G.B. Yankov, INC Report INDC (CCP) $-37 / \mathrm{U}$ in Proc. IAEA Symp. on the Usage of Nucl. Data in Science and Technology, Paris (1973) IAEA Nucl. Data Section Karntner Ring 11, A-1010 Vienna.

4. C.E. Nelson, F.O. Purser, P. von Behren and H.W. Newson, Cont. PH2/L4 to the 1976 Int. Conf. on Interactions of Neutrons with Nuclei, July 6, 1976, Lowell, Massachusetts, U.S.A.
5. V.K. Darucja, F.S. Matus :vich and Kh. Harziev, Atcmnaya Energia, 33(1972) 934.

6. B.L. Cohen and C.E. Falk, Phys. Rev. 84 (1951) 173.

7. J.P. Meulders, P. LeLeux, P.C. Macq and C. Pirart, Phys. Med. Biology 20 (1975) 235.

8. C.J. Parnell, Brit. Journ. of Radiology 45(1972)452.

9. A.N. Goland, C.L. Snead Jr., D.M. Parkin and R.B. Theus, IEEE Transactions on Nuclear Science, Vol. NS-22 (1975) 1776 .

10. R.B. Theus, R.O. Bondelid, F.H. Attix, L.S. August, P. Shapiro, R.E. Surratt and C.C. Rogers, Cancer 34 (1974) 17 .

11. M.J. Saltmarsh, C.A. Ludemann, C.B. Fulmer and R.C. Styles, Report ORNL/TM-5696 Oak Ridge National Laboratory 1976.

12. L. Cranberg, J.P. Barnett, D.S. Cramer and R.D. wilson, Nucl. Inst. and Meth. 96 (1971) 493.

13. J.A. Jungerman, F.P. Brady, W.J. Knox, T. Mont.gomery, M.R. MCGie, J.L. Romero and Y. Ishizaki, Nucl. Inst. and Meth. 94 (1971) 421.

14. M.W. MCNaughton, N.S.P. King, F.P. Brady, J.L. Romero and T.S. Subramanian, Nucl. Inst. and Meth. 130 (1975) 555 .

15. J.W. Wachter, R.T. Santoro, T.A. Love and W. Zobel, Nucl. Instr. and Meth. 113(1973) 185.

16. C.J. Batty, B.E. Bonner, A.I. Kilvington, C. Tschalar, L.E. Williams and A.S. Clough, Nucl. Inst. and Meth. 68(1969) 273.

17. M.C. Scott, J. of Nucl. Energy 25(1971) 405.

18. D.R. Nethaway, R.A. van Konynenburg and T.M. Adams, Measurements of the Neutron Spectrum from the Reaction of $30 \mathrm{MeV}$ Deuterons on a Thick Be Target, UCRL-52024, Lawrence Livermore Laboratory, California 1976.

19. K. Schmidt and H. Munzel. Production of Neutrons through Irradiation of Thick Be Targets with Deuterons in the Energy Range from 15 to $55 \mathrm{MeV}$. Report KFK 1288, Gesellschaft für Kernforschung M.D.H. Karlsruhe 1970.

20. G. Burger and J.J. Broerse, IAEA/SM-179/35, Int. Symp. on the Biological Effects of Neutron Irradiation, Neuherberg (Munchen) Germany, 1973 (IAEA 1974) p.3.

21. S.M. Qaim, NBS-425. Nuclear Cross Sections and Technology, Vol. II, p.664; National Bureau of Standards, 1975.

22. M.A. Lone, C.B. Bigham, J.S. Fraser, H.R. Schneider, T.K. Alexander, A.J. Ferguson and A.B. McDonald, Nucl. Instr. and Meth. (to appear in 1977).

23. R.J. Kurz, UCRL-11339, Lawrence Radiation Laboratory (1964).

24. S.T. Thornton and J.R. Smith, Nucl. Instr. and Meth. 96 (1971) 551 .

25. M.A. Chaudhri, S. Zuberi, A.J. Chaudhri and O.J. Chaudhri, ${ }^{7} \mathrm{Li}(\mathrm{p}, \mathrm{n})$ Be Reaction as a Useful Source of Fast Neutrons for Therapy, reported at the 2nd Meeting on Fundamental and Practical Aspects of the Applications of Fast Neutrons in Clinical Radiotherapy, October, 1973. 


\author{
M. Awschalom \\ Fermi National Accelerator Laboratory* \\ P.O. Box 500 \\ Batavia, Illinois 60510
}

Protons of 35 and $65 \mathrm{MeV}$ and deuterons of $35 \mathrm{MeV}$ were used to bombard beryllium and lithium targets of various thicknesses. Energy spectra were measured by time-of-flight.

(Li, Be, neutron sources, thick-target yields)

\section{Introduction}

This work is part of a much broader survey made for the characterization of various neutron beams by collaborators from four laboratories. The full report, Physical Characterization of Neutron Beams Produced by Protons and Deuterons of Various Energies Bombarding Beryllium and Lithium Targets of Several Thicknesses by H. I. Amols, M. Awschalom, L. Coulson, J. F. Dicello, S. W. Johnsen and R. B. Theus is available as a Fermilab preprint.

While planning a neutron beam irradiation facility for cancer therapy research at the Fermi National Accelerator Laboratory, it was deemed necessary to characterize physically a number of potentially useful neutron beams. The available proton beam could have any energy between 37.54 and $66.18 \mathrm{MeV}$. Hence, the characteristics of the forward scattered neutron beams created during the bombardment of the lithium and beryllium targets of various thicknesses were studied as well as those of neutron beams due to $35 \mathrm{MeV}$ deuterons incident on beryllium. These measurements were done in conjunction with personnel from a medical accelerator development project at LASI. 2 The part reported here is that concerned only with neutron energy spectra.

Although the measurements have produced a large amount of data, they were designed only as a preliminary study. Hence, the uncertainties associated with the present data may be unacceptable for some applications.

\section{Experimental set-Up}

These measurements were performed using the 76-inch isochronous cyclotron at the University of California, Davis. 3 The charged particle beams were directed successively onto eight targets mounted in a target wheel. The neutrons emanating at $0^{\circ}$ from the incident beam were collimated by a $1.5 \mathrm{~m}$ long steel collimator with a rectangular opening $5.7 \mathrm{~cm}$ by $7.0 \mathrm{~cm}$. The collimator exit was $2.85 \mathrm{~m}$ from the upstream face of the targets.

Charged particles exiting the target were swept out of the neutron beam by a magnet placed between the target wheel and the collimator. The incident beam current was measured by placing a $0.012 \mathrm{~mm}$ thick aluminum foil upstream of the target wheel in the charged particle beam and measuring the secondary electron emission current produced by the particles traversing the foil. This system was calibrated by comparison of the secondary electron emission current against a Faraday cup current. This calibration was repeated periodically throughout the course of the experiment.

Operated by Universities Research Assn., Inc. under contract with USERDA.

\section{Targets}

Natural lithium and beryllium were used as targets.

The Li targets were sealed under vacuum ir side stainless steel cases. These cases had one inch inside diameters and $0.025 \mathrm{~cm}$ stainless steel entrance windows. They were machined from commercially available Li extrusions.

The windows caused an energy degradation of the incident beam. Hence, to equalize in cident energies on the lithium and the beryllium targets, $0.025 \mathrm{~cm}$ stainless steel absorbers were also placed on the upstream side of the beryllium targets.

The thicknesses of the targets were choser such that protons traversing them and having incident energies of $65 \mathrm{MeV}$ would loose eithe all their energy, $50,40,30$ or $20 \mathrm{MeV}$ by ior ization. These thicknesses were calculated using Janni's tables.4 The thickness tolerance was such that the actual target would cause the stated energy loss plus or minus $0.5 \mathrm{MeV}$.

The various target configurations are summarized in Table 1 .

Table 1

Target Lengths

\begin{tabular}{lccccc}
\hline $\begin{array}{l}\text { Energy Loss by } \\
\text { Ionization (MEV) }\end{array}$ & 65 & 50 & 40 & 30 & 20 \\
\hline & & \multicolumn{5}{c}{ Be } \\
Thickness (cm) & 2.412 & 2.212 & 1.957 & 1.603 & 1.155 \\
\pm Tolerance (cm) & 0.033 & 0.010 & 0.015 & 0.020 & 0.025 \\
& & & $\frac{\mathrm{Li}}{}$ & & \\
Thickness (cm) & 7.993 & 7.338 & 6.498 & 5.325 & 3.841 \\
\pm Tolerance (cm) & 0.110 & 0.033 & 0.051 & 0.067 & 0.082
\end{tabular}

Neutron Energy Spectra

Experimental Technique

Neutron yield and energy spectra were meas ured for $65.4 \mathrm{MeV}$ protons, $35 \mathrm{MeV}$ protons and $35 \mathrm{MeV}$ deuterons incident upon selected targets. The actual accelerated beam energies were $65.6 \mathrm{MeV}$ and $37.5 \mathrm{MeV}$ for the protons an 39.2 MeV for the deuterons to allow for energ: degradation in the windows.

The detector used for these measurements was a cylindrical NE213* liquid scintillator, $5.08 \mathrm{~cm}$ long by $5.08 \mathrm{~cm}$ diameter mounted coaxially in the neutron beam. The efficiency of the detector as a function of incident neutron energy had been calculated using a

*Nuclear Enterprises, Ltd. 
modified version of the Monte Carlo code by Stanton. 5 In a previous experiment, the efficiency of the detector had been measured at several energies to investigate the accuracy of the calculated values. 6 Pulse shape discrimination techniques were used to distinguish events initiated by gamma rays from those attributed to neutrons.

The detector was placed $2.90 \mathrm{~m}$ downstream from the target wheel and was fully illuminated by the neutron beam. The neutron timeof-flight was measured relative to a stop signal from the cyclotron r.f.

The measured target-to-detector distance, and the position of the gamma ray peak relative to the rest of the time-of-flight spectra were used to calibrate the neutron flight times. The longest flight times observed were limited by the overlapping of successive beam bursts, giving a threshold of five to nine $\mathrm{MeV}$.

Results

The measured neutron spectra are displayed in Figs. 1 through 3. Figures 1 and 2 show spectra obtained from $65.4 \mathrm{MeV}$ protons incident upon beryllium and lithium targets, respectively. The energy resolution corresponding to $65 \mathrm{MeV}$ neutron energy is $\pm 5 \mathrm{MeV}$. The overlapping of beam bursts and the finite time resolution of the detection system, together with phase shifts of the beam bursts relative to the cyclotron r.f., lead to some uncertainties in the shape of the spectra. For example, the curves do not pass through zero at the kinematic limit. The Q-values of the ${ }^{9} \mathrm{Be}(\mathrm{p}, \mathrm{n}){ }^{9} \mathrm{~B}$ and ${ }^{7} \mathrm{Li}(\mathrm{p}, \mathrm{n}){ }^{7} \mathrm{Be}$ reactions are -1.85 and $-1.64 \mathrm{MeV}$ respectively, hence, we would not expect neutrons above $63.8 \mathrm{MeV}$.

These plots show that the thinner targets produce harder spectra as expected. The increase in yield shown in changing from a target which stops the beam to a slightly thinner one is attributed to the absorption of neutrons by the thick target. The additional target material used to stop the beam, produces few neutrons in the energy range measurable, yet attenuates neutrons produced in the upstream portions of the target.

Figure 3 shows spectra measured for $35 \mathrm{MeV}$ protons and deuterons incident upon the 1.16 $\mathrm{cm}$ beryllium and $3.84 \mathrm{~cm}$ lithium targets. The $\mathrm{p}-\mathrm{Li}$ and $\mathrm{p}-\mathrm{Be}$ spectra indicate a large low energy component of evaporation neutrons, as also evidenced in other work. 7 The lithium spectrum has a larger high energy component reflecting a larger neutron production cross section for the inclusive $\mathrm{p}-\mathrm{Li}$ reaction than for $\mathrm{p}-\mathrm{Be}$ near the kinematic limit. 8 The $\mathrm{d}-\mathrm{Li}$ and d-Be spectra display the characteristic shape associated with stripping reactions. The beryllium data agree with other work ${ }^{9}$ within the accuracy of the measurements.

The neutron yield for these spectra is tabulated in Table II. The overall uncertainty in the yield, including beam current integration and detector efficiency, is $\pm 25 \%$.

Greater detail in the analysis of the uncertainties is presented by $S$. Johnsen in an accompanying report at this conference.
Table II

Integral yield of neutrons produced by bombarding lithium and beryllium targets with protons and deuterons.

\begin{tabular}{|c|c|c|c|c|c|}
\hline $\begin{array}{l}\text { Particle } \\
\text { Type }\end{array}$ & $\begin{array}{l}\text { Incident } \\
\text { Energy } \\
\text { MeV }\end{array}$ & $\begin{array}{l}\text { Targ } \\
\text { Thickness } \\
\text { cm }\end{array}$ & $\begin{array}{l}\text { get } \\
\text { Mat'1 }\end{array}$ & $\begin{array}{c}\text { Yield } \\
\text { Neutrons/ } \\
\mu \mathrm{C} / \mathrm{sr}\end{array}$ & $\begin{array}{c}\text { Cut off } \\
\text { Energy } \\
\text { MeV }\end{array}$ \\
\hline prot & 65.4 & 2.41 & $\mathrm{Be}$ & $8.8 \times 10^{10}$ & 9.1 \\
\hline$"$ & $"$ & 2.21 & $\mathrm{Be}$ & $9.4 \times 10^{10}$ & " \\
\hline$"$ & $"$ & 1.96 & $\mathrm{Be}$ & $8.8 \times 10^{10}$ & $"$ \\
\hline$"$ & $"$ & 1.60 & $\mathrm{Be}$ & $7.0 \times 10^{10}$ & $"$ \\
\hline$"$ & $"$ & 7.99 & $\mathrm{Li}$ & $10.6 \times 10^{10}$ & $"$ \\
\hline$"$ & $"$ & 7.34 & $\mathrm{Li}$ & $10.9 \times 10^{10}$ & $"$ \\
\hline$"$ & $"$ & 6.50 & $\mathrm{Li}$ & $10.7 \times 10^{10}$ & " \\
\hline " & $"$ & 5.33 & Li & $9.4 \times 10^{10}$ & $"$ \\
\hline$"$ & 35 & 1.16 & $\mathrm{Be}$ & $1.6 \times 10^{10}$ & 5.1 \\
\hline " & $"$ & 3.84 & $\mathrm{Li}$ & $1.7 \times 10^{10}$ & 5.1 \\
\hline deut & $"$ & 1.16 & $\mathrm{Be}$ & $19.1 \times 10^{10}$ & 5.0 \\
\hline$"$ & $"$ & 3.84 & Li & $21.3 \times 10^{10}$ & 5.0 \\
\hline
\end{tabular}

\section{References}

$1_{H}$. Amols, M. Awschalom, et al. "Physical Characterization of Neutron Beams Produced By Protons and Deuterons of Various Energies Bombarding Beryllium and Lithium Targets of Several Thicknesses", FERIILAB-Pub-76/102-EXP.

2H. Amols, et al. "Fast Neutron Dosimetry and Ion Linear Accelerators", LA-UR-76-1007 (1976).

${ }^{3} \mathrm{~J}$. A. Jungerman and F. P. Brady, "A MediumEnergy Neutron Facility", Nucl. Instr. Meth. $89,167(1970)$.

${ }^{4} \mathrm{~J}$. F. Janni, "Calculations of Energy Loss, Range, Pathlength, Straggling ..... for 0,1 to 1000 MeV Protons", AFWL-TR 65-150 (Sept. 1966).

${ }^{5}$ M. W. McNaughton, N. S. P. King, F. P. Brady and J. L. Ullmann, "Improved Predictions of Neutron Detection Efficiency Resulting from New Measurements of ${ }^{12} \mathrm{C}(\mathrm{n}, \mathrm{P})$ and ${ }^{12} \mathrm{C}(\mathrm{n}, \mathrm{d}) \mathrm{Re}-$ actions at 56 Mev", Nucl. Instr. Meth. 129, 241 (1975).

${ }^{6} \mathrm{P}$. Urone, private communication.

7s. W. Johnsen, "p-Be Neutron Production at 25 to $55 \mathrm{MeV}$ ", to appear in Med. Phys.

${ }^{8} \mathrm{~J}$. A. Jungerman, F. P. Brady, W. J. Knox, T. Montgomery, M. R. McGie, J. L. Romero and Y. Ishizaki, "Production of Medium-Energy Neutrons from Proton Bombardment of Light Elements", Nucl. Instr. Meth. 94, 421 (1971).

${ }^{9} \mathrm{~J}$. P. Meulders, P. Leleux, P. C. Maig and C. Pirat, "Fast Neutron Yields and Spectra from Targets of Varying Atomic Number Bombarded With Deuterons from 16 60 $50 \mathrm{MeV}$ ", Phys. Med. Biol. 20, 235 (1975) 


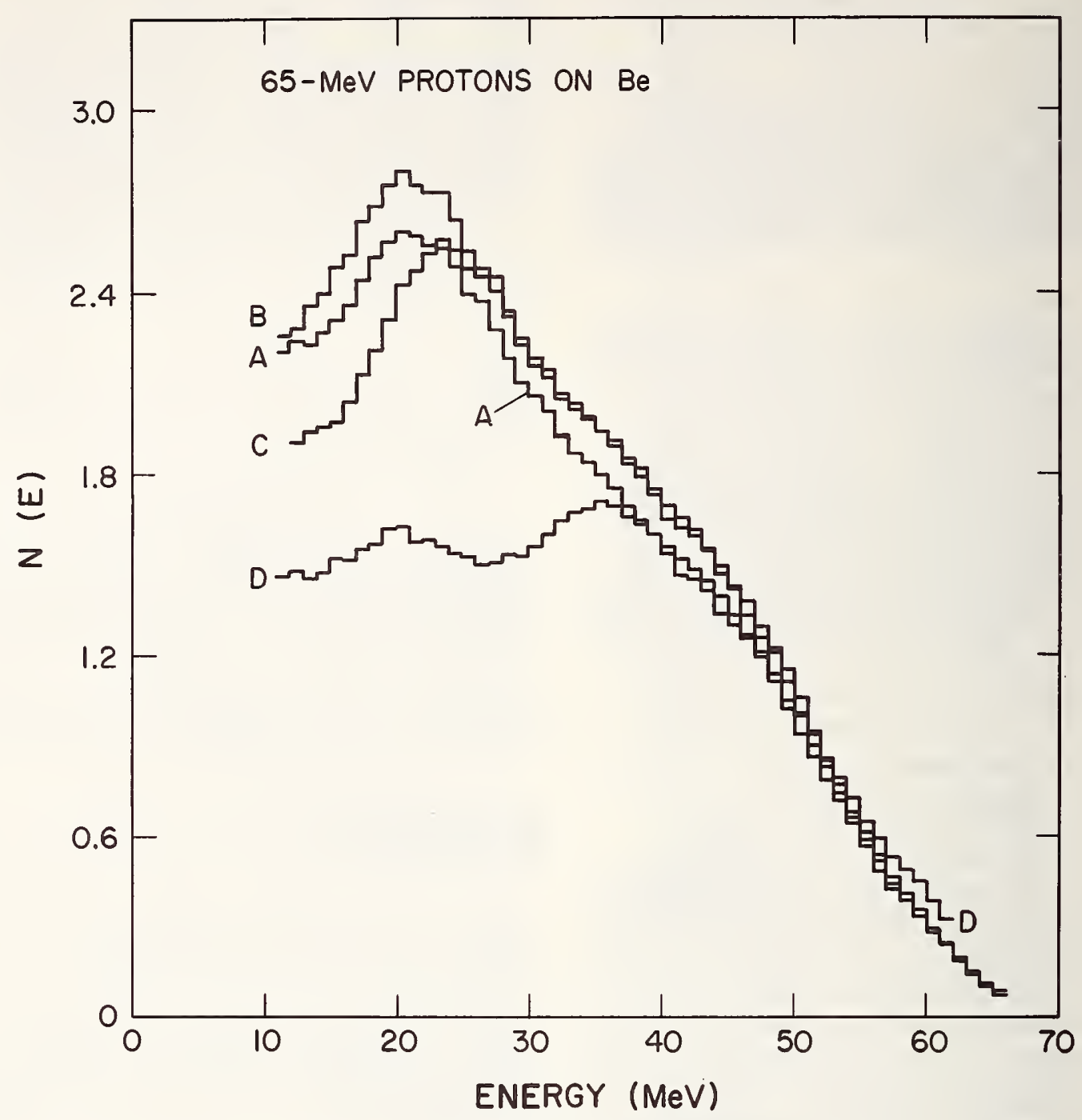

Fig. 1 Spectra of neutrons produced by bombarding beryllium targets with $65.4 \mathrm{MeV}$ protons.

The target thicknesses used to produce each spectrum are: curve $\underline{A}, 2.41 \mathrm{~cm}$; curve $\underline{B}, 2.21 \mathrm{~cm}$; curve $\underline{C}, 1.96 \mathrm{~cm}$; curve D, $1.60 \mathrm{~cm}$. The ordinate is in units of $10^{9} \mathrm{n} \mathrm{sr}-1 \mathrm{Cl}^{-1} \mathrm{MeV}^{-1}$. 


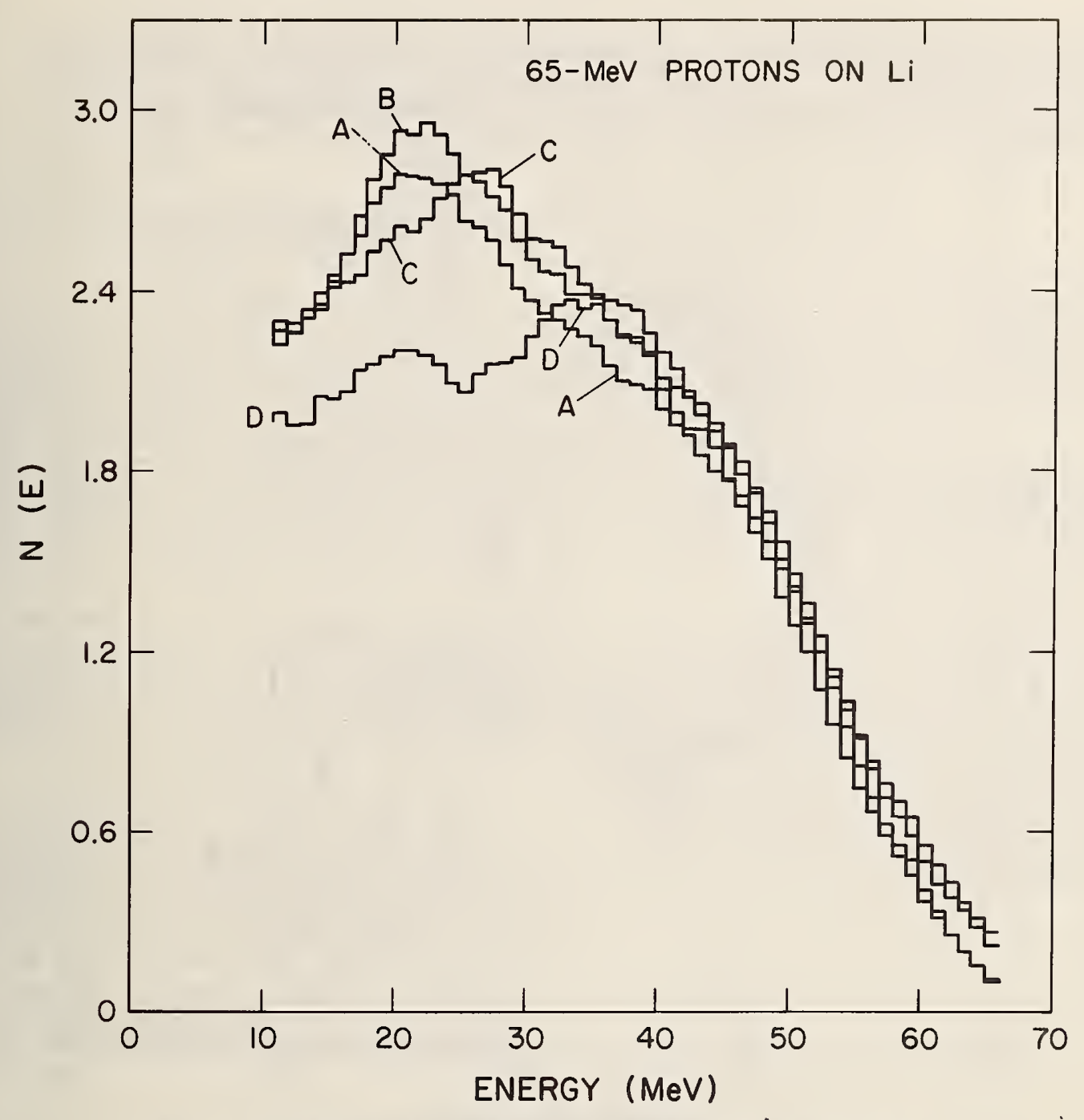

Fig. 2 Spectra of neutrons produced by bombarding lithium targets with $65.4 \mathrm{MeV}$ protons. The target thicknesses usedi to produce edch spectrum are: curve $A, 7.99 \mathrm{~cm}$; curve $B, 7.34 \mathrm{~cm}$; curve $C, 6.50 \mathrm{~cm}$; curve $\mathrm{D}, 5.33 \mathrm{~cm}$. The ordinate is in units of $10^{9} \mathrm{n} \mathrm{sr^{-1 }} \mu \mathrm{C}^{-1} \mathrm{MeV}^{-1}$. 


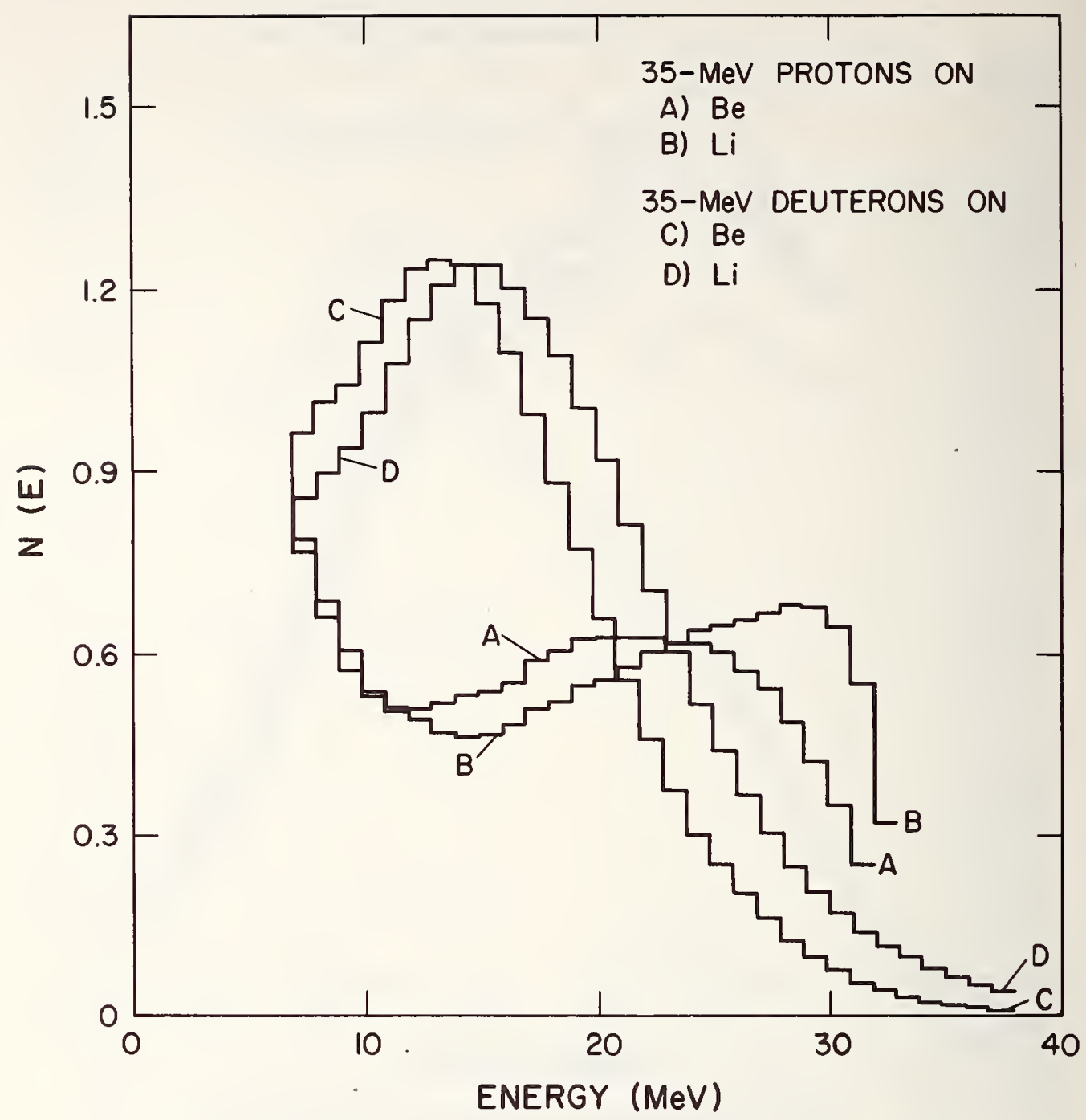

Fig. 3 Spectra of neutrons produced by stopping $35 \mathrm{MeV}$ protons and deuterons in lithium and beryllium. Curves $\mathrm{A}$ and $\mathrm{B}: 35 \mathrm{MeV}$ protons stopping in beryllium and 1 ithium respectively;

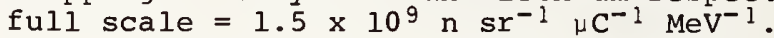
Curves $\mathrm{C}$ and $\mathrm{D}$ : $35 \mathrm{MeV}$ deuterons stopping in beryllium and lithium respectively; full scale $=1.5 \times 10^{10} \mathrm{n} \mathrm{sr}^{-1} \mathrm{\mu C}^{-1} \mathrm{MeV}^{-1}$. 
S. W. Johnsen

Crocker Nuclear Laboratory

University of California

Davis, California 95616

\begin{abstract}
Energy spectra of neutron beams produced by 25, 35, 45 and $55 \mathrm{MeV}$ protons stopping in beryllium have been measured. The spectra exhibit a large low energy component which has small angular dependence and a high energy component which is peaked in the forward direction. The dominant uncertainties in these time-of-fight measurements are the uncertainties in detector efficiency and the energy resolution for neutrons with short flight times.
\end{abstract}

(Distributions; neutrons; resolution; spectra; uncertainties; yield)

\section{Introduction}

Interest in the development of accelerators for use in neutron radiotherapy has prompted the investigation of neutron production using beams of protons bombarding various targets. We have measured the energy spectra and yield of neutrons produced by bombarding thick beryllium targets with protons at energies from 25 to $55 \mathrm{MeV}$. Such data are needed both for accurate dosimetry of these neutron beams and to aid in the design of accelerators dedicated to such use.

Since the results of these measurements are reported in detail elsewhere, they will be only briefly outlined herein. The bulk of this paper will discuss the techniques and tools employed to acquire these data, and the limitations inherent in these methods.

\section{Experimental Methods}

The measurements were performed at the 76-inch isochronous cyclotron of the Crocker Nuclear Laboratory at the University of California, Davis. Proton beams from the cyclotron were transported to a beryllium target placed in a target holder fashioned after that employed at the Naval Research Laboratory, Washington, D.C., radiotherapy facility. ${ }^{2}$ The target assembly included beam current readout capability and electron suppression to insure accurate beam current measurements.

For each proton energy used, the beryllium target was at least thick enough to stop the beam. For the $25 \mathrm{MeV}$ incident proton beam the target was $0.46 \mathrm{~cm}$ thick while for the other energies the thickness was $3.00 \mathrm{~cm}$. The beryllium was backed on the downstream side by $3 \mathrm{~mm}$ of aluminum.

The detector used for these measurements was a cylindrical NE-213 liquid scintillator, ${ }^{3} 5.08 \mathrm{~cm}$ long by $5.08 \mathrm{~cm}$ diameter, mounted coaxially with respect to the incident neutrons. The detector was placed $2.0 \mathrm{~m}$ downstream from the target and was fully illuminated by the neutrons. There was no collimation used between the target and the detector.

Standard fast electronics were used to process each event and the time-of-flight (TOF) spectra were recorded and analyzed on an on-1ine PDP-15/40 computer. The neutron TOF was measured relative to a signal derived from the cyclotron $r . f$. Pulse shape discrimination

* This work was supported in part by grant PHS CA 17419 and in part by NSF grant 71-03400.
(PSD) techniques were used to distinguish events initiated by gamma rays from those attributed to neutrons.

The longest flight times, and therefore the lowest measurable neutron energies, were limited by the overlapping of successive beam bursts.

The overall performance ${ }_{4}$ of the system has been tested in another experiment ${ }^{4}$ using $35 \mathrm{MeV}$ deuterons on beryllium and the agreement with work by others was within the accuracy of the measurements.

\section{Experimental Results}

Figure 1 shows the neutron spectra measured at $0^{\circ}$ produced by bombarding a thick beryllium target with $25,35,45$ and $55 \mathrm{MeV}$ protons. The spectra for all energies are characterized by a large low energy evaporation component together with a broad peak near 20 $\mathrm{MeV}$ which drops to zero at the kinematic limit. A1though this peak becomes more prominent as the proton energy is increased, the position of the peak does not change. The low energy tail also increases substantially in magnitude as the proton energy increases.

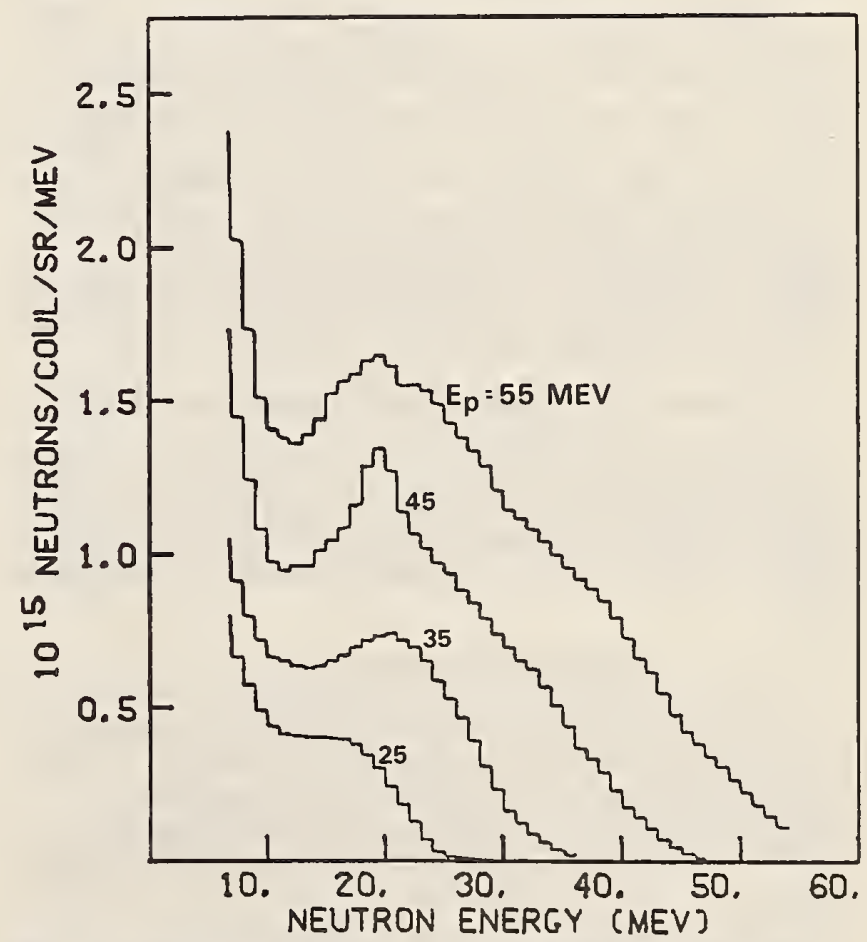

FIG.1. Neutron spectra at $0^{\circ}$ produced by stopping $25,35,45$ and $55 \mathrm{MeV}$ protons in beryllium. 
TABLE 1. P-Be Neutron Yields, $E_{n}>5 \mathrm{MeV}$.

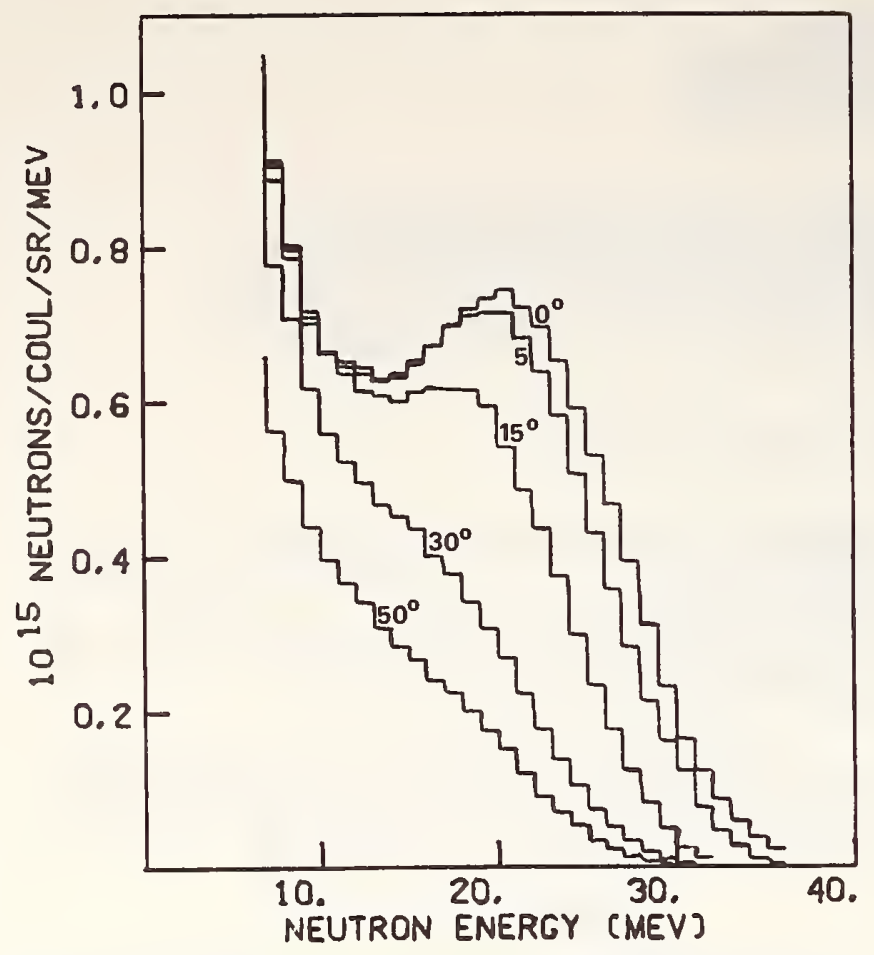

FIG.2. Spectra from $35 \mathrm{MeV}$ protons stopping in a $3.00 \mathrm{~cm}$ thick beryllium target at angles from $0^{\circ}$ to $50^{\circ}$ with respect to the incident proton beam.

As the angle of detection is moved away from zero degrees the peak near $20 \mathrm{MeV}$ decreases in magnitude whereas the low energy tail exhibits very little angular dependence. This is illustrated for the 35 $\mathrm{MeV}$ case in figure 2.

For al1 measurements other than those at $25 \mathrm{MeV}$, the beryllium target was thicker than that required to stop the protons. Using neutron-beryllium cross section data, ${ }^{5}$ the attenuation of neutrons in this excess target length was calculated to be $25 \%, 20 \%$ and $15 \%$ for the 35,45 and $55 \mathrm{MeV}$ yields respectively. The measured yields together with those corrected for excess target lengths are tabulated in table 1.

Figure 3 shows the corrected yields plotted versus the angle of detection. As discussed below, the overall uncertainty in these values is estimated at $20 \%$.

Compared with d-Be spectral measurements in the same energy range, ${ }^{6}$ these $p$-Be measurements show approximately one-twelfth the neutron flux and much less angular dependence of that flux. The increased yield as a function of incident proton energy varies approximately as the cube of the energy, similar to the $d-B e$ case.

\section{Experimental Uncertainties}

The uncertainties in these TOF measurements can be considered as three uncorrelated problems: 1) uncertainties in proton production and measurement,

2) neutron detector efficiency uncertainties, and

3 ) the finite time resolution of the systems involved.

\begin{tabular}{|c|c|c|c|}
\hline $\begin{array}{l}\text { Proton } \\
\text { Energy } \\
\text { (MeV) }\end{array}$ & $\begin{array}{l}\text { Angle } \\
\text { (deg) }\end{array}$ & $\begin{array}{c}\text { Measured } \\
\text { Yield } \\
\text { (n/Coul/Sr) }\end{array}$ & $\begin{array}{l}\text { Yield Corrected } \\
\text { for Excess Target } \\
(n / \text { Coul } / \mathrm{Sr} .)\end{array}$ \\
\hline $\begin{array}{c}25 \\
" \\
" 1 \\
" \\
"\end{array}$ & $\begin{array}{r}0 \\
10 \\
20 \\
30 \\
40 \\
50\end{array}$ & $\begin{array}{l}0.80 \cdot 10^{16} \\
0.74 \\
0.59 \\
0.49 \\
0.43 \\
0.36\end{array}$ & $\begin{array}{l}0.80 \cdot 10^{16} \\
0.74 \\
0.59 \\
0.49 \\
0.43 \\
0.36\end{array}$ \\
\hline $\begin{array}{r}35 \\
\text { " } \\
" \\
" \\
\text { " }\end{array}$ & $\begin{array}{r}0 \\
5 \\
10 \\
15 \\
30 \\
50\end{array}$ & $\begin{array}{l}1.7 \cdot 10^{16} \\
1.6 \\
1.5 \\
1.4 \\
0.9 \\
0.6\end{array}$ & $\begin{array}{l}2.3 \cdot 10^{16} \\
2.1 \\
2.0 \\
1.8 \\
1.2 \\
0.8\end{array}$ \\
\hline $\begin{array}{c}45 \\
" 1 \\
" 1 \\
" \\
"\end{array}$ & $\begin{array}{r}0 \\
5 \\
10 \\
15 \\
30 \\
50\end{array}$ & $\begin{array}{l}3.3 \cdot 10^{16} \\
3.0 \\
2.6 \\
2.3 \\
1.6 \\
0.9\end{array}$ & $\begin{array}{l}4.1 \cdot 10^{16} \\
3.8 \\
3.3 \\
2.9 \\
2.0 \\
1.2\end{array}$ \\
\hline $\begin{array}{r}55 \\
" \\
" \\
" \\
" \\
"\end{array}$ & $\begin{array}{r}0 \\
5 \\
10 \\
15 \\
30 \\
50\end{array}$ & $\begin{array}{l}5.5 \cdot 10^{16} \\
5.3 \\
4.9 \\
4.4 \\
2.9 \\
1.6\end{array}$ & $\begin{array}{l}6.4 \cdot 10^{16} \\
6.2 \\
5.8 \\
5.1 \\
3.4 \\
1.9\end{array}$ \\
\hline
\end{tabular}

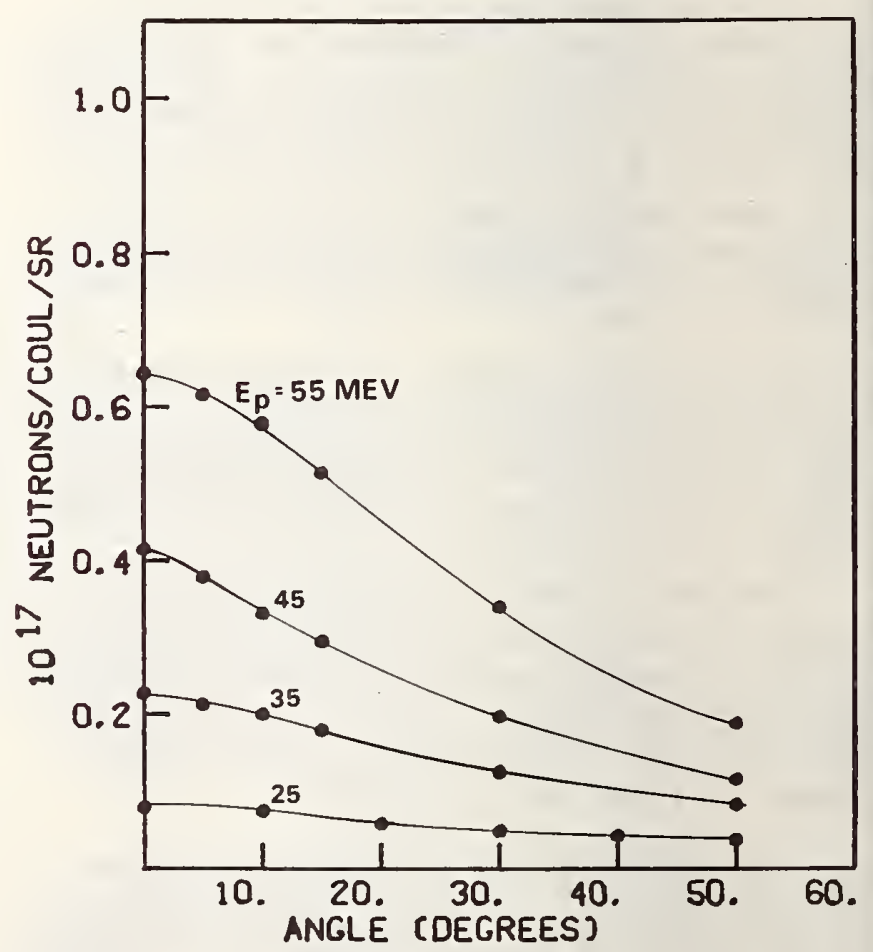

FIG.3. Angular distributions of p-Be yields of neutrons above $5 \mathrm{MeV}$. The data have been corrected for attenuation of neutrons in excess target length. 


\section{Proton Beam Uncertainties}

For protons in the energy range considered here, the beam of the Crocker Nuclear Laboratory cyclotron appears as a succession of bursts, each burst 1 to 1.5 nsec wide with a period of 45 to $85 \mathrm{nsec}$ between bursts depending on the beam selected. For the $55 \mathrm{MeV}$ measurements the overlapping of neutrons from successive beam bursts resulted in an effective neutron threshold of $4.5 \mathrm{MeV}$. The short flight path required to achieve a suitably low overlap energy together with the finite time resolution of the system, as discussed below, compromises the energy resolution for the higher energy neutrons with short flight times.

The beam current was measured using a well calibrated current integrator. The target assembly has been tested to verify that the electron suppression is adequate. Uncertainties in beam current measurement are less than $3 \%$.

The beam current required to give adequate but not excessive count rate was from .5 to 2 nanoamperes. Stability of the beam and instrumentation was more than satisfactory during the approximately 30-minutes run times required to achieve adequate counting statistics.

Due to the approximately $E^{3}$ energy dependence of the neutron flux, the $1 \%$ uncertainty of the accelerated proton energy adds a $3 \%$ uncertainty in the neutron flux determination.

\section{Detection System Uncertainties}

The absolute efficiency of the detector was calculated using a code originally written by Stanton. 7 The code as used has been modified by the inclusion of recent cross section data. ${ }^{8}$ The accuracy of the modified code has been tested at Davis in measurements of the efficiencies of several organic scintillators. Figure 4 compares the measured and computed efficiencies of a $5.1 \mathrm{~cm} \times 7.6 \mathrm{~cm} \times 10.2 \mathrm{~cm}$ rectangular NE-213 liquid scintillator at several energies between 11 and $50 \mathrm{MeV}$. Data are included for three different detector thresholds corresponding to 1,2, and $4 \mathrm{MeV}$ electrons. Over the range 11 to $50 \mathrm{MeV}$ the root-meansquare deviation of the code's prediction from the measured values is $25 \%$ for the $1 \mathrm{MeV}$ threshold data. Over the limited energy range of 11 to $30 \mathrm{MeV}$ the r.m. s. deviation improves to $11 \%$. Limited efficiency measurements of the detector used for the above spectral measurements indicated a comparably accurate efficiency calculation by the code.

For all thresholds tested the code predicts systematically low values for the efficiency at neutron energies above $30 \mathrm{MeV}$. In this energy range the neutron-carbon inelastic processes become significant. The cross sections for these interactions are not well known, particularly the ${ }^{12} \mathrm{C}\left(n, n^{\prime} 3 \alpha\right)$ reaction. Additionally, the light output functions used in the code for low energy alphas are suspect. Since the alphas produced in these reactions have low energies, the ir detection efficiency is highly dependent upon the threshold.

In general, the use of PSD techniques, when incorporated in the prediction code, improves the accuracy of the code's predictions.

By weighing the uncertainties in the efficiency by the energy distributions of the measured p-Be spectra, we estimate the overall uncertainty in the yield measurements due to the efficiency uncertainties to be $20 \%$.

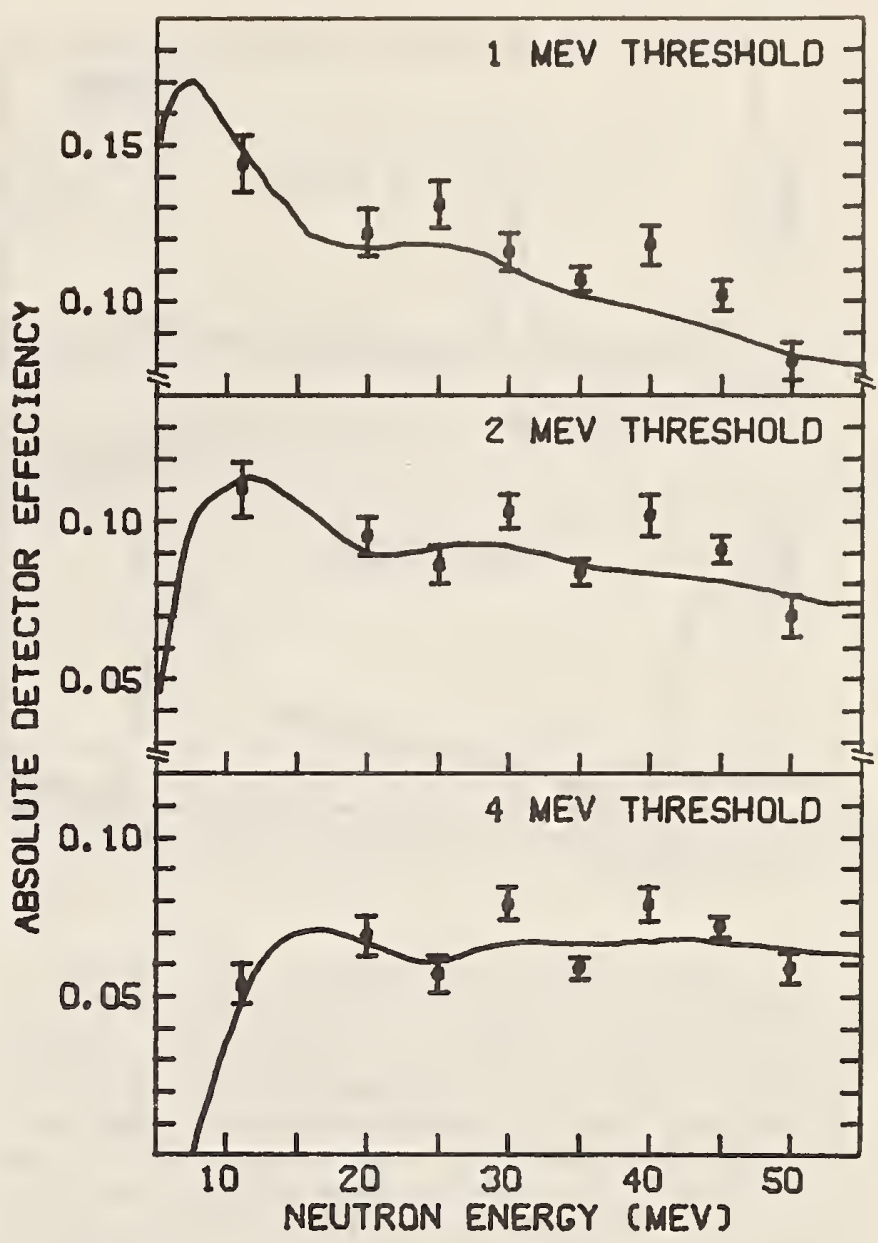

FIG.4. Experimental and code-predicted efficiencies of a $5.1 \mathrm{~cm} \times 7.6 \mathrm{~cm} 410.2 \mathrm{~cm} \mathrm{NE}-213$ liquid scinti]lator.

This uncertainty dominates the other uncertainties in the yield determinations.

\section{Time Resolution}

Figure 5 shows the TOF spectra of gammas and neutrons for the $35 \mathrm{MeV}$ data at $0^{\circ}$. The stop pulses for the time-to-amplitude converter (TAC) which measures the TOF are derived from every second $r$.f. cycle so that the time spectra acquired show nearly two full beam bursts. This allows time calibration of the system using the well determined cyclotron $r . f$. frequency and additionally eliminated any gaps in the spectra from TAC dead time. The width of the prompt gamma burst from the target is a good measure of the overall time resolution of the system, which is better than 3.5 nsec. There are three major contributions to this timing uncertainty.

First, as mentioned above, the intrinsic width of the cyclotron beam bursts is 1 to $1.5 \mathrm{nsec}$. This is a function of the energy and particular tune used.

Secondly, the phase of these bursts relative to the cyclotron $r$.f. varies slightly. This time jitter can be as great as $\pm 1 \mathrm{nsec}$, again depending on the tune and the stability of the cyclotron. The low beam currents employed in these TOF measurements necessitate the use of the cyclotron $r$.f. for timing rather than a beam pick-off unit, which would give a timing signal that was independent of such phase variations. 


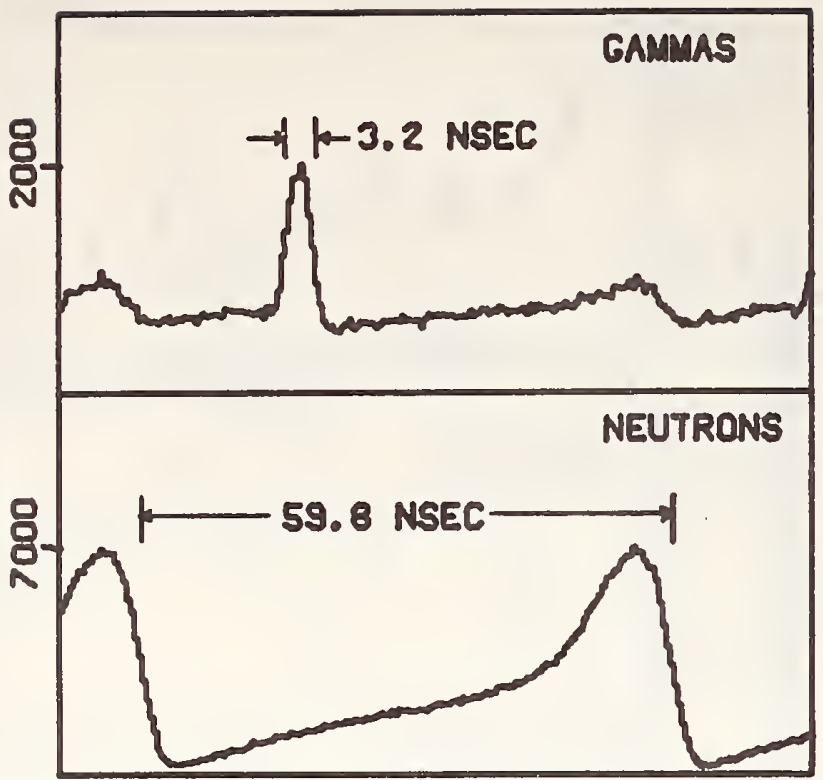

FIG.5. Time spectra of $35 \mathrm{MeV} \mathrm{p-Be} \mathrm{neutrons} \mathrm{and}$ associated ganmas.

Thirdly, there is the intrinsic time resolution of the detection system. For monoenergetic gamma rays this resolution is better than $1.5 \mathrm{nsec}$; with a polyenergetic spectrum of mixed particles it is much worse. The use of PSD techniques implies that the timing will be dependent upon the ionization density of the recoiling particle in the NE-213 scintillator. Using a constant fraction discriminator which triggers when $20 \%$ of the light is collected from an event, the events due to alpha recoils appear late relative to the proton recoil events. This problem is most troublesome at neutron energies above $30 \mathrm{MeV}$ where a relatively large proportion of the events are due to reactions which produce alphas.

The uncertainties in the energies of detected neutrons caused by timing uncertainties are worsened by the use of relatively short flight paths as necessitated by the overlapping of beam bursts. For the 35 $\mathrm{MeV}$ p-Be data shown, the energy resolution at $35 \mathrm{MeV}$ is $\pm 3.5 \mathrm{MeV}$. For this reason some of the neutrons may appear to exceed the kinematic limits. The resolution improves at lower energies as the flight times increase, at $10 \mathrm{MeV}$ neutron energy, the energy resolution is better than $\pm 1 \mathrm{MeV}$.

\section{Conclusions}

The determination of neutron spectra produced by proton beams from a cyclotron striking a beryllium target has been made using TOF techniques. There are two dominant uncertainties in these measurements as described above.

The uncertainties in neutron detector efficiencies lead to significant uncertainties in the neutron fluxes and spectral distributions produced. Additional careful measurements of absolute detector efficiencies are in order. This would not only provide absolute calibration of the particular detectors measured but would also provide benchmarks for testing the predictions of codes such as that used for these experiments. These codes could then be made more accurate in their predictions for other detector assemblies.
For beams where the flux varies slowly with neutron energy, as these $p$-Be spectra appear to, the timeresolution of the experiment is not crucial. If the spectra exhibit sharp peaks or abrupt changes with energy, this may be an important consideration. With out changes in the intrinsic time resolution of the tools used, better energy resolution could be achieved at the expense of a higher neutron threshold by performing the measurements with a longer flight path.

In spite of their limitations, time-of-flight techniques provide a relatively easy and straightforward means of measuring medium energy neutron spectra from pulsed sources. The means are available to improve the techniques illustrated here and improvements in these spectral determinations should be forthcoming

\section{References}

1. S.W. Johnsen, in press, Med. Phys.4:3 (1977)

2. R.B. Theus, LA-5180-C, presented at the PART Conference, Los Alamos Scientific Laboratory, Oct. 1972, p.82.

3. Nuclear Enterprises Inc., San Carlos, California.

4. H.I. Amols, J.F. DiCello, M. Awschalom, L. Coulsor S.W. Johnsen and R.B. Theus. Fermilab-Pub-76/ 102-Exp. 1184.000 (1976) (Submitted to Med.Phys.) See also: H.I. Amols et al. in Basic Physical Data for Neutron Dosimetry, ed. J.J. Broerse, Commission of the European Communities, EUR $5629 \mathrm{e}$ (1976), p.23.

5. I.F. Bubb et a1. Can.J. Phys. 52, 648 (1974)

6. J.P. Meulders, P. Leleus, P.C. Macq and C. Pirat. Phys. Med. Biol. 20, 235 (1975)

7. N.R. Stanton, C00-1545-92 (1971)

8. M.W. McNaughton, N.S.P. King, F.P. Brady and J.L. Ul Imann. Nucl. Instr. \& Meth. 129, 241 (1975).

9. P. Urone et al. in Progress Report to the N.S.F. UCD-CNL 187 (1976) p. 91. 
PROTONS AND DEUTERONS ON Be AT $E_{p}=100 \mathrm{MeV}$ AND $E_{d}=30 \mathrm{MeV}^{*}$

\author{
G. H. Harrison, C. F. Cox, E. B. Kukiczek, arid T. E. Robinson \\ Division of Radiotherapy \\ University of Marylarid \\ School of Medicine \\ Baltimore, Maryland 21201
}

The dose rate of neutrons produced by $80 \mathrm{MeV}$ deuterons on a thick Be target was measured to be $56.0 \mathrm{rad}_{\mathrm{amp}} \mathrm{min}^{-1}$ at a target-to-surface distance (TSD) 1 ? $5 \mathrm{~cm}$ and fiela size $10 \mathrm{~cm}$ $x 12 \mathrm{~cm}$. The maximum of the neutron energy spectrum occurred at $32 \mathrm{MEV}$. The LET spectrum $(I \cdot D(I))$ indicates that 33 percent of the absorbed neutron dise 1 s due tc events with L<I00 $\mathrm{KeV} / \mu$, and emphasizes the need for measurements of high energy neutron reaction cross sections of ${ }^{12} \mathrm{C},{ }^{14} \mathrm{~N}$, and ${ }^{16} \mathrm{O}$. $100 \mathrm{MeV}$ protons on a Be target $62 \mathrm{MeV}$ thick backed with alumirum yield-

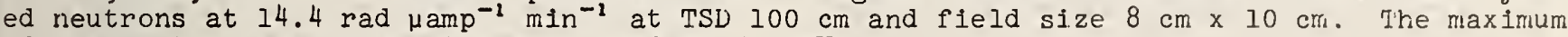
of the neutron energy spectrum occurred at $50 \mathrm{MeV}$.

(dosimetry, energy spectra, high energy, LET, neutrons, yields)

\section{Introduction}

Over the past several years we have performed a variety of experiments using high energy neutrons at the University of Maryland cyclotron. These experiments were designed to yield biological and physical data relevant to the evaluation of these neutron beams for use in cancer therapy. ${ }^{1-4}$ Using $80 \mathrm{MeV}$ deuterons and $100 \mathrm{MeV}$ protons on Be targets, we have demonstrated high neutron dose rates, depth-dose profiles superior to ${ }^{60} \mathrm{Co}$ radiation, and a higher proportion of dose due to high LET events, compared to lower energy neutron beams. Although our physical data were obtained in geometries convenient for radiobiological studies and are expressed in rads instead of neutron fluence, some of our data are relevant to the purposes of this Symposium. We will present:

1. LET spectra of neutrons produced by $80 \mathrm{MeV}$ deuterons on beryllium measured with a Rossi-type spherical proportional counter;

2. Dose rates and estimated yields with a Spokas tissue equivalent ( $T E$ ) ion chamber for neutrons produced by $\mathrm{Be}$ bombarded by $80 \mathrm{MeV}$ deuterons, $100 \mathrm{MeV}$ protons and also $61 \mathrm{MeV}$ protons for comparison with results of other investigators;

3. Neutron energy spectra produced by $80 \mathrm{MeV}$ deuterons and $100 \mathrm{MeV}$ protons on $\mathrm{Be}$;

4. A discussion of needed nuclear cross section measurements.

\section{Experimental Set-Up}

Charged particle beams from the Maryland cyclotron pass through a series of focusing magnets to the neutron production target. The beams are centered and focused on a beryllium oxide scintillator mounted on the front of the target and viewed by a television came$\mathrm{ra}$. The beam spot diameter is approximately $15 \mathrm{~mm}$ for deuterons and $3 \mathrm{~mm}$ for protons.
A cross section of the water-cooled holder for targets $2 \mathrm{~cm}$ thick is shown in Fig. 1. To provide the $4.25 \mathrm{~cm}$ thick Be target used in $100 \mathrm{MeV}$ protor irradiations, the threaded aluriinum plug shown in Fig. I is replaced with a threaded aluminum cup containing additional Ee.

The possibility of electron emissior from the front surface of the neutron-producing element, causing errors in bearn current integration, ${ }^{5}$ is minimized by the geometry of the surrounding aluminum and the fact that most of the ionization from high erergy charged particles occurs deep within the target. While high energies may obviate the problem of significant electron emission, a new factor is introduced: the range straggling occurring with full energy loss could lead to unintegrated beam current if the target thickness is only a few $\mathrm{mm}$ greater than the mean particle range. For this reason the neutron-producing target element is backed by $1.11 \mathrm{~cm}$ aluminum beyond the mean particle range. An additional consequence of using high-energy deeply penetrating charged particles to produce neutrons is that the neutron source is a line source coincidert with the central axis, and may lead to diffiSCALF
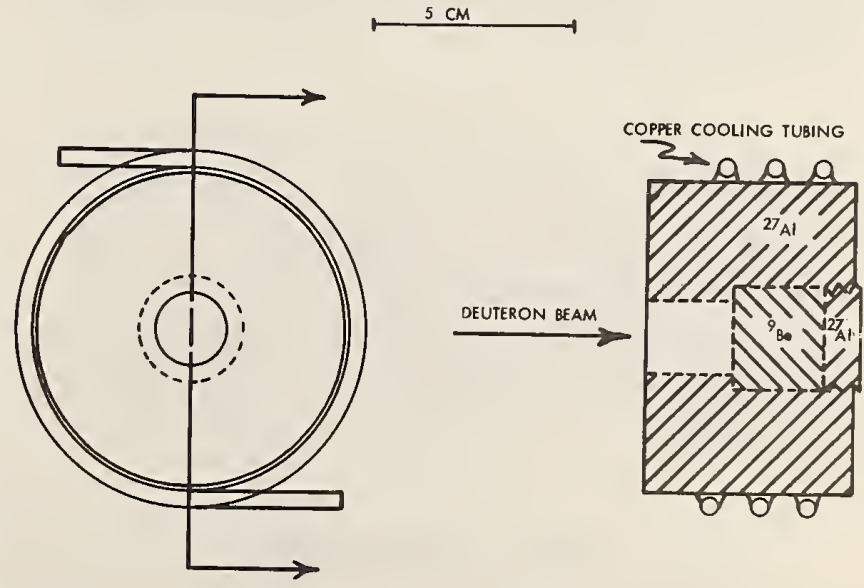

Figure 1. Neutron production target. 
culties in neutron beam collimatior and inverse square correctior:s of dose.

AII neutron beams are filtered by the $1.11 \mathrm{~cm}$ thick aluminum plug ( $F 1 \xi$. I) ard a $0.32 \mathrm{~cm}$ thick aluminum plate (not shown). Lower-energy data ${ }^{6}$ show that such filtration should have little effect on the neutrori energy spectrum; however, the overall attenuation can be included in cilculations of the intrinsic dose rate of each reutron source configuration.

The geometry of neutric beam collimation was changed several times during the course of the measurements to be reported in this paper. The collimation geometry is important in absolute dosimetry, and will be tabulated along with corresponding dosimetric results.

\section{LET Spectra}

We have measured the linear energy transfer (LET) characteristics of the neutron beam produced by $80 \mathrm{MeV}$ deuterons using an EG\&G Rossi-type gas-filled proportional chamber. This consists of a $12.8 \mathrm{~mm}$ diameter spherical chamber which is filled with a tissue equivalent gas $\left(55 \% \mathrm{C}_{3} \mathrm{H}_{3}, 39.6 \% \mathrm{CO}_{2}\right.$ and $\left.5.4 \% \mathrm{~N}_{2}.\right)$ and surrounded by a $1.3 \mathrm{~mm}$. thick wall of tissue-equivalent plastic. The chamber was filled to a pressure of $34.5 \mathrm{~mm}$ of mercury corresponding to a $l \mu$ sphere of unit density tissue.

Measurements were made in a $40 \mathrm{~cm}$ cubic tissue-equivalent Iiquid (Frigerio's threecomponent formula with density $=1.1)^{7}$ with the center of the detector at depths of $I$ and $5 \mathrm{~cm}$. The phantom was positioned at a TSD of $125 \mathrm{~cm}$ and the neutron field was $10 \mathrm{~cm} \mathrm{x}$ $12 \mathrm{~cm}$. The data were assembled in a pulse height analyzer and a paper tape record was made for input to a computer program. This program unfolds the effect of the variable path length of the detector's spherical geometry and computes the LET distribution. The data were collected in three segments because of the widely varying event rate in different portions of the spectrum. The analysis method is similar to that outlined by Grant et al.

Figure 2 shows L.D(L) plotted against $L$, where $L$ is LET and $D(L)$ is the dose delivered at a given value of $L$. With this choice of variables, equal areas under the curve represent equal doses. The results show several peaks over a continuum up to about $800 \mathrm{KeV} / \mu$. The peaks are interpreted as being due to Bragg peaks of protons, alphas and heavier fragments. 33 percent of the dose is delivered at LET values above $100 \mathrm{KeV} / \mu$.

\section{Neutron Dose Rates}

Neutron dose was measured with a $0.5 \mathrm{cc}$ Spokas ion chamber constructed of Shonka type A-150 TE plastic. It is customary to observe

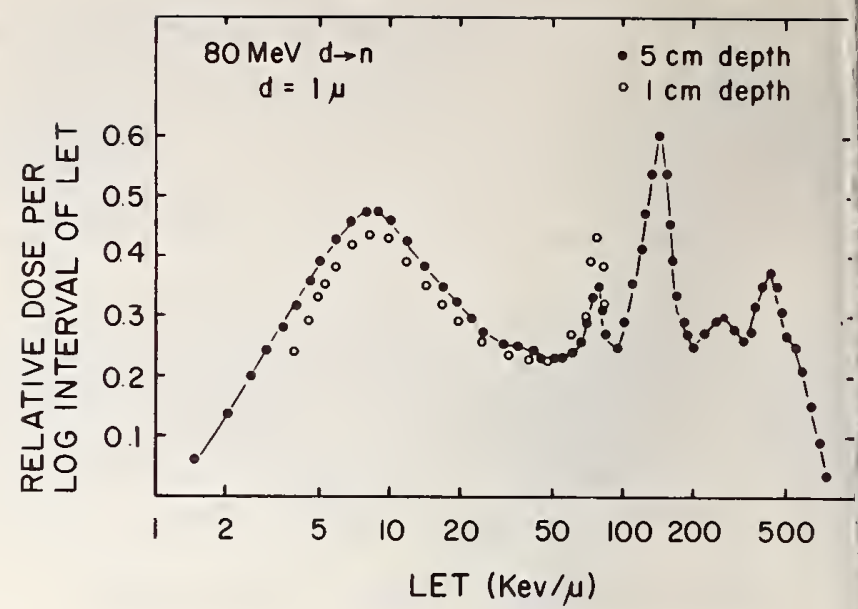

Figure 2. L.D(L) vs. L for $80 \mathrm{MeV}$ deuterors on Be at the depths 1 and $5 \mathrm{~cm}$ in a TE Iiquici phantom TSD $=1.25 \mathrm{~cm}$. There is no discerribl. difference in the spectra beyond $100 \mathrm{KeV} / \mu$.

trat this plastic is not really tissue equiva lent for neutrons because of the replacement of oxygen by carbon. This problem is amplifled at the high neutron energies reported here; our LET spectra demonstrate that a large proportion of high-energy neutron dose in tissue is caused by $n-{ }^{12} \mathrm{C}$ and $n-{ }^{16} \mathrm{O}$ reactions.

\section{Dosimetric Methods}

Neutron dose at $5 \mathrm{~cm}$ depth $1 \mathrm{r} \mathrm{TE}$ Ilquid phantoms was determined from the charge collected from the air filled ion chamber according to the Bragg-Gray principle as outlined in neutron dosimetry intercomparisons at lower energies. ${ }^{9}$ First the mass of air in the chamber was determined by measuring the chamber response to a known dose of ${ }^{6} \mathrm{Co}$ gamma rays. The mass was $6.458 \mathrm{x}$ $10^{-7} \mathrm{~kg}$ at STP, so that the actual chamber volume is measured to be $0.5 \mathrm{cc}$ to within one percent.

The ion chamber was then exposed to the Naval Research Iuboratory (NRL) neutron beam. Th1s beam, generated by $35 \mathrm{MeV}$ deuterons on $B \epsilon$ has been carefully calibrated and intercompared with other lower energy neutron facilities. Using the air mass and the measured charge collected in our ion chamber, along with NRL values for neutron stopping power ratios (Sn) and energy to create an ion pair (Wn) in air, 5 our calculated neutron dose agreed with the stated NRL dose to within one percent.

The next step was to select appropriate parameters for the calculation of higher energy neutron doses according to the Bragg-Gray relation.

$$
D=\frac{100 Q W_{n} S_{n}}{M C_{k}}
$$


where $D=$ dose to tissue (rads)

$Q=$ collected charge (coulombs)

$W_{n}=$ average energy from secondary charged particles to create an ion pair in air (ev/lon pair)

$S n=$ ratio of average stopping power of secondary charged particles (TE plastic/air)

$M=$ mass of air in ion chamber $(\mathrm{kg})$

$\mathrm{Ck}=$ Kerma correction factor (TE plastic:tissue)

For the most part we have followed the procedure used at the highest energy neutron facility for which there exists careful dosimetry with intercomparisons: the Texas A\&M cyclotron ( $50 \mathrm{MeV}$ deuterons on $\mathrm{Be}$ ). ${ }^{10}$ There are two alterations. First, in the computation of Wn, the alpha contribution is taken to increase from 19 to 33 percent based on our LET spectrum. Second, $\mathrm{Ck}$ is taken to be 1.00 . Usually $\mathrm{Ck}$ is greater than 1 because of the oxygen deficiency in TE plastic compared to tissue; but according to ICRU-13 the ratio of neutron kerma in oxygen to kerma in carbon appears to approach unity as the neutron ener5y increases to $20 \mathrm{MeV}$, above which energy there is no data.

Our resulting dosimetric constants are shown in Table $I$. resulting in the final relationship for high energy neutron rads in tissue measured with our ion chamber: Dny= 6.46Q (nanocoulombs) after temperature and pressure correction. Our measurements were performed in liquid phantoms using Frigerio's three-component TE formula with density $=1.10$. All collimation was provided by untapered apertures in steel shielding.

Dose Rate Results

Most of the measured dose rates were obtained in geometries inconvenient for compari-

TABLE II. Neutron dose rates.
TABLE I. Dosimetry constants

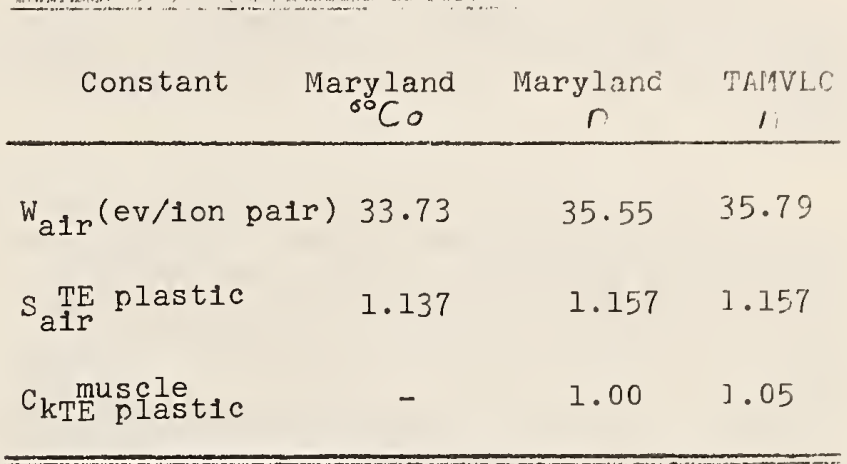

son with other yield results. Table II describes the geometries and measured dose rates, along with estimated dose rates and under standard conditions of $125 \mathrm{~cm}$ TSD, $1 \mathrm{~cm}$ deptr. in TE phantom $(p=1.10)$, using unattenuated neutron beams. The measured dose rates urder the stated conditions have estimated uncertainties of 12 percent. These results are more reliable than the calculated expected dose rates under standard corditions. These expected dose rates require additional corrections for neutron attenuation in the $1.45 \mathrm{~cm}$ of aluminum immediately downstream from the site of neutron production, changes in TSD, changes in depth within the phantom, and changes in phantom dimension. The combined error for these corrections is estimated to be nine percent, with the total uncertainty 15 percent.

The dose rate for $80 \mathrm{MeV}$ deuterons on Be under standarc conditions ( $56 \mathrm{rad} \mathrm{min}^{-1} \mu a m p^{-1}$ ) conforms to the NRL yield predictions 11 ; at $\mathrm{E}_{\mathrm{d}}=80 \mathrm{MeV}, 1.24 \times 10^{-4} \times \mathrm{E}_{\mathrm{d}}^{2.99}(\mathrm{MeV})=6 \mathrm{C}^{2} .7 \mathrm{rad}$ $\mathrm{mln}^{-1} \mu_{\mathrm{amp}}{ }^{-1}$, while $1.53 \times 10^{-4} \mathrm{E}_{\mathrm{d}}^{2.92} \quad(\mathrm{MeV})=$ 55.2 rad $\min ^{-1}$ namp $^{-1}$.

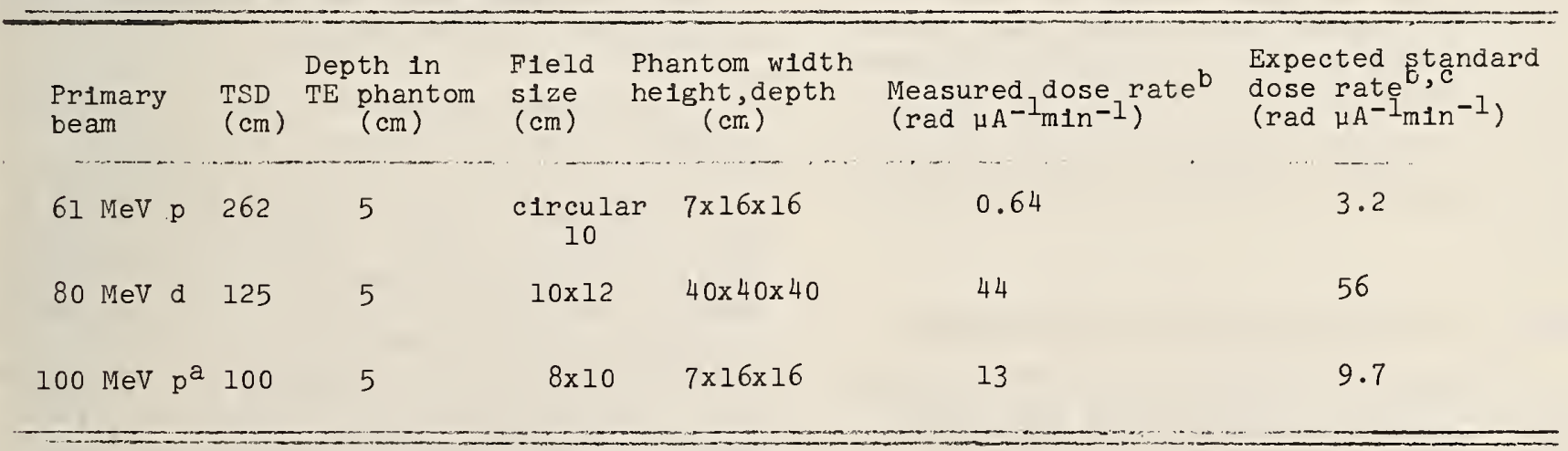

$a_{\text {Be target }} 62 \mathrm{MeV}$ thick backed with aluminum.

${ }^{\mathrm{b}} \mathrm{All}$ neutron beams attenuated by $1.45 \mathrm{~cm}$ aluminum as explained in text.

cStandard conditions are TSD $=125 \mathrm{~cm}$, dose measured at $1 \mathrm{~cm}$ depth, and subtraction of attenuation in aluminum. These corrections include experimental data on depth-dose curves and deviations from inverse square law. 
The dose rate for $6 ! \mathrm{MeV}$ protons on Be ur:der standard conditons ( $3.2 \mathrm{rad} \mathrm{min}^{-1} \mu \mathrm{mp}^{-1}$ ) compares well. with the value measured by Amols et al ${ }^{12}$ for $65.4 \mathrm{MeV}$ protons $\left(3.4 \mathrm{rad} \mathrm{min}^{-1}\right.$ $\mu a m p^{-1}$ ).

Nelitron yields have been estimated for the standard conditions by use of fluerice-torad data in NBS Handbook 107. For neutrons produced by $61 \mathrm{MeV} \mathrm{p}, 80 \mathrm{MeV} d$ and $100 \mathrm{MeV} \mathrm{p}$, the calculated yields at $125 \mathrm{~cm}$ are $1.1,20$, and $2.6 \times 10^{11}$ neutrons $\mu \mathrm{C}^{-1} \mathrm{sr}^{-1}$ respec-

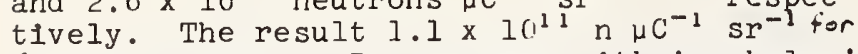
$6 ! \mathrm{MeV}$ protons on Ee compares with Awschalom's experimentally observed value $0.88 \times 10^{11}$ $n \mu \mathrm{C}^{-1} \mathrm{sr}^{-1}$ for $65.4 \mathrm{MeV}$ protons. ${ }^{12}$ These numbers may be consistent in view of the $9 \mathrm{MeV}$ neutron cutoff in Awscholom's yield. Our re-

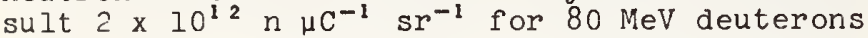
on Be can be compared to the yield of $50 \mathrm{MeV}$ deuterons on Be measured by Meulders et al. ${ }^{3}$ by applying the NRL power law $(50 / 80)^{2.92}$ as suggested above. Our yield estimate at 80 $\mathrm{MeV}$, scaled by the NRL power law predicts a

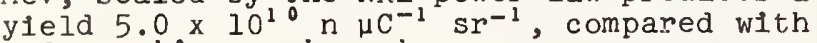

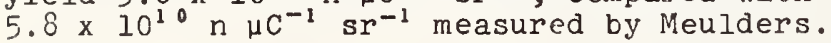

\section{Neutron Energy Spectra}

Neutron energy spectra were obtained by a time-of-flight technique similar to that of Theus et al. ${ }^{6}$ In the present work, the flight path lengths were between $3 \mathrm{~m}$ and $5 \mathrm{~m}$. Use of the $3 \mathrm{~m}$ flight path permitted a clieck on the d-Be energy spectrum down to a lower limit of $5 \mathrm{MeV}$. Neutrons were detected in a NEIO2 plastic scintillator. The detector efficiency as a function of neutron energy was calculated using a modifled versisn of the Kurz program. ${ }^{4}$ The nelitron energy spectrum for $80 \mathrm{MeV}$ deuterons, $61 \mathrm{MeV}$ protons, and $100 \mathrm{MeV}$ protons on beryllium is shown in Fig. 3. For comparison the NRL spectrum from $35 \mathrm{MeV}$ deuteroninduced neutrons ${ }^{6}$ is shown. The $80 \mathrm{MeV}$ deuteron-induced neutron spectrum is the expected extrapolation from lower energies, or about $32 \mathrm{MeV}$. The spectrum of neutrons from 100 $\mathrm{MeV}$ protons shows a mean energy near $50 \mathrm{MeV}$. In this latter case, the target was designed to maximize the neutron energies at the expense of dose rate: the $4.25 \mathrm{~cm}$ of beryllium does not stop the protons, but slows them to about $38 \mathrm{MeV}$, after which they stopped with reduced neutron production in the aluminum backing.

\section{Needed Nuclear Cross Section Measurements}

Most of the material presented in this paper suffers in some way from the lack of basic high energy nuclear data standards. A list of basic data needed for the work reported here includes:

\section{Charged particle production cross} sections for $\mathrm{n}^{-{ }^{12} \mathrm{C}}$, and $\mathrm{N}-{ }^{16} \mathrm{O}$ above 20 $\mathrm{MeV}$ to evaluate the effect of substituting ${ }^{12} \mathrm{C}$ for ${ }^{16} \mathrm{O}$ in the wall of the LET counter and the ion chamber, and to determine the spectra of secondary charged particles in the ion chamber.

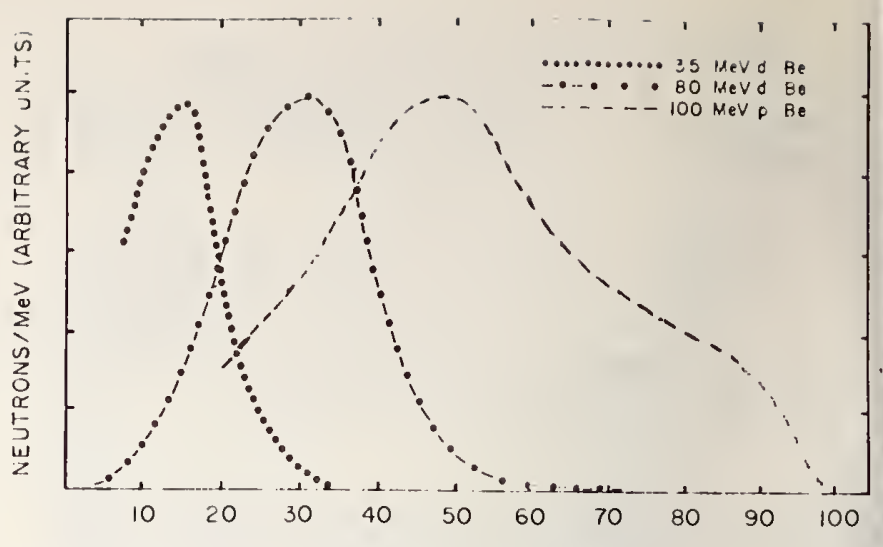

NEUTRON FNF RGY (MeV)

Figure 3. Neutron energy spectra.

2. Stupping powers of protoris, alphas, and heavier fragmerts above $20 \mathrm{MeV}$ in ${ }^{1} \mathrm{H},{ }^{12} \mathrm{C},{ }^{14} \mathrm{~N}$, and 0 to permit the calculation of Sn.

3. W values of protons, alphas, and heavier fragments above $20 \mathrm{MeV}$ in air.

4. Kerma in ${ }^{1} \mathrm{H},{ }^{12} \mathrm{C},{ }^{14} \mathrm{~N}$, and ${ }^{16} \mathrm{O}$ between 20 and $100 \mathrm{MeV}$.

5. Data of the type specified in 1tem 1 for $n-1{ }^{2} \mathrm{C}$ reactions in hydrocarbon scintillation detection efficiency calculaticns. (The wcrk of McNaughton et al.' 5 represents some progress in this direction).

Unfortunately, nuclear data other than $n-p$ cross sections become both increasingly important and ircreasingly scanty as neutron energy increases. In the case of neutron reactions in tissue, these ideas are demonstrated by the LET spectrum of neutrons from $80 \mathrm{MeV}$ deuterons on $\mathrm{BE}(\mathrm{F} I \mathrm{~g} .2)$. At this energy at least 33 percent of the dose is due to the events other than $n-p$, while similar data from $50 \mathrm{MeV}$ deuterons show that 19 percent of the dose 1 s due to other than $n-p$, and at $35 \mathrm{MeV}$ the figure is only 1] percent.

Two factors should be helpful in obtairing the needed high energy nuclear data. Fir'st, all of the needed data listed above should vary slowly with energy from about 40 up to $100 \mathrm{MeV}$; only a small number of incident particle energies need to be studied. Second, as we have shown previously ${ }^{3}$, protoninduced reactions should give similar results to neutron-1ndiced reactions above $20 \mathrm{MeV}$ provided that Coulomb effects can be subtracted. This approximation should be especially valid for even-even target nuclei ${ }^{12} \mathrm{C},{ }^{1}{ }^{4} \mathrm{~N}$, and ${ }^{10} \mathrm{O}$. This means that much easier proton experiments can be performed to obtain needed neutron cross sections.

* Work supported in part by the American Cancer Society and NIH National Cancer Institute.

${ }^{1}$ G.H. Harrison, Radiat. Res. 50, 124 (1974). 
2 G.H. Harrison, J.E. Robinson, and E.B. Kub1czek, Br1t. J. Rad101. 48, 409 (1975).

3 Q.H. Harrison, Med. Phys. 2 15s (1975).

4 G.H. Harrison, E.B. Kublczek, and J.E. Robinson, Brit. J. Radiol. 49, 733 (1976).

5 F.H. Att1x, et.al., Phys. Med. Blol. 16, 497 (1973).

6 R.B. Theus, et.al., cancer 34, 17 (1974).

T N.A. Friger1o, R.F. Coley, and M.J. Sampsor, Phys. Med. B1ol. 17, 792 (1972).

6 W.H. Grant III, G.D. Oliver, and B.A. Mitchell, Health Phys. 22, 35] (1972).

A.R. Smith, et.al., Med. Phys. 2, 195 (1975).

${ }^{10}$ P.R. Almond, et.al., Radiat. Res. 54, 24 (1973).

${ }^{11}$ L.S. August, et.al., Phys. Med. B1ol. 2l, 931 ( I976).

${ }^{12}$ H.I. Amols, et.al., Ferinilab 76/102 (1976).

$1{ }^{3} \mathrm{~J} . P$. Meulders, et.al., Phys. Med. Biol. 20, 235 (1975).

I R.J. Kurz, UCRL 11339 (1965).

$1{ }^{5}$ M.W. McNaughton et.al., Nucl. Instr. Meth. 129, 241 (1975). 
NEUTRON YIELDS ANI) DOSIMETRY FOR Be $(d, n)$ AND Li $(d, n)$ NEUTRON SOUR(I:S AT l ${ }_{d}=40 \mathrm{MeV}^{*}$

M. J. Saltmarsh, C. A. Ludeniann, C. B. Fulmer, and R. C. Styles** Oak Ridge National Láboratory

Oak Ridge, Tennessee 37830

Time-of-flight measurements are reported for the thick-target neutron yields fron the $\mathrm{Be}(\mathrm{d}, \mathrm{n})$ and $\mathrm{Li}(\mathrm{d}, \mathrm{n})$ reactions over an angular range of $0-90^{\circ}$ at a deuteron energy of $40 \mathrm{MeV}$. Foil activation measurements are also described for the $B e(d, 11)$ reaction. A dosimetry technique based on these measurements is discussed.

[Dosimetry: measured thick-target neutron yields, $B e(d, n), \operatorname{Li}(d, n) ; 1:{ }_{d}=40 \mathrm{McV}$; $\left.\mathrm{E}_{\mathrm{n}}>2 \mathrm{MeV} ; \theta=0-90^{\circ}\right]$

\section{Introduction}

In recent years there has been growing interest in the use of neutron sources based on the $B e(d, n)$ and $\mathrm{Li}(\mathrm{d}, \mathrm{n})$ reactions for fusion-related materials studies. In this paper we report on measurements of the thicktarget neutron yields from these two reactions, measurements which were made using a $40-\mathrm{MeV}$ deuteron beam from the Oak Ridge Isochronous Cyclotron (ORIC). Timeof-flight (TOF) data were obtained for both reactions over the angular range 0 to $90^{\circ}$, and foil activation measurements were made for the $\operatorname{Be}(d, n)$ reaction in the range 0 to $80^{\circ}$. The results were used to develop a dosimetry technique suitable for the existing ORIC $\operatorname{Be}(d, n)$ neutron source, ${ }^{l}$ and to evaluate the performance expected from the recently proposed $\mathrm{Li}(\mathrm{d}, \mathrm{n})$ intense neutron sources. ${ }^{2}$

\section{Time-of-Flight Measurements}

The TOF measurements were made using a $40-\mathrm{MeV}$ deuteron beam from the ORIC. This beam is pulsed at the cyclotron orbital frequency of $12.97 \mathrm{MHz}$, providing 2-ns-wide pulses every $77.10 \mathrm{~ns}$. With the maximum available flight path of $3 \mathrm{~m}$ the resultant energy resolution varied from $4 \%$ at a neutron energy of $5 \mathrm{MeV}$ to $\sim 15 \%$ at $40 \mathrm{MeV}$. However, neutron energies below $5 \mathrm{MeV}$ could not be reliably measured with this flight path because of overlapping events from successive beam bursts. Accordingly most of the measurements were repeated using a flight path of $0.75 \mathrm{~m}$, which allowed the data to be extended down to $\mathrm{E}_{\mathrm{n}} \sim 2 \mathrm{MeV}$.
The experimental arrangement is shown in Fig. 1. The deuteron beam passed through a thin $\left(7.5 \mathrm{mg} / \mathrm{cm}^{2}\right)$ gold scattering foil, used in monitoring the beam, and onto the thick beryllium (or lithium) target. Neutrons and gamma rays emitted at an angle $\theta$ were detected in a cylindrical cell of NE213 1iquid scintillatort $37.3 \mathrm{~mm}$ in diameter by $34.1 \mathrm{~mm}$ long viewed by a 56AVP photomultiplier tube. The fast timing signal from the photomultiplier tube was used to start a time-to-amplitude converter, the stop signal being derived from every second cycle of the cyclotron RF. A neutron-gamma discrimination circuit was used to route an event into one of two 400-channel TOF spectra. Background events, for example neutrons scattered from the experimental room floor or walls, were measured by placing a 20-cm-thick lead shadow shield midway between the target and the detector. When the lead shield was removed, it was displaced by the smallest possible distance $(6 \mathrm{~cm})$, so that the effect of in-scattering from the lead was similar for both foreground and background runs.

\footnotetext{
* Research sponsored by Energy Research and Development Administration under contract with Union Carbide Corporation.

**0ak Ridge Associated University undergraduate trainee. Present address: University of Georgia, Athens, Georgia.

†Manufactured by Nuclear Enterprises, Inc., 935 Terminal Way, San Carlos, CA 94070.
}

ORNL-DWG 76-13772

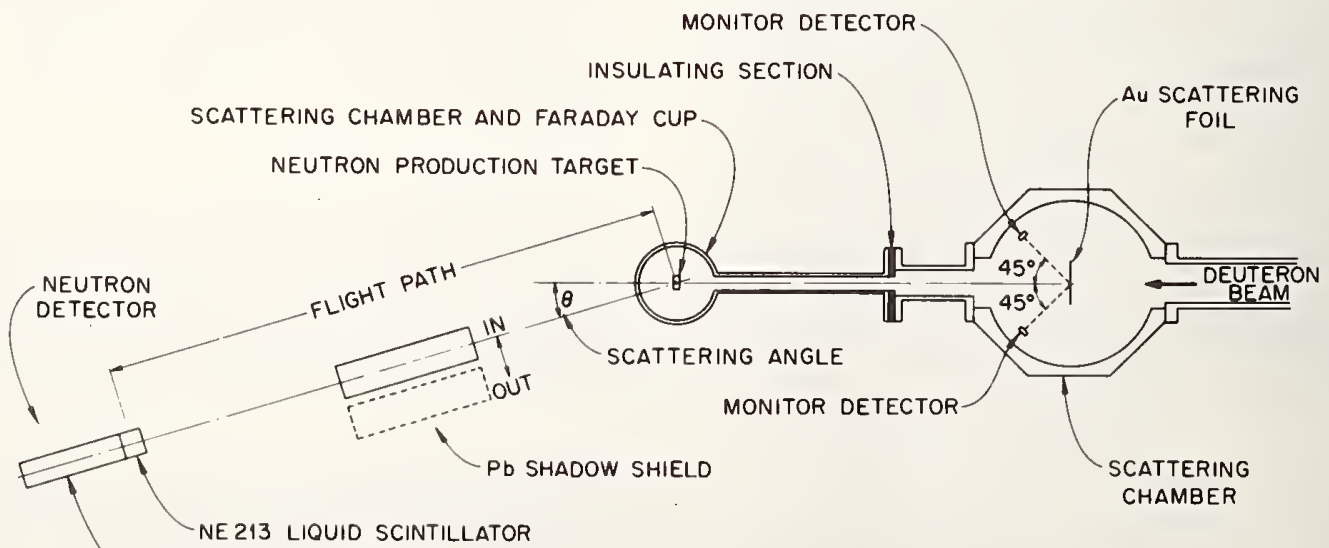

Fig. 1. The lay-out of the time-of-flight apparatus. 
The bean current required for these measurenent: was sinall, $\$ 0.1 \mathrm{nA}$. The beam was monitored by counting deuterons scattered at $\pm 45^{\circ}$ from the thin gold foil. Two detectors were used to eliminate errors dile to movements of the beam spot on the gold foil. This secondary monitor was calibrated at intervals during the experiment by increasing the beam current and using the second scattering chamber as a Faraday Cup.

The neutron detector threshold was set relative to the half-height of the Compton edge from a ${ }^{22} \mathrm{Na}$ source. Following the definitions of Verbinski et al. ${ }^{3}$ this corresponds to 0.89 light units (LU). For the $3-\mathrm{m}$ runs the threshold was set to be $1.00 \mathrm{LU}$ $\left(E_{n} \sim 3.5 \mathrm{MeV}\right)$, while for the $0.75-\mathrm{m}$ data a setting of $0.266 \mathrm{LU}\left(\mathrm{E}_{\mathrm{n}} \sim 1.3 \mathrm{MeV}\right)$ was used. The detector efficiency at each threshold was calculated for a number of neutron energies in the range $1-50 \mathrm{MeV}$, using the Monte Carlo code $055 .^{4}$

For data analysis the positions of the two gamma peaks in the appropriate spectrum were obtained by fitting a gaussian peak to the data. The time calibration was obtained from these peak locations by assuming a linear dependence of TOF versus channel number. The neutron spectrum was then converted to an energy spectrum, defining the flight path to be the distance from the geometrical center of the target to the geometrical center of the liquid scintillator. Allowance was made for neutron absorption in the aluminum walls of the scattering chamber ( $3 \mathrm{~mm}$ thick) and the scintillator cell ( $\sim 1.5 \mathrm{~mm}$ thick) as well as the air along the flight path. The measured energy spectra from $\mathrm{d}+\mathrm{Be}$ at 0 and $90^{\circ}$ are shown in Fig. 2, with the error bars showing statistical uncertainties only. The data from $d+B e$ and $d+\mathrm{Li}$ at all angles studied are shown as smooth curves in Figs. 3 and 4, respectively. The curves for $7^{\circ}$ and $45^{\circ}$ do not

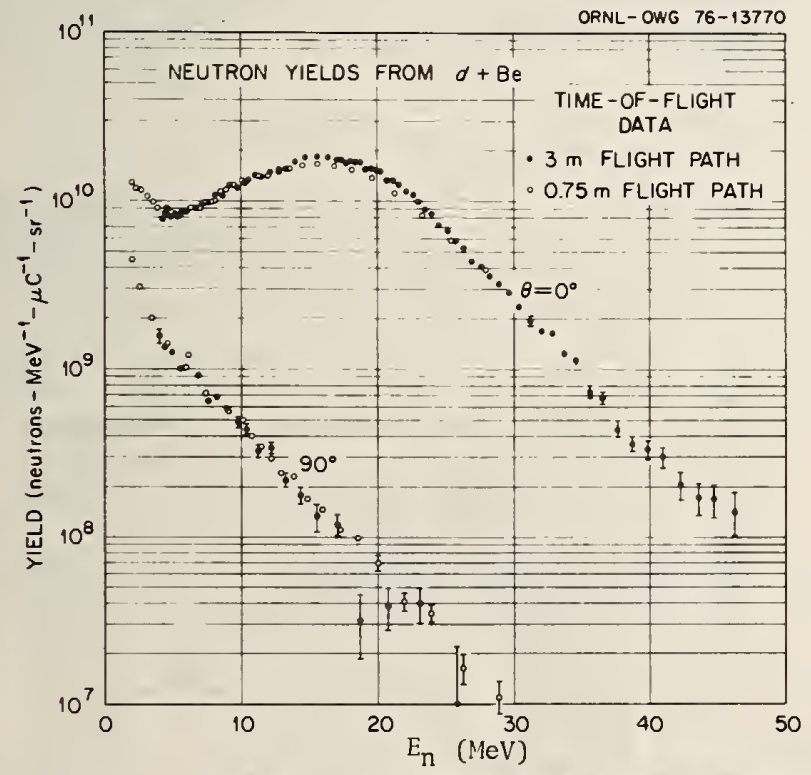

Fig. 2. Time-of-flight data from $40-\mathrm{MeV}$ deuterons on a thick Be target, showing representative error bars. The $0.75-\mathrm{m}$ data (open circles) have been normalized to the 3 -m data in the energy ranges $7.5 \mathrm{MeV}<\mathrm{E}_{\mathrm{n}}<$

$12.5 \mathrm{MeV}$. The system resolution (3-m data) varies from $\approx 200 \mathrm{keV}$ at $E_{n^{-}}=5 \mathrm{MeV}$ to $\approx 6 \mathrm{MeV}$ at $E_{\mathrm{n}}=40 \mathrm{MeV}$. extend below $5 \mathrm{MeV}$ as no runs were made at these angles with a $0.75-\mathrm{m}$ flight path. Monitor uncertanties for the $0.75-m$ data were typically $8-15 \%$ as against $3-4 \%$ for the $3-m$ data. Accordingly, the relative normalization for the two data sets was derived from the total neutron yields for $7.5 \mathrm{MeV}<$ $\mathrm{E}_{\mathrm{n}}<12.5 \mathrm{MeV}$, and the overall normalization defined by the monitor counts for the $3-m$ data.

The experimental uncertainties for these data come from three sources. First, there are the statistical uncertainties indicated by the error bars

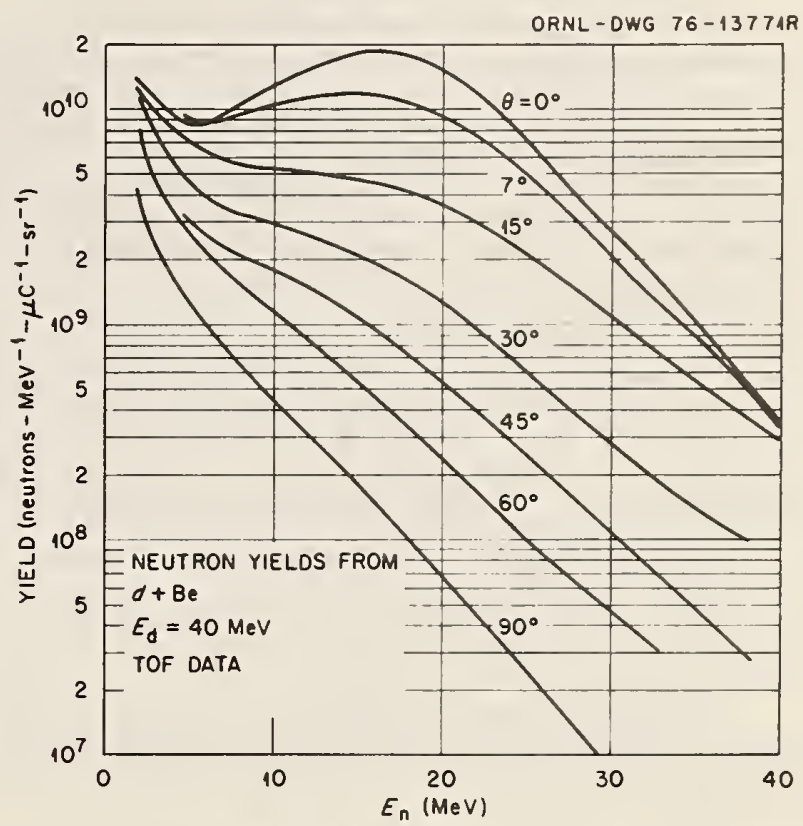

Fig. 3. Time-of-flight data obtained by drawing smooth curves through the results typified by those in Fig. 2.

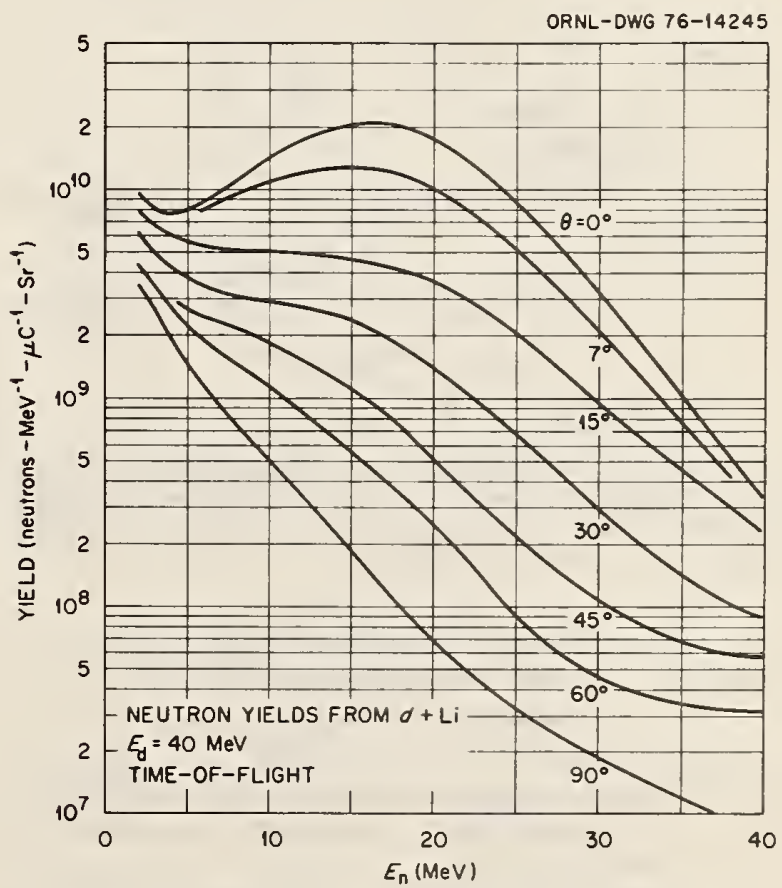

Fig. 4. Neutron yields from $40-\mathrm{MeV}$ deuterons on a thick Li target. 
in Fig. 2. These are generally small. Second, there is a beam monitor uncertainty at each angle, which amounts to $\sim 4^{\circ}$ at all angles, except for $45^{\circ}$ wherc it is $6 \%$. Finally, and most important, there are uncertainties due to the errors in the cfficiency calculations. The resultant overall normalization uncertainty is estimated to be $\pm 15 \%$. Errors in the measured shape of the energy spectrum due to errors in the shape of the efficiency curve are difficult to assess, but are probably less than $10 \%$.

\section{Foil Activation Measurements}

The activation measurements of the $B e(d, n)$ neutron yields required much higher deuteron beam intensities than did the TOF measurements. Therefore, the existing ORIC neutron source, which comprises a water-cooled beryllium target, was used; permitting deuteron beam intensities $\approx 20 \mu \mathrm{A}$. In order to make these measurements in a well-defined geometry, the activation foils were placed at a distance from the target which was large compared to the dimensions of the interaction region within the beryllium target. The arrangement adopted is shown schematically in Fig. 5. Rectangular foils, $50 \times 120 \mathrm{~mm}$, were mounted on a support in the shape of a circular arc $76.2 \mathrm{~mm}$ in radius, and the whole assembly located with the center of the arc at the center of the $d+B e$ interaction region. After exposure for $4 \mathrm{hr}$ at a deuteron beam level of $20 \mu \mathrm{A}$, the foils were removed, allowed to cool for several days, and 6.3-mm-diam discs were punched from them in the pattern indicated in Fig. 5 . The discs were weighed and the gamma activities 1 isted in Table 1 were measured using a $\mathrm{Ge}(\mathrm{Li})$ detector whose efficiency was calibrated using a standard source.

To convert the measured activities to neutron yields the spectrum-averaged cross sections for the

ORNL- OWG $76-14018$

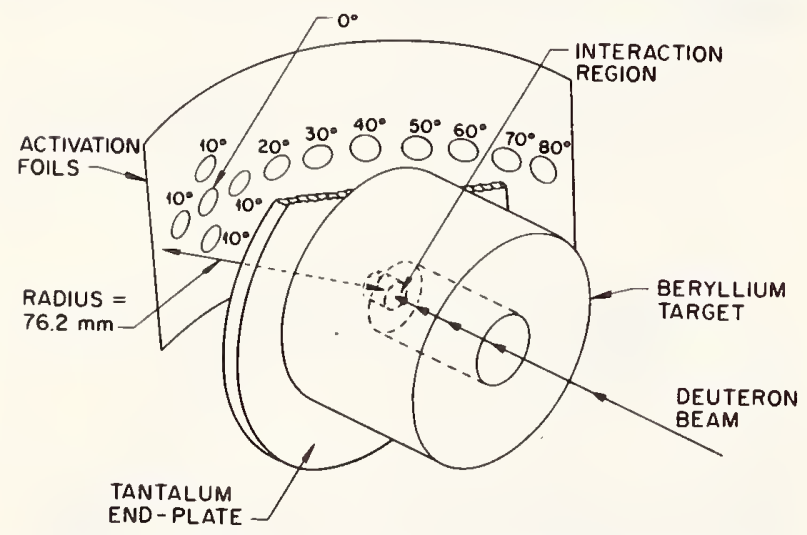

Fig. 5. The experimental arrangement used for the activation measurements in a well-defined geometry. The dimensions of the interaction region were $6 \mathrm{~mm}$ in length, $<5 \mathrm{~mm}$ in diameter.

Table 1. Reactions Used for Activation Measurements

\begin{tabular}{lrr}
\hline Reaction & $\begin{array}{c}\text { Q-Value } \\
(\mathrm{MeV})\end{array}$ & $\begin{array}{c}\mathrm{E}_{\mathrm{V}} \\
(\mathrm{keV})\end{array}$ \\
\hline${ }^{58} \mathrm{Ni}(\mathrm{n}, \mathrm{p}){ }^{58} \mathrm{Co}$ & 0.39 & 810.5 \\
${ }^{59} \mathrm{Co}(\mathrm{n}, 2 \mathrm{n}){ }^{58} \mathrm{Co}$ & -10.47 & 810.5 \\
${ }^{93} \mathrm{Nb}(\mathrm{n}, 2 \mathrm{n}){ }^{92 \mathrm{~m}_{\mathrm{Nb}}}$ & -8.95 & 934 \\
\hline
\end{tabular}

threc reactions were computed as a function of scattering angle by folding the spectrum shapes as measured in the rol russ with the excitation functions shown in Fig. 6. For encrgies $\$ 20 \mathrm{McV}$ the available data ${ }^{5,6}$ for the ${ }^{59} \mathrm{Co}(\mathrm{n}, 2 \mathrm{n})$ and ${ }^{93} \mathrm{Nb}(\mathrm{n}, 2 \mathrm{n})$ reactions appear to be in reasonably good agrecment, but considerable scatter of the experimental results is apparent for the ${ }^{58} \mathrm{Ni}(\mathrm{n}, \mathrm{p})$ case. $^{7}$ Above $20 \mathrm{MeV}$ there arc no data, so the excitation functions were extrapolated using the shapes calculated with the code THRESII. ${ }^{8}$ The overall uncertainties in the calculated spectrumaveraged cross sections were estimated to be $\pm 10 \%$ for the ${ }^{59} \mathrm{Co}(\mathrm{n}, 2 \mathrm{n})$ and ${ }^{93} \mathrm{Nb}(\mathrm{n}, 2 \mathrm{n})$ reactions, and $\pm 15 \%$ for the ${ }^{58} \mathrm{Ni}(\mathrm{n}, \mathrm{p})$ reaction. In Fig. 7 we show the cxperimental values of neutron yield $\left(E_{n}>2 \mathrm{MeV}\right)$ versus

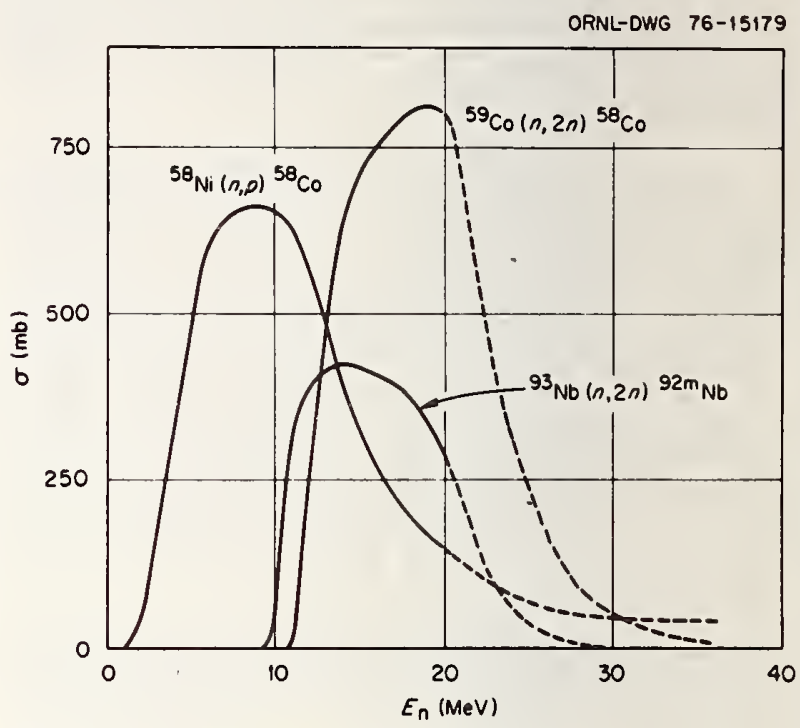

Fig. 6. Excitation functions used to calculate spectrum-averaged cross sections. The solid lines represent the energy regions for which data $5,6,7$ were available; the dotted portions were extrapolated from Ref. 8.

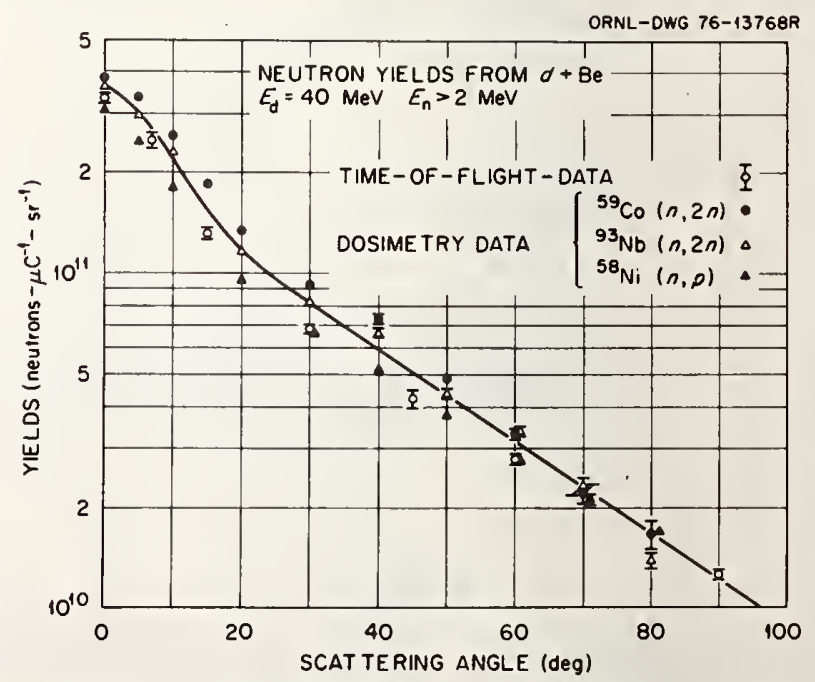

Fig. 7. Experimental values of neutron yield obtained in the present work for $40-\mathrm{MeV}$ deuterons on thick beryllium targets. 
angle obtained from the three activation foils, corrected for absorption in the tantalun end plate. The TOF data are also shown. The error bars indicate statistical uncertainties only. The solid line represents the mean of the TOF and activation results. The four sets of data are displaced from this curve by an average of $-10 \%$ (TOF), $+10 \%,\left[{ }^{59} \mathrm{Co}(n, 2 n)\right],+1 \%$ $\left[{ }^{93} \mathrm{Nb}(\mathrm{n}, 2 \mathrm{n})\right]$, and $-15 \%\left[{ }^{58} \mathrm{Ni}(\mathrm{n}, \mathrm{p})\right]$, in reasonable agreement with the estimated uncertainties.

In Table 2 the results of four separate measurements of $\mathrm{d}+\mathrm{Be}$ neutron yields $\left(\mathrm{E}_{\mathrm{n}}>2 \mathrm{MeV}\right)$ are listed, together with the average values represented by the solid line in Fig. 7 .

The total $d+L i$ neutron yields for $E_{n}>2 \mathrm{MeV}$ are given in Table 3 . From the beryllium data we see that the TOF results are $10 \%$ lower than the average values for the total yields, accordingly the lithium data should be renormalized upwards by this amount, as shown in the final column of Table 3 . The errors quoted in this column reflect not only statistical errors, but also those due to uncertainties in the shape of the detector efficiency curves.

Thick-target neutron yields from the $d+B e$ reaction have previously been measured by Schweimer ${ }^{9}$ at $\mathrm{E}_{\mathrm{d}}=40$ and $53.8 \mathrm{MeV}$, and by Meulders et a1. ${ }^{10}$ at $E_{d}=16,33$, and $50 \mathrm{MeV}$. Schweimer's measurement of

Table 2. Thick-Target Neutron Yields $\left(E_{n}>2 \mathrm{MeV}\right)$ from $d+8 e, E_{d}=40 \mathrm{MeV}$. Units are $10^{10} \mathrm{n} / \mu \mathrm{C} / \mathrm{sr}$

\begin{tabular}{|c|c|c|c|c|c|}
\hline \multirow{3}{*}{$\begin{array}{c}\text { Scattering } \\
\text { Angle } \\
\text { (deg) }\end{array}$} & \multicolumn{4}{|c|}{ Neutron Yields } & \multirow{3}{*}{ Average* } \\
\hline & \multirow{2}{*}{ TOF Data } & \multicolumn{3}{|c|}{ Activation Data } & \\
\hline & & ${ }^{59} \mathrm{Co}(n, 2 n)$ & ${ }^{58} \mathrm{Ni}(n, p)$ & ${ }^{93} \mathrm{Nb}(2,2 \mathrm{n})$ & \\
\hline 0 & $33.6 \pm 1.3$ & $38.7 \pm 0.4$ & $30.9 \pm 0.3$ & $35.7 \pm 0.4$ & $36.0 \pm 1.8$ \\
\hline 5 & & $33.7 \pm 0.4$ & $24.8 \pm 0.3$ & $29.9 \pm 0.3$ & $30.0 \pm 1.5$ \\
\hline 7 & $25.1 \pm 1.3$ & & & & $26.6 \pm 1.3$ \\
\hline 10 & & $26.0 \pm 0.2$ & $18.0 \pm 0.2$ & $23.1 \pm 0.2$ & $22.2 \pm 1.1$ \\
\hline 15 & $13.2 \pm 0.5$ & $18.5 \pm 0.3$ & & & $15.4 \pm 0.8$ \\
\hline 20 & & $13.4 \pm 0.2$ & $9.51 \pm 0.13$ & $11.6 \pm 0.2$ & $11.7 \pm 0.6$ \\
\hline 30 & $6.8 \pm 0.2$ & $9.26 \pm 0.17$ & $6.59 \pm 0.11$ & $8.19 \pm 0.2$ & $8.1 \pm 0.4$ \\
\hline 40 & & $7.29 \pm 0.23$ & $5.12 \pm 0.12$ & $6.65 \pm 0.2$ & $5.9 \pm 0.3$ \\
\hline 45 & $4.2 \pm 0.25$ & & & & $5.05 \pm 0.25$ \\
\hline 50 & & $4.86 \pm 0.15$ & $3.74 \pm 0.06$ & $4.36 \pm 0.16$ & $4.30 \pm 0.22$ \\
\hline 60 & $2.77 \pm 0.1$ & $3.30 \pm 0.13$ & $2.79 \pm 0.07$ & $3.34 \pm 0.11$ & $3.14 \pm 0.16$ \\
\hline 70 & & $2.21 \pm 0.16$ & $2.10 \pm 0.08$ & $2.31 \pm 0.14$ & $2.30 \pm 0.12$ \\
\hline 80 & & $1.66 \pm 0.16$ & $1.68 \pm 0.06$ & $1.39 \pm 0.08$ & $1.67 \pm 0.08$ \\
\hline 90 & $1.26 \pm 0.04$ & & & & \\
\hline $\begin{array}{l}\text { Scale } \\
\text { uncertainty }\end{array}$ & $\pm 15 \%$ & $\pm 10 \%$ & $\pm 15 \%$ & $\pm 10 \%$ & $\pm 7 \%$ \\
\hline
\end{tabular}

*Corresponds to solid line in Fig. 7.

Table 3. Thick Target Neutron Yields $\left(E_{n}>2 \mathrm{MeV}\right)$ from $d+L i, E_{d}=40 \mathrm{MeV}$ Units are $10^{10} \mathrm{n} / \mu \mathrm{C} / \mathrm{sr}$

\begin{tabular}{ccc}
\hline $\begin{array}{c}\text { Scattering } \\
\text { Angle } \\
\text { (deg) }\end{array}$ & \multicolumn{2}{c}{ Neutron Yield } \\
\cline { 2 - 3 } & TOF Data & Renormalized \\
\hline 0 & $36.7 \pm 1.8$ & $40.9 \pm 2.9$ \\
7 & $25.3 \pm 1.3$ & $38.2 \pm 2.0$ \\
15 & $11.6 \pm 0.4$ & $13.0 \pm 0.9$ \\
30 & $6.28 \pm 0.25$ & $6.99 \pm 0.50$ \\
45 & $3.73 \pm 0.17$ & $4.15 \pm 0.30$ \\
60 & $2.48 \pm 0.09$ & $2.76 \pm 0.19$ \\
90 & $1.43 \pm 0.05$ & $1.59 \pm 0.11$ \\
$\begin{array}{c}\text { Scale } \\
\text { uncertainty }\end{array}$ & $\pm 15 \%$ & $\pm 7 \%$ \\
\hline
\end{tabular}

${ }^{a}$ Statistical errors only. the neutron energy spectrun at $0^{\circ}$ extends down to it neutron energy of $11.5 \mathrm{MeV}$, and the shape is in good agreement with our results, however, his estimate of the overall yield is approximately $35 \%$ lower.

Meulders' data include energy spectra at a number of angles for neutron energies $E_{n}>3 \mathrm{MeV}$. No direct

comparison with these data is possible due to the differing deuteron energies, but our data follow the same trends as regards spectral shapes, angular distributions and overall yields.

\section{Dosimetry for the $d+$ Be Neutron Source}

All the yield measurements described in the previous section were made in we11-defined geometries. However, irradiations performed with the ORIC source generally require samples to be placed within a few millimeters of the beryllium target so that a given position on the sample corresponds to a range of scattering angles from the target. Furthermore both the neutron flux and the energy spectrum vary strongly with distance from the beam axis. Thus the dosimetry must provide a measure of both quantities with a spatial resolution $\sim 1 \mathrm{~mm}$. The basis of the method is to assume that the neutron energy spectrum at any point on the sample is adequately represented by the neutron spectrum seen far from the target at some effective scattering angle $\left(\theta_{\text {eff }}\right)$. Then the neutron dose at a given point on the sample can be completely described by two numbers, the total neutron yield for $\mathrm{E}_{\mathrm{n}}>2 \mathrm{MeV}$ and the spectrum shape parameter $\theta_{\text {eff }}$

The response of the nickel and cobalt foils in terms of these two parameters is obtained from the yield measurements described in the preceding section. From the activation measurements done in a welldefined geometry, the ratio of the cobalt and nickel activities at each scattering angle are obtained, and used to calculate the ratio of the spectrum-averaged cross sections, $\vec{\sigma}(\mathrm{Co}) / \bar{\sigma}(\mathrm{Ni})$, as a function of angle. The results are shown in Fig. 8. The solid line in Fig. 7, which is our best estimate of the total neutron yield, is used in conjunction with the same activation measurements to calculate the value of $\bar{\sigma}(\mathrm{Co})$

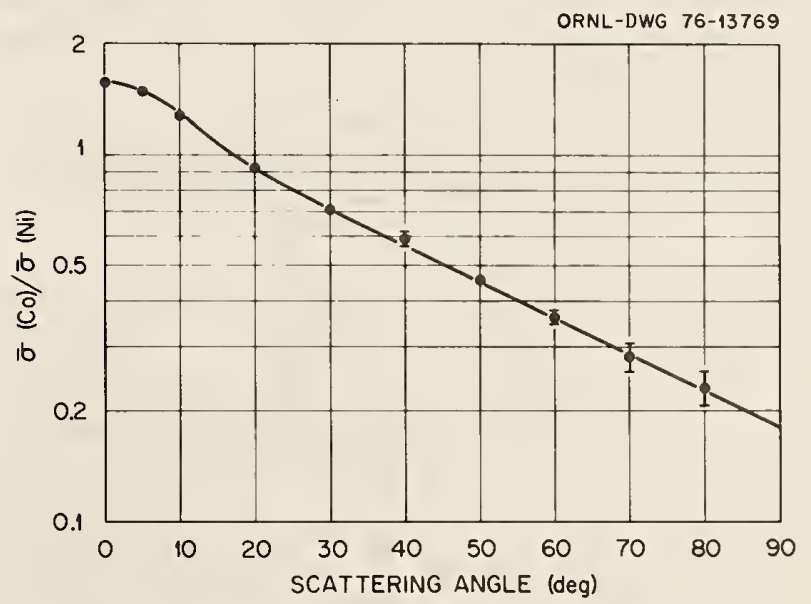

Fig. 8. Experimental dependence of $\bar{\sigma}(\mathrm{Co}) / \bar{\sigma}(\mathrm{Ni})$ as a function of angle for neutrons emitted from a thick target bombarded with $40-\mathrm{MeV}$ deuterons. 
and $\bar{\sigma}(\mathrm{Ni})$ as function of scattering angle. These results (at) are given in l'able 4, together with the values (b) previously estimated from the TOF data and the published cross sections. [Strictly speaking the uichel values include a contribution from competing reactions such as ${ }^{60} \mathrm{Ni}(n, t){ }^{58} \mathrm{Co}$, however, the correction is prohably $<5 \%$ and does not affect the present discussion. The dosinetry procedure which we use is to meisure the activity induced in cobalt and nichel foils at a given location, compute the ratio $\bar{\sigma}(\mathrm{Co}) / \bar{\sigma}(\mathrm{Ni})$ and then obtain $\theta_{\text {eff }}$ from Fig. 8. Knowing $\theta_{\text {off }}$ the value of $\bar{\sigma}(\mathrm{Co})$ [or $\left.\bar{\sigma}(\mathrm{Ni})\right]$ can be obtained from rable 4 and the total neutron fluence calculated.

An example of the method is illustrated in lig. 9. The cobalt and nickel foils were in the form of 25-mm-diam dises, approximately $0.05 \mathrm{~mm}$ thick, placel perpendicular to the beam axis at a distance of $10 \mathrm{~mm}$ from the center of the beryllium target. ifter an irradiation lasting $\sim 26 \mathrm{hr}$, the pair of foils was removed and allowed to cool for several wechs. Dises 1.5 mm in diameter were then punched from the foils in the radial pattern shown on the insert of the upper part of Fig. 9. Each small disc was weighed, and the $810-\mathrm{keV} \gamma$-activity measured with a lie(Li) detector. From these data the location of the center of the neutron spot (i.e., the maximum activity) was estimated, and the activity of each lise plotted against its distance $r$ from this center, as show in Fig. 9. There is an implicit assumption in this procedure that the neutron intensity contours are circular, which appears to be well justified by the small scatter of the data points in these plots. From the data in the upper part of Fig. 9 the two dose parameters, $\theta_{\text {eff }}$ and neutron yield were calculated and plotted as a function of $r$ as shown in the lower part of the figure. The neutron spot is seen to have a roughly gaussian profile, with a full width at half maximum of $8.5 \mathrm{~mm}$, and a maximum of $\sim 10^{17} \mathrm{n} / \mathrm{cm}^{2}$, corresponding to an average flux $\sim 2.1 \times 10^{12} \mathrm{n} / \mathrm{cm}^{2} / \mathrm{sec}$ during the irradiation.

The overall uncertainty in the neutron fluence is estimated to be $\pm 10 \%$ due largely to the $7 \%$ uncertainty of the yield measurements used to calibrate the activation foils. The uncertainty in the definition of spectral shape is difficult to quantify, but in terms of the effective scattering angle it amounts to $\pm 2^{\circ}$, as indicated in Fig. 9 .

Table t. Estimates of the Spectrum-Averaged Cross Sections (in mb) for larious Reactions as a Function of Scattering tungle. lalues labeled (a) are used for dosimetry (see text). Calues labeled (b) were calculated from TOF data and available cross-section data.

\begin{tabular}{|c|c|c|c|c|c|c|}
\hline \multirow{3}{*}{$\begin{array}{l}\text { Seattering } \\
\text { Angle } \\
\text { (deg) }\end{array}$} & \multirow{2}{*}{\multicolumn{2}{|c|}{$\frac{{ }^{5 S_{\mathrm{Ni}},(\mathrm{n}, \mathrm{p})}{ }^{58} \mathrm{Co}}{\bar{\sigma}(\mathrm{Ni})}$}} & \multirow{2}{*}{\multicolumn{2}{|c|}{$\frac{{ }^{59} \mathrm{Co}(n, 2 n){ }^{58} \mathrm{Co}}{\bar{\sigma}(\mathrm{Co})}$}} & \multicolumn{2}{|c|}{${ }^{9} \mathrm{Nb}(\mathrm{n}, 2 \mathrm{n})^{92 \mathrm{~m}} \mathrm{Nb}$} \\
\hline & & & & & & $(\mathrm{Nb})$ \\
\hline & $(a)^{*}$ & (b) & (a) & (b) & (a) & (b) \\
\hline 0 & $\therefore 70$ & $310 \pm 47$ & 424 & $394 \pm 39$ & 205 & $210 \pm 20$ \\
\hline 5 & 270 & & 400 & & 195 & \\
\hline 7 & 270 & $330 \pm 50$ & 383 & $332 \pm 33$ & 187 & $183 \pm 18$ \\
\hline 10 & 272 & & 348 & & 174 & \\
\hline 15 & 278 & $341 \pm 51$ & 300 & $257 \pm 26$ & 149 & $146 \pm 15$ \\
\hline 20 & 283 & & 260 & & 131 & \\
\hline 30 & 298 & $369 \pm 55$ & 212 & $186 \pm 19$ & 116 & $117 \pm 12$ \\
\hline 40 & 315 & & 175 & & 103 & \\
\hline 45 & 520 & $386 \pm 58$ & 161 & $168 \pm 17$ & 98 & $113 \pm 11$ \\
\hline 50 & 329 & & 148 & & 93 & \\
\hline 60 & $5+3$ & $375 \pm 56$ & 124 & $116 \pm 12$ & 83 & $83 \pm 8$ \\
\hline 70 & 561 & & 101 & & 74 & \\
\hline 80 & 380 & & 87 & & 67 & \\
\hline 90 & 400 & $368 \pm 55$ & 72 & $76 \pm 8$ & 58 & $60 \pm 6$ \\
\hline
\end{tabular}
${ }^{\circ 0} \mathrm{vi}(\mathrm{n}, \mathrm{t})^{5 \mathrm{~S}} \mathrm{Co}$.
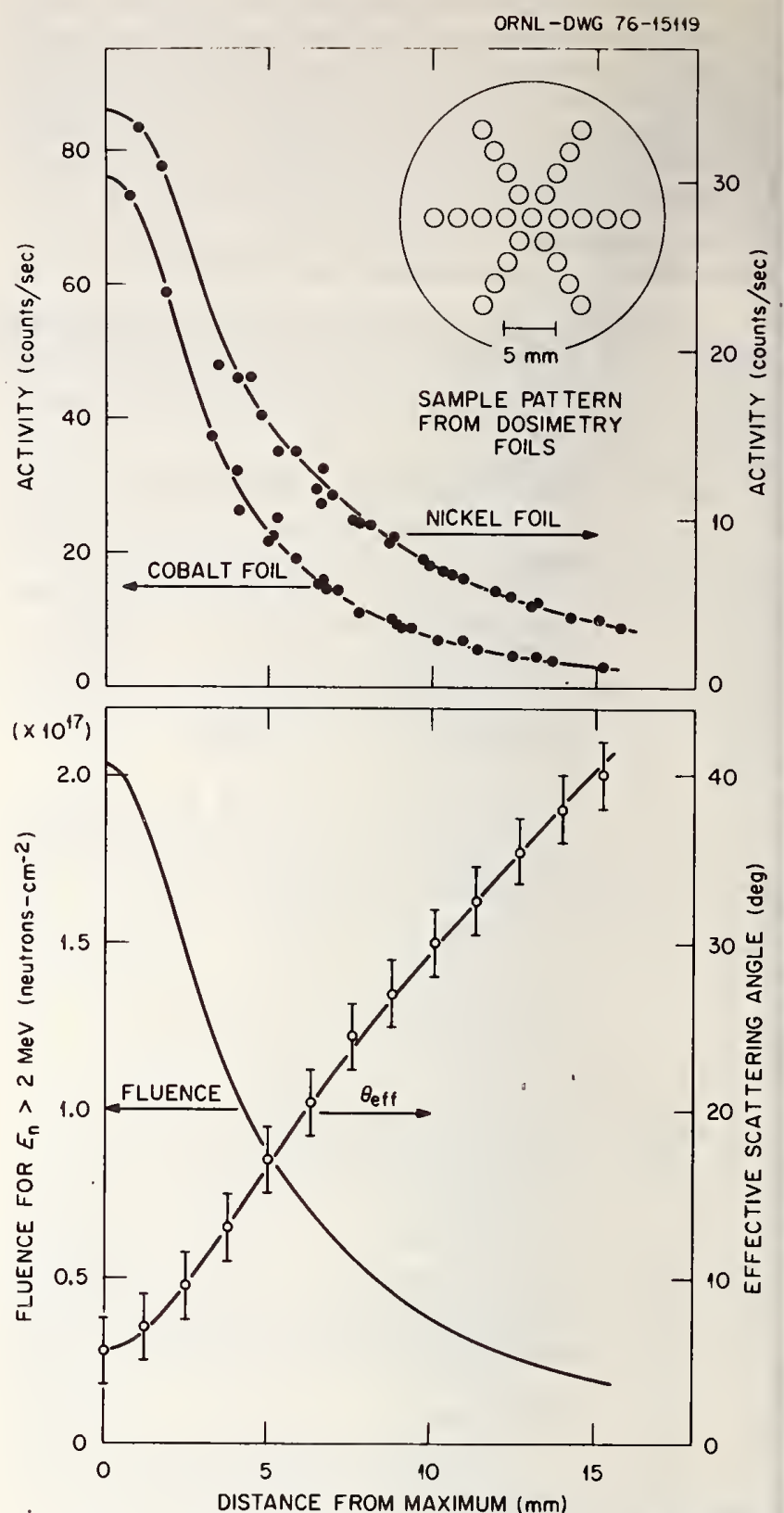

Fig. 9. Dosimetry method used for $d+$ Be neutron source. The upper graphs show the distribution of ${ }^{58}$ Co activity for the cobalt and nickel dosimetry foils. The lower plots show the spatial dependence of $\theta_{\text {eff }}$ and neutron yield inferred from these measurements 


\section{Conclusions}

The neutron yield data described above provide an adequate basis for assessing the performance of $B e(d, n)$ and $L i(d, n)$ neutron sources which use a $40-\mathrm{MeV}$ deuteron beam. It would be useful to extend these measurements to lower neutron energies $\left(E_{n}<2 \mathrm{MeV}\right)$, although the contribution of such neutrons to the total radiation damage is not large $(\leqslant 5 \%)$, at least in the high-flux regions of the neutron sources.

Because of the similarity of the spectral shapes from the $B e(d, n)$ and $L i(d, n)$ reactions, the dosimetry technique developed for the ORIC $B e(d, n)$ source should be also applicable to $\operatorname{Li}(d, n)$ sources. However, more accurately known neutron activation cross sections are needed, particularly in the energy region $E_{n}>15 \mathrm{MeV}$. There will also be a need for measurements of transmutation product cross sections, particularly those for hydrogen and helium. Integral measurements for helium production could be made with existing $B e(d, n)$ sources and would provide a useful check on the theoretical predictions.

\section{References}

1. M. J. Saltmarsh, C. A. Ludemann, C. B. Fulmer, and R. C. Styles, "Characteristics of an Intense Neutron Source Based on the d + Be Reaction," (submitted to Nucl. Inst. and Meth.).

2. M. J. Saltmarsh and R. E. Worsham (ED.), ORNL-TM-5223 (1976).

3. V. V. Verbinski, W. R. Burrus, T. A. Love, W. Zobe1, N. W. Hil1, and R. Textor, Nuc1. Inst. and Meth. 65, 8 (1968).

4. R. E. Textor and V. V. Verbinski, ORNL-4160 (1968).

5. ENDF-B-IV, MAT-1199, BNL 17541 (ENDF-201) (1975).

6. A. Paulsen and R. Widera, Z. Physik 238, 23 (1970).

7. ENDF-B-IV, MAT-1199, BNL 17541 (ENDF-201) (1975).

8. S. Pearlstein, J. Nucl. Eng. $\underline{27}, 81$ (1973).

9. G. W. Schweimer, Nuc1. Phys. A 100, 537 (1967).

10. J. P. Meulders, P. Leleux, P. C. Macq, and C. Pirart, Phys. Med. Biol. 20, 235 (1975). 
II.H. Barschal1

University of Wisconsin, Madison, Wisconsin 53706

Neutron spectra measured by time of $\mathrm{flight}$ and doses measured with a tissue-equivalent ionization chamber have been studied at the Lawrence Livermore Laboratory for deuterons up to $20 \mathrm{MeV}$ on targets of $\mathrm{D}, \mathrm{Li}, \mathrm{Be}$, and $\mathrm{C}$. Al1 the results have been previously published in the following references:

Keith A. Weaver, Ph.D. thesis, University of Wisconsin, Madison, available as Report UCRL-51310 (1973); additiona1 data in UCRL-51310 (addendum) .

K.A. Weaver, J.D. Anderson, H.H. Barscha11, and J.C. Davis, Nucl. Sci. Eng. 52, 35 (1973).

K.A. Weaver, J.D. Anderson, H.H. Barscha11, and J.C. Davis, Phys. Med. Biol. 18, 64 (1973) .

R.H. Howell and H.H. Barschal1, Phys. Med. Biol. 21, 643 (1976). 


\section{NEUTRON SPECTRAL MEASUREMENTS AND INTERPRETATION AT THE NAVAL RESEARCH LABORATORY}

L. S. August, P. Shap1ro, and R. B. Theus

NAVAL RESEARCH LABORATORY, WASHINGTON, D. C. 20375 USA

The thick-target, neutron energy spectra and ylelds produced at $0^{\circ}$ with respect to the

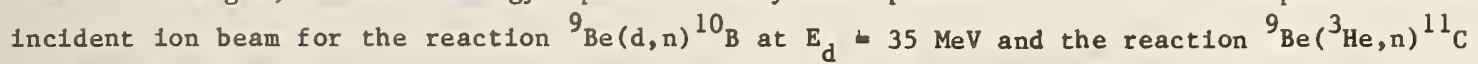
at $\mathrm{E}_{3_{\mathrm{He}}}=81.4 \mathrm{MeV}$ have been measured by time-of-flight techniques. The same data are analyzed dosimetrically in order to extract kerma-to-fluence factors for the NE 213 scintillator. The ${ }^{9} \mathrm{Be}(\mathrm{d}, \mathrm{n}){ }^{10_{\mathrm{B}}}$ results are compared with predictions of the Serber theory as applied to a thick target. Rossi counter measurements in the phantom have shown that the fast neutron spectral quality does not change signiflcantly along the beam axis from at least $2 \mathrm{~cm}$ to $20 \mathrm{~cm}$ depth in tissue-equivalent fluid.

(Neutrons; energy spectra; ylelds; thick target; time-of-flight; ${ }^{9} \mathrm{Be}(\mathrm{d}, \mathrm{n}){ }^{10} \mathrm{~B} ;{ }^{9} \mathrm{Be}\left({ }^{3} \mathrm{He}, \mathrm{n}\right){ }^{11} \mathrm{C}$; Serber theory; Ross1-counter measurements)

\section{Introduction}

The Naval Research Laboratory, in collaboration with a consortium of east coast therapeutic radiologists, is presently engaged in a clinical trial comparing neutrons with gamma rays in the local control of cancerous tumors. The neutron beam is produced by bombarding a thick beryllium target with $35-\mathrm{MeV}$ deuterons. Many measurements have been performed to study the physical characteristics of this neutron beam. These studies include the spectral distribution of the neutron beam by time-of-flight techniques, and investigations of the change in spectral characteristics as the beam penetrates tissue-equivalent material. Additionally, the time-of-flight data can be analyzed to yleld kerma-to-fluence information as a function of neutron energy as well as the dose dependency of the neutron beam in penetrating tissue-equivalent slabs.

\section{Time of Flight Measurements}

In these measurements a 50-ohm capacitive coupler was used to sense the timing of the deuteron beam burst 1tself, rather than the radiofrequency ( $\mathrm{ff}$ ) dee voltage. This method has the advantage of not depending on a constant phase relation between the rf signal and the extracted beam burst. This beam burst signal determined the time at which the neutrons left the beryllium target. The neutron-beam attenuators were 20-cm-square boxes of various thicknesses, constructed of 3-mm Lucite and filled with TE liquid. Geometrical considerations are shown schematically in FIg. 1. A 5-cm diameter NE-213 11quid scintillator coupled to a RCA 8575 photo-multiplier tube was used to detect the neutrons at the end of the 3-m flight path. The fast timing signal from the photomultiplier assembly determined the arrival time of the neutrons. These neutronflight, start and stop signals provided the input timing signals for a time-to-amplitude converter (TAC). The TAC output was fed into an analogue-to-digital converter ( $A D C)$ connected to an EMR-6050 computer. The scintillation amplitude or linear signal from the photomult1plier tube base was entered into a second ADC unit, and neutron gamma pulse-shape discrimination signals were routed into a third ADC. The flight time and pulse-helght signals from the first two ADC's were recorded in a two-parameter mode, subfect to a neutron software gate on the output of the third ADC. This sof tware gate assured that only those scintillation events due to neutrons were processed by the computer. A schematic representation of this system is also shown in Fig. 1. The two-parameter accumulation of data records the number of events, $N\left(E_{n i}, E_{p j}\right)$, in the ith $j$ th

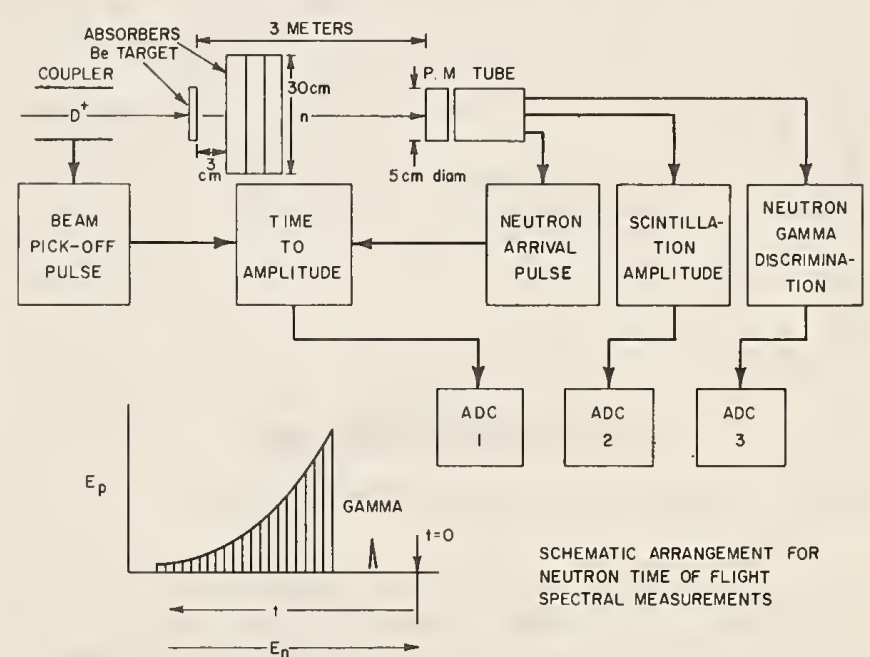

FIG. 1. Time-of-flight spectrometer.

bin. This bin has neutron energy width $E_{p}$. The $x$-axis 1s in equal increments of time but not energy; hence the bin-width dependency on the channel index "1." The neutron energy spectrum $f\left(E_{n}\right)$ for a speciflc number of incident deuterons is defined such that $f\left(E_{n}\right) \cdot E_{n}$ is the number of neutrons per coulomb-steradian having energy in the bin-between $E_{n}$ and $E_{n}+\delta E_{n}$. This spectral distribution is then related to the accumulated data by the expression:

$$
f\left(E_{n}\right)=\frac{1}{0 Q_{n i} \Delta E_{n i}} \sum N\left(E_{n i}, E_{p i}\right)
$$

in which $Q$ is the integrated target current in coulombs, $Q$ is the detector solid angle, and $\varepsilon_{n 1}$ is the detector efficiency which is calculated by the use of the Kurz code. This spectral expression is evaluated in the computer and is presented on a line printer and digital plotter together with the average neutron energy given by:

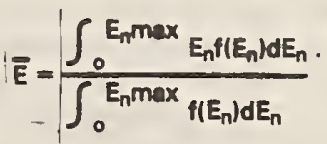


In evaluating this average energy the neutron spectral amplitude is extrapolated to zero for vinishing meutron energy. A spectrum as determined by thess techniqui's is shown in Fig. 2 with the differential yields in gond agreement with those of lleulders et al.

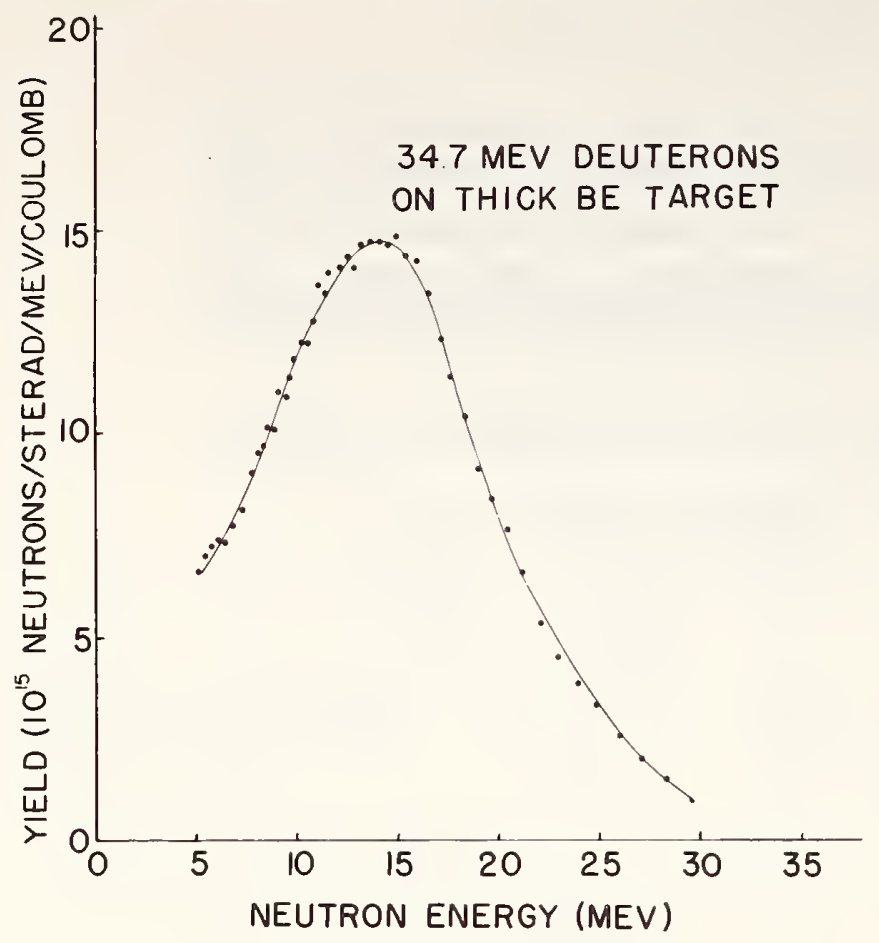

FIC. 2. Neutron spectral yield at $0^{\circ}$ angle.

This spectrum changes very little with TE fluid thickness, the average energy of the primary and forward-scattered neutron component being increased by only $8 \%$ in penetrating $24 \mathrm{~cm}$ of TE fluid (Fig. 3 ).

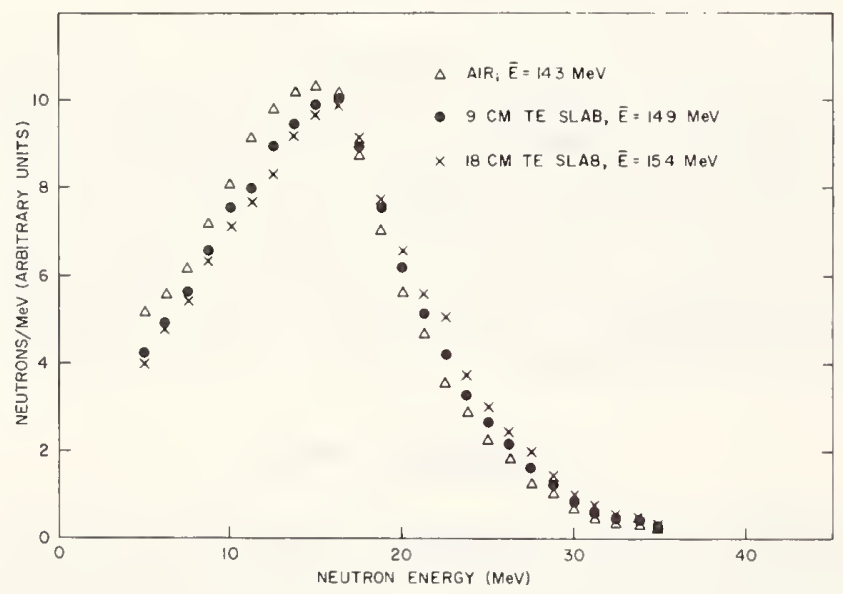

FIC. 3. Neutron spectral distributions after the penetration of 0,9 , and $18 \mathrm{~cm}$ of tissue-equivalent fluid slabs, respectively.

This result implies that the relative biological effectiveness (RBE) of the beam should be essentially independent of tissue depth (assuming constant dose levels), which is desirable from the standpoint of treatment planning. Radiobiological experiments have verified the constancy of the RBE values with depth in a tissue equivalent phantom.
Tine-of-Flight Dosimetry

If the $y-3 x i s$ of the two-parameter datid mat $r i x$ is. calibrated surh that $E$ is the energy per unit miss deposited in the NE-213 detector to produce the recorded scintillation amplitude, then $E_{p j} H_{n i}\left(E_{p j}\right)$ is the energy $i n$ the ith $j$ th bin. Summing all enorgy in thes. bins, and including a sum over charged particle type (alpha or proton) yields:

$$
E=\frac{1}{Q M} \sum_{p} \sum_{i} \sum_{j} E_{p j} N\left(E_{n i}, E_{p j}\right)
$$

which is the dose (erg $\mathrm{g}^{-1}$ ) deposited in the scintillator per coulomb of deuteron charge on the target. In this expression, $M$ is the mass of the NL-213 detector, and $\mathrm{E}_{\mathrm{pj}}$ is selected as the proton recoil energy, since the majority of recorded events is due to elastic proton recoils. The integrated quantity $E$ in Equation (3), which is related to the total energy per gram deposited in the detector, was determined for different TE slabs placed adjacent to the Be target. The neutron beam in this case was produced by $35-\mathrm{MeV}$ incident deuterons. For this geometrical arrangement, the dose rate as a function of slab thickness was obtained with a spherical TE ionization chamer with wall material sufficiently thick $(5 \mathrm{~mm})$ to assure charged-particle equilibrium. A comparison of these two results is shown in Fig. 4.

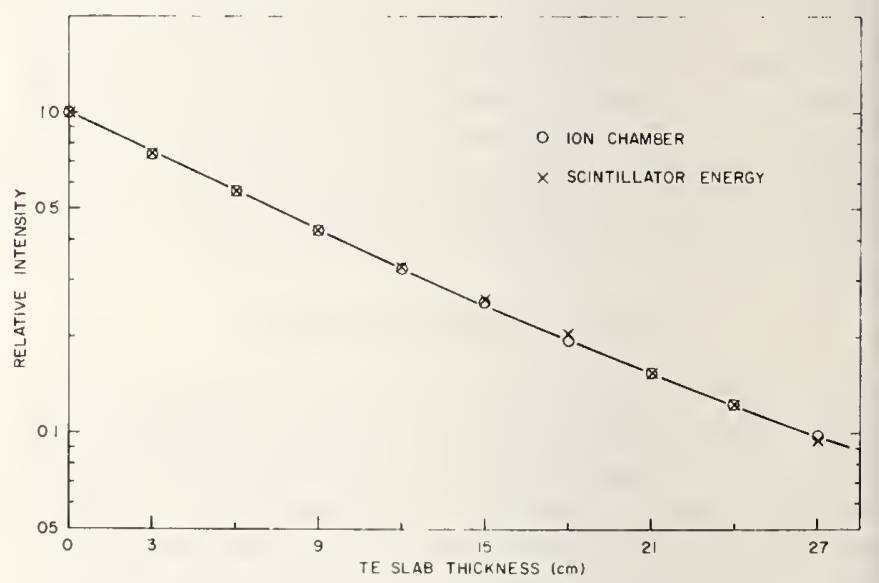

FIG. 4. Comparison of the attenuation of neutron dose by tissue-equivalent slabs as measured by an ionization chamber and recoil proton energy deposited in a scintillator by time-of-flight technique.

The comparative agreement indicates that the time-offlight determinations of total deposited "energy" offer a good quantitative measure of the depth dependence of the absorbed dose in tissue.

Another quantity of interest in dosimetry is the kerma-to-fluence factor. This factor specifies the kinetic energy transferred in charged particles in a gram of material per incident neutron per $\mathrm{cm}^{2}$ of a given energy $E$. It is easy to show that the kerma-tofluence factor, in units of rad neutron ${ }^{-1}-\mathrm{cm}^{-2}$ relative to the accumulated spectral distribution, is obtained by the expression:

$$
\eta_{n i}=\frac{A \sum_{p} \sum_{j} E_{j} N\left(E_{n i}, E_{p j}\right)}{f\left(E_{n i}\right) \Omega Q M \Delta E_{n}}
$$


where $A$ is the detector area, and $M$ is the mass of the detector. In equation (4) the units of dose are expressed as a function of neutron energy, and can be separated into components due to alphas or protons if is omitted. With proper corrections this equation should yield information relative to dose calculations for monoenergetic neutron beams based on neutron elastic and reaction cross sections. In this effort kerma components are obtained by converting scintillation amplitude to particle energy using the appropriate scintillation output relationship for each particle type, and then summing the energy deposited by that particle.

By utilizing various neutron-producing reactions, kerma-to-fluence factors can be obtained over a large range of neutron energies. Consequently, higher energy spectral distributions were produced by other cyclotron accelerated particles. An example resulting from $81.4 \mathrm{MeV}^{3} \mathrm{He}$ particles bombarding a thick Be target is shown in Fig. 5. This neutron spectrum and

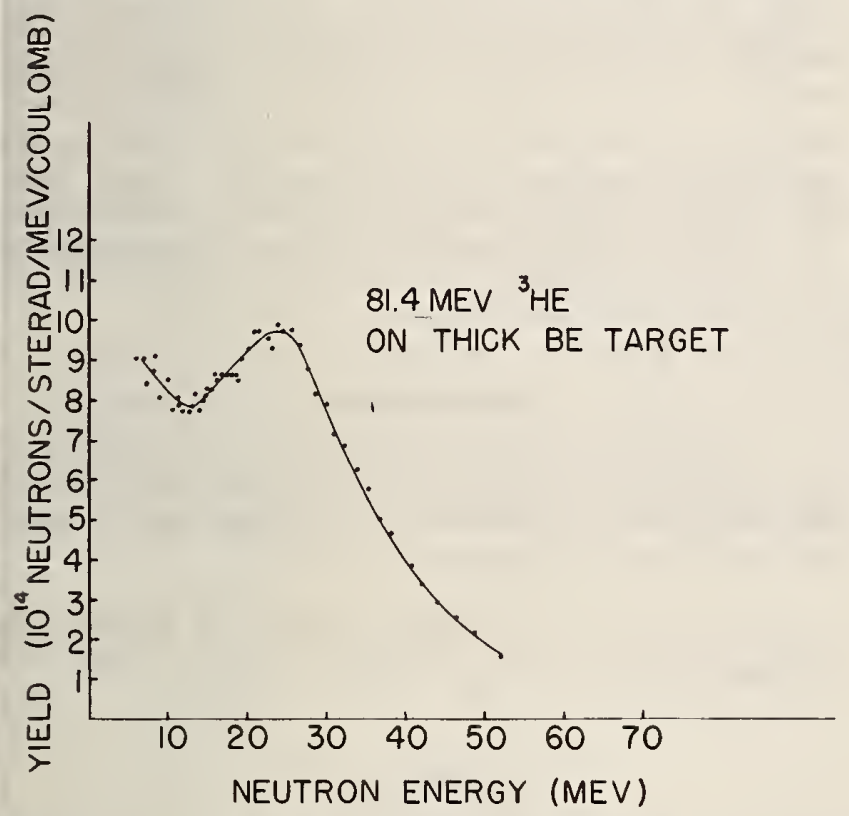

FIG. 5. Neutron spectral yield at $0^{\circ}$ angle.

the ${ }^{3} \mathrm{He}-\mathrm{Be}$ reaction were used to obtain the kerma-tofluence factors for the NE-213 hydrocarbon scintillator over a range of energies for which cross section data does not exist. The results for proton kerma shown in Fig. 6 agree well with calculations due to Bach and Caswell. The alpha kerma results cannot be compared with Bach and Caswell because of the high alpha threshold in this experiment.

In an attempt to understand the fundamental processes which result in the thick target yield of neutrons when deuterons are the bombarding particles, a theory due to Serber was integrated over the slowing-down process of monoenergetic deutrons incident on a Be target. This comparison of the Serber Theory with spectral measurements is shown in Fig. 7. These calculations also predict the observed ${ }_{6}$ cubic dose dependency on the incident deuteron energy.

A further measurement which indicates that the physical characteristics of the absorbed dose is not significantly altered when the neutron beam penetrates tissue is shown by the invariance with depth of the pulse-heighth distribution obtained with a "Rossi" proportional counter.

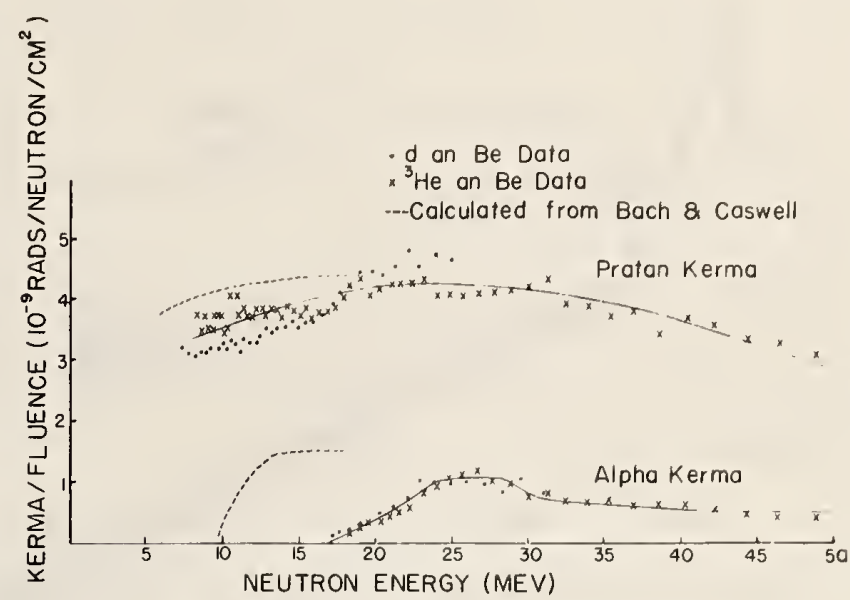

FIG. 6. Neutron kerma/fluence in a NE-213 scintillator. The kerma due to energy deposited by protons and by alphas, as inferred from measurements with the $\mathrm{d}-\mathrm{Be}$ and the ${ }^{3} \mathrm{He}-\mathrm{Be}$ reactions, are compared with calculations based on the work of Bach and Caswe1l. The onset of the experimental values for alpha kerma is at a higher neutron energy than shown in the calculations because of the alpha-detection threshold in the equipment.

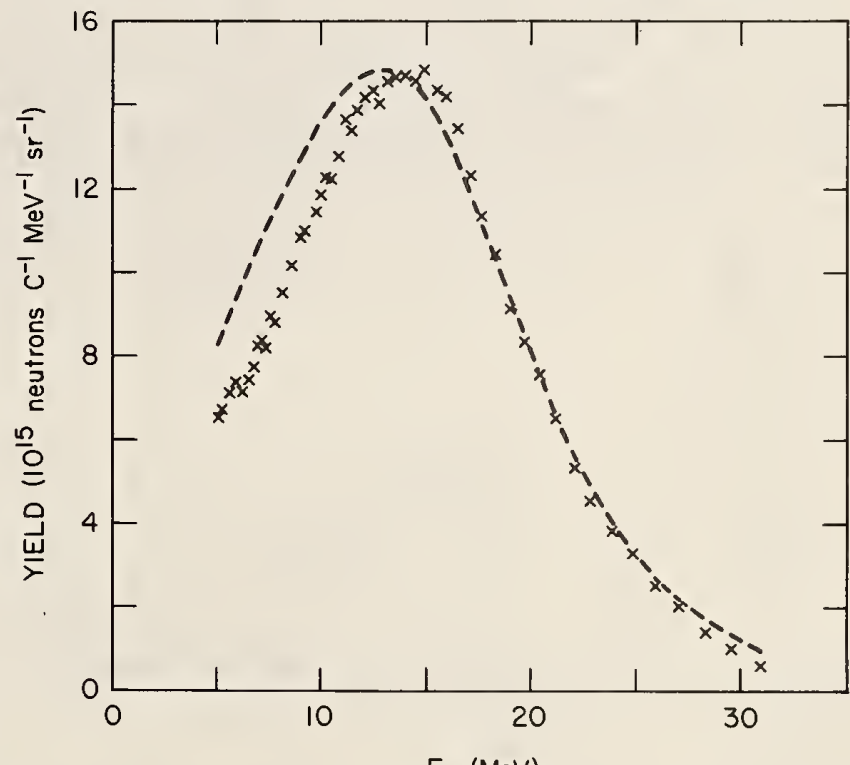

$E_{n}(\mathrm{MeV})$

FIG. 7. The $0^{\circ}$ neutron spectrum produced by $35-\mathrm{MeV}$ deuterons incident on a thick beryllium target. The crosses are experimental data determined from time-offlight techniques. The dashed curve is the result of a calculation using Serber theory.

Fig. 8 provides a quantitative measure of the energy sensitivity of the Rossi counter to changes in average neutron energy. Two pulse-height spectra were taken with the counter at a depth of $10 \mathrm{~cm}$ in the phantom and on the beam axis. The neutrons were produced by incident deuteron beams of energies of 30 and $35 \mathrm{MeV}$, and the spectra are indicated by filled and open circles, respectively. The spectra are normalized at the maxima of the energetic knock-on proton peaks. Clearly, for the higher energy beam, more alphas and heavy ions are produced than at the lower energy. If one takes the ratio of predominantly alpha events to predominantly proton events, 


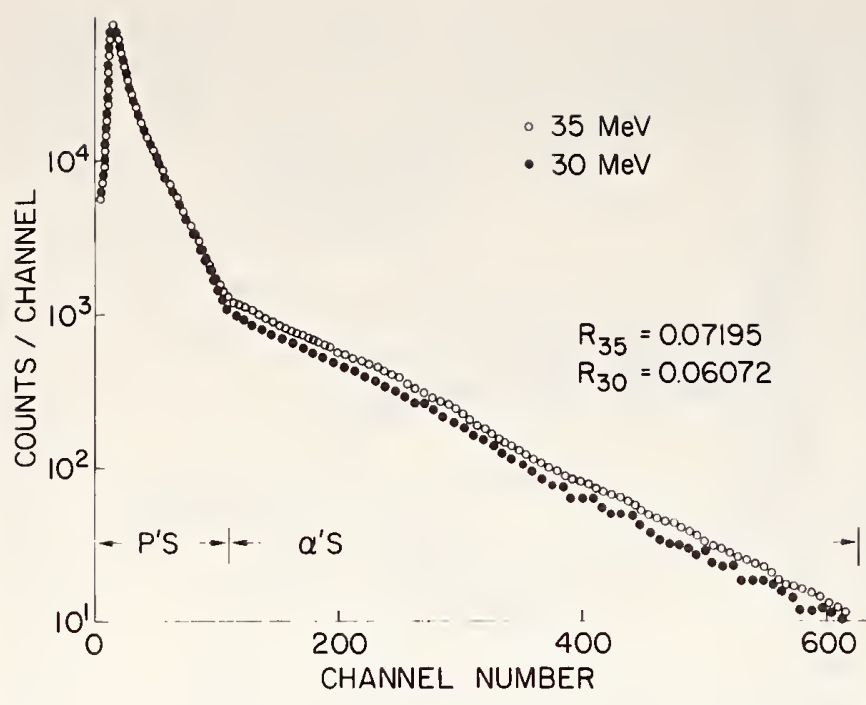

FIG. 8. Rossi-counter pulse-height spectra for a depth in the phantom of $10 \mathrm{~cm}$ and incident deuteron energies of $35 \mathrm{MeV}$ and $30 \mathrm{MeV}$.

there is an $18 \%$ change in this ratio for a $16 \%$ change in either the incident deuteron energy or the average neutron energy. Data obtained on the center line in the TE phantom at depths of $2 \mathrm{~cm}$ and $10 \mathrm{~cm}$ are shown in Fig. 9. The filled circles are for the $2 \mathrm{~cm}$ data, and the open ones for the data at $10 \mathrm{~cm}$. On inspection, there seems to be no difference in the pulse height spectra. If the same ratios are taken as indicated on the previous figure, they agree to within $1 \%$.

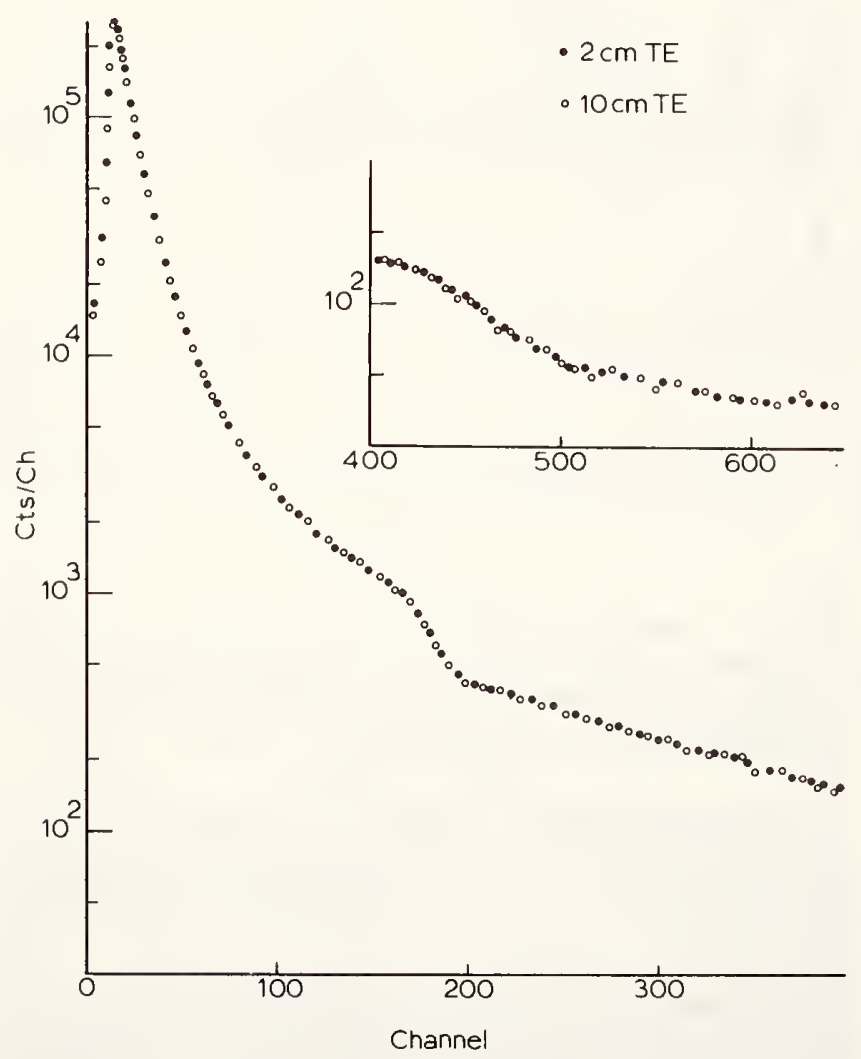

FIG. 9. Rossi-counter pulse-height spectra for an incident deuteron energy of $35 \mathrm{MeV}$ and depths of $2 \mathrm{~cm}$ and $10 \mathrm{~cm}$.
Data taken at depths of $2 \mathrm{~cm}$ and $20 \mathrm{~cm}$ are nearly identical to these, with the ratios agreeing to $1 / 2 \%$. We conclude from these data that the fast neutrui spectrum in the phantom is essentially constant on the center line from at least $2 \mathrm{~cm}$ to $20 \mathrm{~cm}$.

\section{Conclusions}

Neutron therapy beams can be characterized by means of time-of-flight measurements (TOF) and by event distributions in a "Rossi" proportional counter. TOF measurements furnish spectral information, neutron fluence, kerma-to-fluence factors, and indicate relative energy deposition due to protons and alpha particles. Event spectra from the "Rossi" counter are used to indicate the quality of the neutron therapy beam. These measurements can be used to show changes in relative dose deposited by alpha and protons as a function of neutron energy as well as to verify beam quality as a function of depth in a tissue-equivalent phantom. our results are generally in good agreement with measurements reported by other laboratories. Over quite a range of energy, the shape of thick-target, deuteron produced high-energy neutron spectra may be characterized as of a skewed-gaussian type which reaches a maximum at $0.4 \mathrm{E}_{d}$, where $\mathrm{E}_{d}$ is the incident deuteron energy. Serber theory, as applied to a thick target, can explain reasonably well this shape. Serber theory describes the gross features of neutron production in the forward direction, and reflects the importance of the internal momentum of the neutron in the deuteron prior to the interaction.

\section{Acknowledgments}

The authors wish to thank Dr. R. 0. Bondelid for his continuing interest in and support of this work. They also wish to thank Mr. G. E. Miller and his staff for their help in obtaining the data.

This work was supported in part by the National Cancer Institute under Interagency Grant Number 1401 C0 40001-01.

\section{References}

1. R. J. Kurz, "A 709/7090 FORTRAN II Program to Compute the Neutron-Detection Efficiency of Plastic Scintillators for Neutron Energies from 1 to $300 \mathrm{MeV}^{\prime \prime}$, UCRL-11339, , University of California (1.964).

2. J. P. Meulders, P. Leleux, P. C. Macq, and C. Pirart, Phys. Med. Biol. 20, 235 (1975).

3. Paul Todd, Carter B. Schroy, F. H. Attix, and Richard B. Theus, Cancer 34, 33 (1974).

4. R. L. Bach and R. S. Caswe 11, Rad. Res. 25, 1 (1965).

5. R. Serber, Phys.Rev. 72, 1008 (1947).

6. L. S. August, F. H. Attix, G. H. Herling, P. Shapiro and R. B. Theus, Phys. Med, Biol. 21, 931 (1976).

7. H. H. Rossi and W. Rosenzweig, Radiology 64, 404 (1955). 
U.S. DEPT. OF COMM.

BIBLIOGRAPHIC DATA

SHEET

4. TITLI: AND SUBTITLI:
1. DUIBLIT:ATION OR RLIPOR'T NO.

NBSIR-77-1279
No.

Accession

Acessing

Cross Sections and Yields for High Energy Neutron Source Reactions
5. Publication I)atc

\section{July 1977}

6. Proforming Organization (.ods

7. AUTHOR(S) Editors:

M. A. Lone, L. Stewart, A. D. Carlson, and C. D. Bowman

9. PERFORMING ORGANIZATION NAME, AND ADDRESS

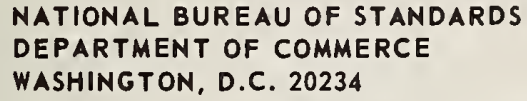

8. P'erforming Organ. Report No.

10. Projcet/Task/Work Unit No.

11. Contract/Grant No.

13. Type of Report \& Period Covered

12. Sponsoring Organization Name and Complete Address (Street, City, State, ZIP)

U. S. Energy Research and Development Administration, and others

14. Sponsoring Agency Code

15. SUPPLEMENTARY NOTES

16. ABSTRAC'I (A 200-word or less factual summary of most significant information. If document includes a significant bibliography or literature survey, mention it here.)

Eight papers were presented at a workshop on thick-target yields from high-energy neutron source reactions on March 30th, 1977 in Bethesda, Md. Presentations were made on several source reactions including $D(d, n), L i(p, n)$, $\mathrm{Li}(d, n), \mathrm{Be}(p, n), \mathrm{Be}(d, n)$, and $C(d, n)$ including energy and angular distributions. Special emphasis was placed on these sources due to the needs in medical applications and for studies of radiation damage expected in an operating fusion reactor.

17. KEY WORDS (six to twelve entries; alphabetical order; capitalize only the first letter of the first key word unless a proper name; separated by semicolons)

$B e(d, n)$ source; $B e(p, n)$ source; $C(d, n)$ source; $D(d, n)$ source; dosimetry; $L i(d, n)$ source; Li $(p, n)$ source; neutrons; neutron angular distributions; neutron energy distributions; nuclear reactions; thick-target yields

18. AVAILABILITY Unlimited

For Official Distribution. Do Not Release to NTIS

Order From Sup. of Doc., U.S. Government Printing Office Washington, D.C. 20402, SD Cat. No. C13

Order From National Technical Information Service (NTIS) Springfield, Virginia 2215I

\begin{tabular}{|l|l|}
$\begin{array}{l}\text { 19. SECURITY CI.ASS } \\
\text { (THIS REPURT) }\end{array}$ & 21. NO. OF PAGES \\
UNCL ASSIFIED & \\
\hline $\begin{array}{l}\text { 20. SECURITY CLASS } \\
\text { (THIS PAGE) }\end{array}$ & 22. Price \\
UNCLASSIFIED &
\end{tabular}


